Check for updates

Cite this: RSC Adv., 2022, 12, 7009

\section{Photocatalysis and perovskite oxide-based materials: a remedy for a clean and sustainable future}

\author{
Muneeb Irshad, (D) *a Quar tul Ain, ${ }^{a}$ Muhammad Zaman, ${ }^{a}$ Muhammad Zeeshan Aslam, ${ }^{a}$ \\ Naila Kousar, ${ }^{a}$ Muhammad Asim, ${ }^{a}$ Muhammad Rafique, (D) ${ }^{\mathrm{b}}$ Khurram Siraj, ${ }^{a}$ \\ Asif Nadeem Tabish, ${ }^{\mathrm{C}}$ Muhammad Usman, ${ }^{\mathrm{d}}$ Masood ul Hassan Farooq, ${ }^{\mathrm{e}}$ \\ Mohammed Ali Assirif and Muhammad Imran (D) ${ }^{f}$
}

\begin{abstract}
The massive use of non-renewable energy resources by humankind to fulfill their energy demands is causing severe environmental issues. Photocatalysis is considered one of the potential solutions for a clean and sustainable future because of its cleanliness, inexhaustibility, efficiency, and costeffectiveness. Significant efforts have been made to design highly proficient photocatalyst materials for various applications such as water pollutant degradation, water splitting, $\mathrm{CO}_{2}$ reduction, and nitrogen fixation. Perovskite photocatalyst materials are gained special attention due to their exceptional properties because of their flexibility in chemical composition, structure, bandgap, oxidation states, and valence states. The current review is focused on perovskite materials and their applications in photocatalysis. Special attention has been given to the structural, stoichiometric, and compositional flexibility of perovskite photocatalyst materials. The photocatalytic activity of perovskite materials in different photocatalysis applications is also discussed. Various mechanisms involved in photocatalysis application from wastewater treatment to hydrogen production are also provided. The key objective of this review is to encapsulate the role of perovskite materials in photocatalysis along with their fundamental properties to provide valuable insight for addressing future environmental challenges.
\end{abstract}

Received 8th November 2021 Accepted 21st February 2022 DOI: $10.1039 / \mathrm{d} 1 \mathrm{ra0} 8185 \mathrm{c}$ rsc.li/rsc-advances dangerous for all living things on the earth. The current decade 2021-2030, is the decade of ecosystem system restoration. Therefore, it is essential to pay attention to clean ways to tackle environmental issues. The new global challenge is the achievement of ecological sustainability. The research focus of this era is oriented toward the way to achieve the eco-friendly system. ${ }^{1-6}$

The blissful gift of Mother Nature, the Sun is an ultimate renewable energy resource that irradiates 3.85 yotta joule $(\mathrm{YJ})$ of energy yearly on the earth's surface. Sunlight is one of the best routes to deal with environmental issues owing to its cleanness and abundant availability. Sunlight can be utilized as an energy medium by photovoltaic, photoelectrochemical catalysis, or photocatalysis in daily activities. ${ }^{7,8}$

Photocatalysis is defined as the science of employing a catalyst that uses light to speed up the chemical reaction. In photocatalysis, the photocatalyst material is used, and the energy of the light acts as a source to generate electron-hole pair. The photogenerated electron-hole pair then initiates the redox reaction at the surface of the photocatalyst. This redox reaction can be utilized to degrade water pollutants and convert abundant earth elements $\left(\mathrm{H}_{2} \mathrm{O}, \mathrm{CO}_{2}\right.$, and $\mathrm{N}_{2}$ ) into fuel (pure $\mathrm{H}_{2}$, or organic fuel like $\mathrm{CH}_{4}, \mathrm{CH}_{3} \mathrm{OH}$, and $\mathrm{NH}_{3}$ ). The conversion of water into the fuel $\left(\mathrm{H}_{2}\right)$ by using light and photocatalyst 
material is known as photocatalytic water splitting. The conversion of $\mathrm{CO}_{2}$ into the hydrocarbons is known as $\mathrm{CO}_{2}$ reduction, and conversion of nitrogen into $\mathrm{NH}_{3}$ is called nitrogen fixation. All these application deals with the viable way to clean the environment. The main challenge while dealing with photocatalysis is the region of operation of the photocatalyst in the solar spectrum. Most photocatalysts operate under UV radiations, which is only $5 \%$ of the sunlight reaching earth. Therefore, suitable photocatalysts are required to respond to the extensive range of the solar spectrum..$^{9-18}$

\section{History of photocatalysis}

The word catalysis was first used in 1836 by the Jöns Jakob Berzelius, derived from the Greek word "kata", meaning down or loosen. Catalysis is the process of fasting or accelerating the reaction in the presence of the catalyst. The catalyst itself doesn't participate in the reaction but increases the reaction rate. The term photocatalysis first appeared in 1911, when Eibner studied the effect of light irradiation on transition metal oxide ( $\mathrm{ZnO})$ for the decolorization of Prussian blue. Photocatalysis term also appeared simultaneously in the title of the article investigating the degradation of the oxalic acid in the presence of the uranyl salts upon light irradiation. In 1921 Edward Charles Cyril Baly studied the production of formaldehyde using colloidal uranium salts and ferric hydroxides as a catalyst. Soon after, in 1924, the Baur and the Perret at the ETH of Zurich reported the effect of light irradiation on the $\mathrm{ZnO}$ suspension and observed that $\mathrm{ZnO}$ suspension enhanced reduction of $\mathrm{Ag}^{+}$salts to $\mathrm{Ag}^{\mathrm{o}}$ upon irradiation. The mobility for the $\mathrm{TiO}_{2}$ as a photosensitizer for the dyes was first studied by Doodeve and Kitchener in 1938. This work reported that $\mathrm{TiO}_{2}$ upon light irradiation decolorized the dyes, and $\mathrm{TiO}_{2}$ remains unchanged during the process. ${ }^{19-22}$

Many researchers from 1940 to 1972 investigated different parameters of the photocatalyst. Photocatalysis gained significant attention when electrochemical photolysis of the water was done by using titanium dioxide under UV irradiation. The oil crisis in 1973 also changed the social and economic status of the western world. The first time, the shortage of fossil fuels became a significant issue, which led to an unprecedented increase in the efforts for alternative energy resources, including photocatalysis. The application of photocatalysis is not limited to energy fuels but can also clean the environment. Much attention has been given to photocatalysis during the last two decades due to its wide range of applications. ${ }^{21,23}$

Photocatalysis has its application in the pollutant degradation and production of fuel. Material can be an excellent photocatalyst if it is responsive to light, especially (UV or visible), biologically and chemically inert, has low cost, and exhibits adsorption and absorption capacity. Normally the metal oxide semiconductors are used in the application of the photocatalyst. Perovskite materials, due to their unique optical properties, also gained importance in the application of photocatalyst during the last decade..$^{24,25}$

\section{Perovskite oxide based materials}

Perovskite material was first discovered in 1839 in the Ural Mountains by the German scientist Gustave Rose. The mineral was named perovskite after Russian mineralogist Count Lev Aleksevish von Perovski. ${ }^{\mathbf{2 6 - 2 8}}$ The first discovered perovskite material was $\mathrm{CaTiO}_{3} \cdot{ }^{29}$ The basic chemical formula of the single perovskite is $\mathrm{ABX}_{3}$, where $\mathrm{A}$ and $\mathrm{B}$ are cations while $\mathrm{X}$ is an anion. Normally, A is alkaline earth metals or lanthanides, B is the transition metal, and $\mathrm{X}$ is oxygen or any halide. The perovskite is known as perovskite oxide when the anion is oxygen and is known as perovskite halide when the anion is a halide. In single perovskite, the coordination number of A site is 6 , the coordination number of $\mathrm{B}$ site is 12 , and the coordination number of $\mathrm{O}$ anion is 6 . In single perovskite, the perfect structure of the $\mathrm{BO}_{6}$ octahedral connection results in the cubic lattice..$^{30-33}$ The structure of single perovskite is shown in Fig. 1.

The tolerance factor can indicate the distortion and the crystallographic structure of the perovskite material. The tolerance factor of the single perovskites ions was defined by V. M Goldschmidt in 1926. The tolerance factor of the perovskite structure tells the stability of the perovskite structure and the compatibility of the ions in the crystal structure. ${ }^{34-39}$ The tolerance factor is a dimensionless quantity given by eqn (1). ${ }^{\mathbf{3 8 , 4 0}}$

$$
t=\frac{r_{\mathrm{A}}+r_{\mathrm{X}}}{\sqrt{2}\left(r_{\mathrm{B}}+r_{\mathrm{X}}\right)}
$$

In eqn (1), $r_{\mathrm{A}}$ and $r_{\mathrm{B}}$ are the ionic radii of the electropositive ions, while $r_{\mathrm{X}}$ is the radius of the oxygen or halide ions. ${ }^{41}$ The perovskite structure can be divided into octahedral hexagonal, tetragonal, and ideal cubic structures on the basis of the tolerance factor. When the tolerance factor is between 0.9 and 1 , the structure is the ideal cubic structure with the length of the unit cell $(a)$ as: $^{42}$

$$
a=r_{\mathrm{A}}+r_{\mathrm{O}}=\sqrt{2}\left(r_{\mathrm{B}}+r_{\mathrm{X}}\right)
$$

In non-ideal cases, the tolerance factor deviates from 1, which shows the mismatch in the $\mathrm{A}-\mathrm{O}$ and $\mathrm{B}-\mathrm{O}$ bond lengths. The corundum structure $\left(\alpha-\mathrm{Al}_{2} \mathrm{O}_{3}\right)$ and its derivative are

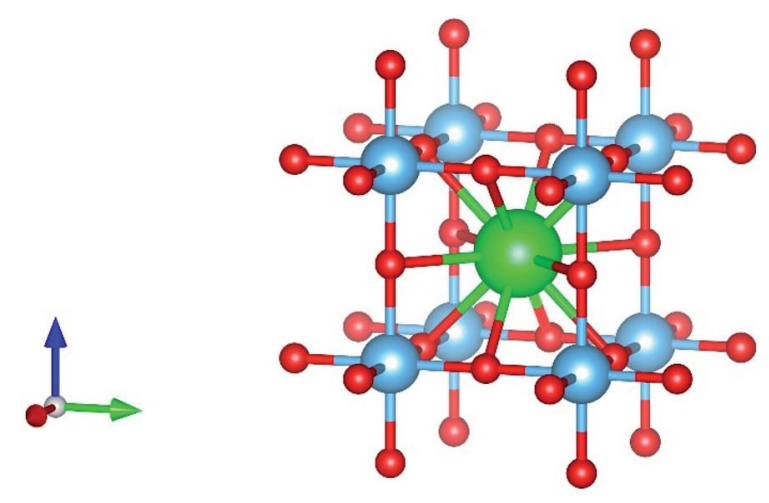

Fig. 1 Perovskite structure. 
considered when the tolerance factor is less than $0.75 .{ }^{43}$ The stable bixbite polymorph $\left(\alpha-\mathrm{Mn}_{2} \mathrm{O}_{3}\right)$ is favored when the factor decreases. If the tolerance factor is greater than 1 , the structure of perovskite is hexagonal close-packed ( $\mathrm{HCP})$, and $\left[\mathrm{BO}_{6}\right]-$ octahedra share faces with the hexagonal $c$-axis. ${ }^{30,44}$

The sum of the charges of cations and anion of the perovskite structure should equal one for perovskite material to be electrically neutral. Different cations having different ionic radii and valences can be doped in the structure of perovskite material by employing the method of partial substitution at A and B-site. Deficiency at A and B-site cations and excess or deficiency of oxygen anions can change the composition of ions and the non-stoichiometry phenomenon. ${ }^{45,46}$

Double perovskite structures were used at a significant scale in the 1980s. The double perovskite exhibits structure that is twice the single perovskite. The coordination number of the A and B cation is the same as that of the single perovskite. Double perovskites are generally of two types depending upon the types of the cations $\mathrm{A}^{\prime} \mathrm{A}^{\prime \prime} \mathrm{B}_{2} \mathrm{O}_{6}$ (double A-site) or $\mathrm{A}_{2} \mathrm{~B}^{\prime} \mathrm{B}^{\prime \prime} \mathrm{O}_{6}$ (double Bsite). ${ }^{47,48}$ The double perovskite strain energy depends on the charge difference between the two types of $\mathrm{B}$ cations (B and $\mathrm{B}^{\prime}$ ). There are three ways to arrange the B-type cation based on the charge difference between $\mathrm{B}$ and $\mathrm{B}^{\prime}$. The arrangement is random if the charge difference is one $(\Delta Q=1){ }^{49}$ The most common arrangement of the double perovskite is the rock-salt arrangement, also called elpasolite structure, in which the cations change in all three dimensions, and it dominates when the charge difference between the $\mathrm{B}$ and $\mathrm{B}^{\prime}$ is greater than $2(\Delta Q$ $>2$ ). Due to the difference in the charge size of the B cation in the rock salt order, the crystal symmetries are less than their single perovskite structure. Another arrangement is the layered arrangement of the $\mathrm{B}$ and $\mathrm{B}^{\prime}$, where the cations can change in only one dimension (Fig. 2). ${ }^{50-54}$

The perovskite structures are preferred due to their structural and compositional flexibility.

\section{Structural flexibility}

The ideal single perovskite structure is with the high symmetry of $P m \overline{3} \mathrm{~m}$. It comprises a highly flexible network built up from chains of corner-sharing $\left[\mathrm{BO}_{6}\right]$ octahedra with A cations occupying the resulting holes with cubic octahedral symmetry. The symmetry of the structure can be transformed into the tetragonal, hexagonal, octahedral, monoclinic, triclinic, and rhombohedral structures by changing the size of cations or anions in the structure. Double perovskites generally have a double B site. Double perovskites are modified single perovskite; the high symmetry ideal single perovskite with the space group of $P m \overline{3} m$ is reduced to $F m 3 m$ in double perovskite. The double perovskite structure with double B site has two elements in the corner linked and has alternatively arranged $\mathrm{BO}_{6}$ and $\mathrm{B}^{\prime} \mathrm{O}_{6}$ octahedra double A site. ${ }^{55,56}$

The tolerance factor of both single and double perovskite changes by altering the size of cations or anions in the perovskite. The resulting lattice distortion affects the dielectric, electronic, magnetic, and optoelectronic properties. The lattice distortion also influences the movement and excitation of the photo-generated charge carrier under the influence of light..$^{27,57-59}$ The sintering temperature also affects the structure of the perovskite material. The structure generally becomes ideal cubic at high temperatures, and as the temperature goes down, the octahedral rotation in the perovskite changes to lower symmetry. ${ }^{60,61}$

Octahedral tilting also has an indispensable role in the structural flexibility of single and double perovskite structures. Octahedral tilting is the rotation along with the orthogonal symmetry of the $\mathrm{BO}_{6}$; Glazier explained the octahedral tilting in 1972. Currently, there are twenty-three different perovskite structures available depending on the octahedral tilt. ${ }^{62,63}$

The ferroelectric properties of the perovskite structure are also dependent on the octahedral tilting. Octahedral tilting breaks the centro-symmetry, which affects the ferroelectricity. The bandgap of the perovskite can also be changed by changing the octahedral tilting. Calculation of the electronic structure of the oxide perovskites on the tilted phase depicts that bandgap due to the different tilt can change up to the $0.2 \mathrm{eV}$ and is even more significant in the case of halide perovskites..$^{30,64,65}$

The large distortion in the perovskite lattice can break the structure and result in low dimension perovskite formation (1D, $2 \mathrm{D})$. The distortion in the crystal structure affects the $\mathrm{BO}_{6}$ octahedral, breaks the $\mathrm{B}-\mathrm{O}$ bond, and forms a 1D/2D perovskite derivative. In $1 \mathrm{D}$ wires with linear or zigzag configuration, the $\mathrm{BO}_{6}$ octahedral network can be edge-sharing, face-sharing, or corner-sharing. While in the case of a $2 \mathrm{D}$ stacked-layer, the $\mathrm{BO}_{6}$ octahedra are edge-sharing. Low dimension perovskites are helpful in the application of photocatalysis due to their high surface to bulk ratio. ${ }^{65-67}$

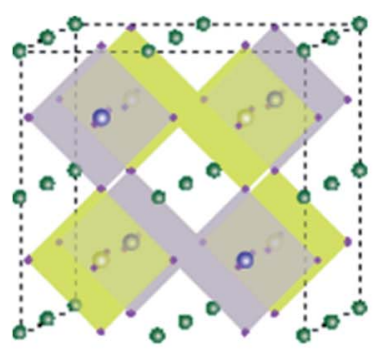

a. Rock salt

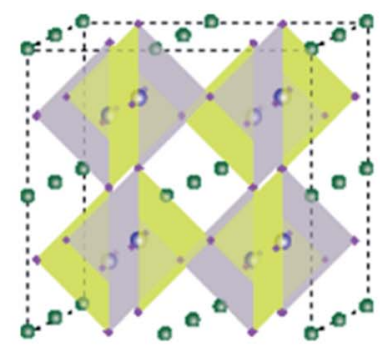

b. Random

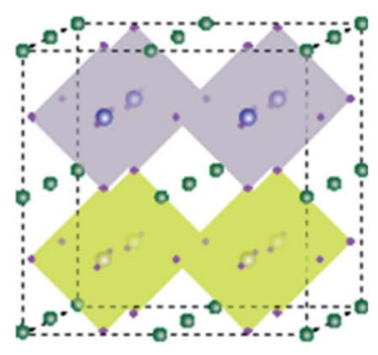

c. Layered

Fig. 2 Double perovskite structures. 
Stoichiometric and compositional flexibility. The perovskite structure exhibits a high degree of stoichiometric and compositional flexibility. Theoretically, 346 different kinds of $\mathrm{ABO}_{3}$, 264 are experimentally investigated. The $\mathrm{ABO}_{3}$ perovskite structure is divided into five groups depending upon the $\mathrm{A}$ and $B$ site charges that are $\mathrm{A}^{1+} \mathrm{B}^{5+} \mathrm{O}_{3}, \mathrm{~A}^{2+} \mathrm{B}^{4+} \mathrm{O}_{3}, \mathrm{~A}^{3+} \mathrm{B}^{3+} \mathrm{O}_{3}, \mathrm{~A}^{4+} \mathrm{B}^{2+} \mathrm{O}_{3}$, and $\mathrm{A}^{5+} \mathrm{B}^{1+} \mathrm{O}_{3}$. Theoretically, there are $10^{5}$ possible material double perovskite, out of which $10^{3}$ double perovskites are experimentally investigated. For material to be double perovskite, the charge balance of all the charges present in the structure should be equal to 12 . Double perovskite allows the elements with high valence shells to accommodate in structure, thus expanding the compositional flexibility. ${ }^{49,68}$

Perovskites' compositional flexibility is often represented by their ease of alloying on A and B sites. Normally, the mixing element in semiconductors is isovalent, while in perovskite, the mixing element is non-isovalent. The simplicity of cation mixing in perovskite materials makes it easy to alter its chemical and physical characteristics. The double perovskite structure also shows interesting properties like half-metallicity, hightemperature ferromagnetism, and many magnetic interactions. The infrastructure of the complicated oxide unit cell depends upon the electronic configuration and the atoms located at the A and B-site. The B-site atoms are considered to be more critical than A-sited cations. The size of the $\mathrm{A}^{2+}$ cation is larger compared to the $\mathrm{A}^{3+}$ cation. As the $\mathrm{A}^{3+}$ cation has a smaller size, it limits the size of B-site cations. More than one thousand double perovskite materials are reported in the literature, all of which are prepared at ambient pressure. Some new materials were synthesized at high pressure. More than 720 compounds are reported as the divalent A-site compounds and 200 as trivalent A-site..$^{30,69-71}$

The structural network of $\mathrm{BO}_{6}$ octahedra can be maintained in the presence of vacancies at $\mathrm{A}, \mathrm{B}$, and $\mathrm{O}$ sites because of the perovskite's excellent structural and compositional flexibility. Applications of the perovskite materials are broad due to these vacancies, and therefore, they carry applications in photocatalysis, photovoltaics, supercapacitors, batteries and fuel cells, etc. ${ }^{30}$

Stability of perovskite oxide materials. The challenge to make use of perovskite photocatalyst materials come from two significant restraints: (1) chemical instability in polar solvents and (2) vulnerability of the surface to transform with chemical species present in solution. Recent progress in this field improved these issues and illustrated different courses of actions to make use of perovskite materials in photocatalytic processes. ${ }^{72}$ There are two main stability issues; (1) intrinsic stability-stability issues, and (2) extrinsic stability-stability issues of perovskite. Intrinsic stability involves structural stability, electronic band structure, and thermodynamic phase stability. In contrast, extrinsic stability encompasses interaction with water molecules and pathways of degradation, thermochemical stability, light induced ion redistribution, light stability, photochemical degradation, and oxidation/photooxidation of charge-transporting layers and perovskites. ${ }^{73}$

Perovskite material and photocatalysis. Perovskite materials, due to their structural, compositional, and stoichiometric flexibility, are considered promising materials for photocatalysis (Fig. 3). Perovskites-based photocatalysts operate in UV, IR, and visible regions. There are three different sites of alteration in perovskite material which makes tuning of the bandgap in perovskite material easy. In this review, the applications of the perovskite material in photocatalysis are discussed in detail. ${ }^{74,75}$

General reaction mechanism of photocatalysis. The light interacts with the surface of the nano photocatalyst, which generates the electron $\left(\mathrm{e}^{-}\right)$and hole $\left(\mathrm{h}^{+}\right)$pair. The photogenerated electron-hole pair then initiates the redox reaction at the photocatalyst's surface. There are three steps involved in the mechanism of photocatalysis. The first one is photo-excitation, provided that the energy of the light source should be high enough to overcome the bandgap. The second step is trapping the electron-hole pairs to increase the recombination time. The recombination of photoinduced charges produces heat, which decreases the efficiency. The third and final step is the degradation of the pollutant by the reactive species produced due to a redox reaction or the production of the fuel..$^{76-79}$ The general reaction mechanism for all the reactions is given by;

1st step: photoexcitation of photocatalyst

$$
\text { Photo catalyst }+h v \rightarrow \mathrm{e}^{-}+\mathrm{h}^{+}
$$

2nd step: trapping of electron and hole:

$$
\begin{aligned}
\mathrm{e}^{-} & \rightarrow \mathrm{e}_{\text {trap }}^{-} \\
\mathrm{h}^{+} & \rightarrow \mathrm{h}_{\text {trap }}{ }^{-}
\end{aligned}
$$

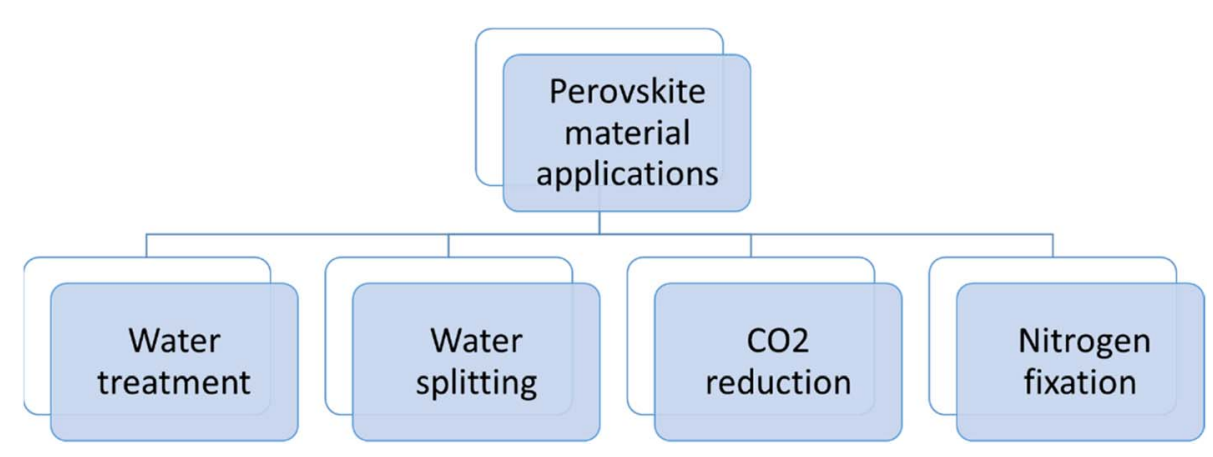

Fig. 3 Applications of perovskite materials. 


$$
\text { Oragnics (pollutant) }+ \text { radicals } \rightarrow \text { degarded pollutant }
$$

The final step varies for each application of photocatalysis and governing equations:

For water splitting:

$$
\mathrm{H}^{+}+\mathrm{e}^{-} \rightarrow \mathrm{H}_{2}
$$

For $\mathrm{CO}_{2}$ reduction:

$$
\mathrm{H}^{+}+\mathrm{e}^{-}+\mathrm{CO}_{2} \rightarrow \text { fuel }\left(\mathrm{H}_{2}+\mathrm{CH}_{4}\right)
$$

For nitrogen fixation:

$$
6 \mathrm{H}^{+}+6 \mathrm{e}^{-}+\mathrm{N}_{2} \rightarrow \mathrm{NH}_{3}
$$

The photogenerated electron-hole pair can be used in various applications depending upon the redox potential for the applications, as depicted in Fig. 4.

The selection of the photocatalyst material for the particular application is crucial and an important step to achieve better results. ${ }^{80}$ The semiconductor material is selected by balancing the band edge potential of the semiconductor material with the reaction potential. The main hurdles in photocatalysis are the less recombination time of the photoinduced electron-hole pair and absorption wavelength corresponding to the photocatalyst material. Most materials are UV activated, and in the solar spectrum, the UV region is only $5 \%$; therefore, for enhanced photocatalytic activity, the material bandgap should be responsive to visible and NIR radiations along with the high recombination time of electron-hole pair. ${ }^{81,82}$

In the perovskite structure, there are three sites of the alteration (A site, B site, and $\mathrm{O}$ site). The doping at these sites can enhance light absorbance in the visible and NIR regions by bandgap alteration. The recombination time can also be addressed by employing the different strategies that includes tuning of bandgap and repression of electron-hole recombination. To solve both light absorption and recombination time problems, a new innovative solution known as defect

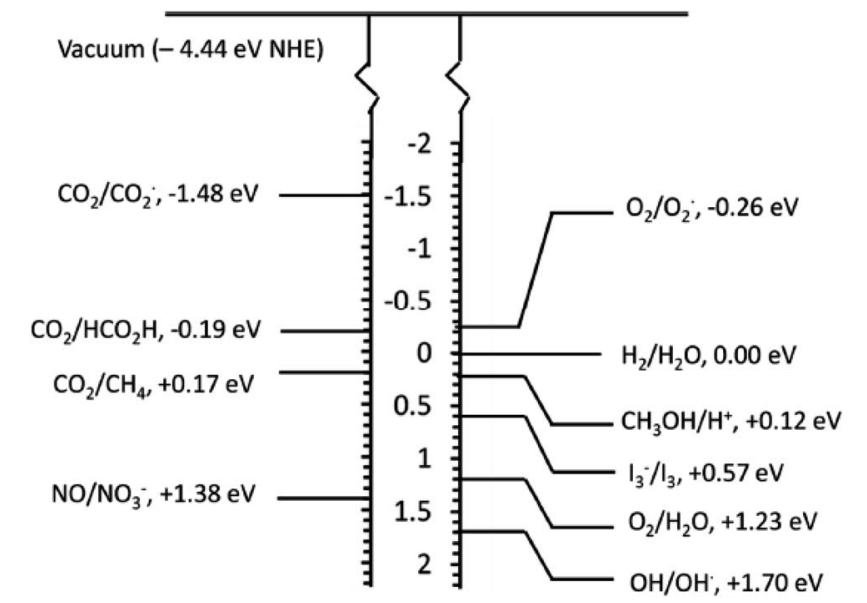

Fig. 4 Redox potential required for the various photocatalytic applications. ${ }^{10}$ engineering has been proposed. ${ }^{8,83-85}$ The strategies for tuning the bandgap are;

(i) Bandgap engineering

(ii) Repression of electron-hole pair recombination

(iii) Defect engineering

The bandgap of the various perovskite materials is given in Table 1.

Bandgap engineering. Most perovskite materials respond to UV light due to their wide-bandgap. The conduction band of perovskite materials contains d-orbital, slightly above or equal to zero $\mathrm{eV}$. The valence band has the $2 \mathrm{p}$ orbital, due to which energy of the valence band in perovskite material is generally greater than $3 \mathrm{eV}$. The perovskite bandgap provides enough redox potential to execute different photocatalytic reactions, like $\mathrm{H}_{2}$ generation, $\mathrm{CO}_{2}$ reduction, contaminants degradation, and nitrogen fixation. The donor and acceptor impurities in the perovskite crystal structure can adjust the bandgap. The donor and acceptor impurities in a perovskite can tune the material's bandgap. The doping at the cations or anions at different sites of perovskite structure enhances the photocatalytic activity by introducing the intra-band energy levels; the shallow and deep intraband energy levels trap the photogenerated electron-hole pair. Doping also reduces the bandgap of the perovskite material (Fig. 5). ${ }^{30,95}$

In perovskite material, doping of the transition metals (delectrons rich cations) led to the production of donor impurities in the perovskite structure. The high atomic energy of the transition metal ensures better electron mobility without changing conduction band minima of perovskite host material. ${ }^{96}$

The doping at the different sites of the perovskite structure changes the absorption peak of the material, thus increasing the light absorption. Doping also tailors the material's bandgap and increases the efficiency of the photocatalyst material. Incorporating a new transition energy level in the perovskite structure improves the higher wavelength absorption without changing the intrinsic absorption properties of the material. Hybridization of orbital in perovskite structure and formation heteroatom due to the doing changes the absorption spectra of material. The hybridization decreases the bandgap and therefore increases the absorption of light. Thus, the doping changes the bandgap and increases the recombination time. ${ }^{83,97-99}$

The bandgap of pure $\mathrm{SrTiO}_{3}$ is $3.25 \mathrm{eV}$, and doping with noble metals like $\mathrm{Ru}, \mathrm{Rh}, \mathrm{Au}$, etc., introduces the intra-band

Table 1 Bandgap of some perovskite materials

\begin{tabular}{lll}
\hline Material & Bandgap (eV) & Ref. \\
\hline $\mathrm{SrTiO}_{3}$ & 3.20 & 86 \\
$\mathrm{NaTaO}_{3}$ & 4.0 & 87 \\
$\mathrm{CaTiO}_{3}$ & 3.62 & 88 \\
$\mathrm{BiFeO}_{3}$ & 2.40 & 89 \\
$\mathrm{LaFeO}_{3}$ & 2.00 & 90 \\
$\mathrm{NaNbO}_{3}$ & 3.48 & 91 \\
$\mathrm{LaCoO}_{3}$ & 2.1 & 92 \\
$\mathrm{Bi}_{2} \mathrm{WO}_{6}$ & 2.70 & 93 \\
$\mathrm{La}_{2} \mathrm{Ti}_{2} \mathrm{O}_{7}$ & 3.28 & 94
\end{tabular}



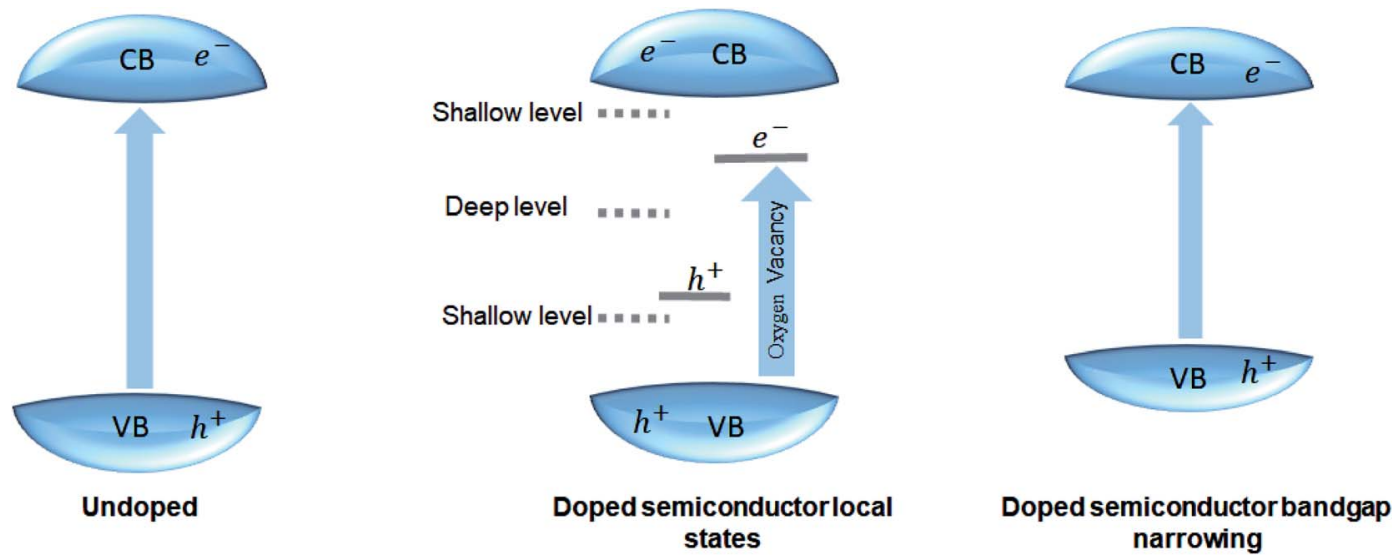

Fig. 5 Effect of doping on the bandgap.

local states, making the doped $\mathrm{SrTiO}_{3}$ a suitable photocatalyst. $^{100}$ The $\mathrm{Ru}$ doping introduces the intra-band energy state between conduction band (Ti 3d) and valence band (O 2p, $\mathrm{Sr} 4 \mathrm{p}$ ). The ionic radius of $\mathrm{Ru}$ is greater than $\mathrm{Sr}$ and nearly equals $\mathrm{Ti}$; therefore, the $\mathrm{Ru}$ substitutes $\mathrm{Ti}$ atom in $\mathrm{SrTiO}_{3}$. Ru doping at the B site of the $\mathrm{SrTiO}_{3}$ introduces the local states and increases the photocatalytic performance. The doping of noble metals in $\mathrm{SrTiO}_{3}$ makes it a Vis-IR responsive photocatalyst. ${ }^{86}$

Similarly, doping the bismuth (Bi) or copper $(\mathrm{Cu})$ at A site of $\mathrm{SrTiO}_{3}$ introduces the intra-band energy level and reduces the bandgap. The change in the absorption shift was also reported due to the change in the bandgap with doping. ${ }^{101}$ It is reported that doping of the sulfur at the $\mathrm{O}$ site of the $\mathrm{ABO}_{3}$ introduces the intraband energy level at $1.23 \mathrm{eV}$. Researchers also noted that doping the nitrogen at the $\mathrm{O}$ site of the perovskite material increases photocatalytic activity. ${ }^{102,103}$

The amount and the quantity of the dopant should also be optimized to impede the recombination of the photogenerated charge carrier. Synthesis methods for preparing the perovskite material also affect the bandgap, recombination of charges, and migration properties of photocatalyst. ${ }^{104,105}$

Repression of the photogenerated electron-hole pair recombination. The movement of photoinduced charge carriers at the photocatalyst's surface initiates the redox reaction at the surface of the photocatalyst. The recombination of charge carriers can occur either at the surface or in bulk. The recombination reduces efficiency, so it must be repressed. ${ }^{106-108}$

The crucial step in photocatalysis is selecting the material, which depends upon the absorption coefficient of the photocatalyst material. The absorption coefficient of photocatalyst depends upon the bandgap and photon energy. ${ }^{109-111}$ The incident light generates the electron-hole pair below the catalyst surface, known as the absorption length. The development of the space charge region takes place at the phase of the solidliquid interface, and if the absorption extent exists in the space charge region, the photoinduced electron-hole pair can be easily separated. However, in the case of the bulk material, the recombination rate will be high. ${ }^{112,113}$ After separating the photo-induced charges, the next step is the migration of the charge carriers. The migration mainly depends on the material's symmetry and diffusion length. Diffusion length is the distance that photogenerated charges travel without recombining or scattering. Diffusion length is the governing factor for controlling the movement of the charges in the absence of the potential gradient. Separation of the photogenerated charges beyond the charge separation region is feasible with materials whose diffusion length is longer. The diffusion length is multiple of the lifetime of the charge carrier and diffusion constant, and it should be of high value to generate the maximum photogenerated charge carriers. ${ }^{114-116}$ The limiting factor for the range of charge space region is the particle size. The width of the charge space region should not surpass the particle's radius, and therefore the use of nano-size crystals improves the photocatalytic activity. ${ }^{108,117,118}$

The perfection in the crystal structures affects the lifetime of the photogenerated charge carrier. The potential gradient also affects the photocatalytic activity because it efficiently separates the photo-induced charges through the support interfaces between the semiconductor-semiconductor, semiconductormetal, and semiconductor-conductor surfaces, forming the heterojunctions. Therefore, it is necessary to introduce the potential gradient for attaining better efficiency of photocatalytic material. Furthermore, combining the two semiconductors with different bandgaps represses the electron-hole pair recombination. Co-catalyst can also enhance efficiency by introducing active sites and better charge transfer. ${ }^{79,119-126}$

Charge transfer mechanism. Charge transfer mechanisms are of different types, depending on the photocatalyst system. The coupling of two photocatalyst semiconductor materials gives the heterojunction, further categorized into three types. The heterojunction type formed by the semiconductor materials depends on their bandgap. ${ }^{119,127}$ The three types of heterojunctions are type I, type II, and type III. The combination of the semiconductor materials forms the Z-scheme, p-n junction, and the Schottky junction based on the type of the semiconductor used (Fig. 6)..$^{121,128,129}$

Type I, a heterojunction known as straddling gap heterojunction, involves one semiconductor photocatalyst (SP I) with 
(a)

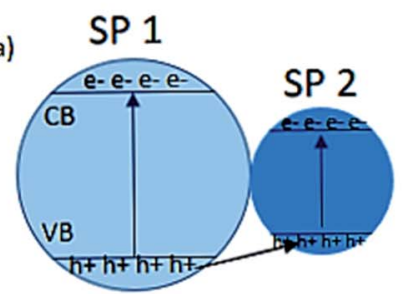

(b)

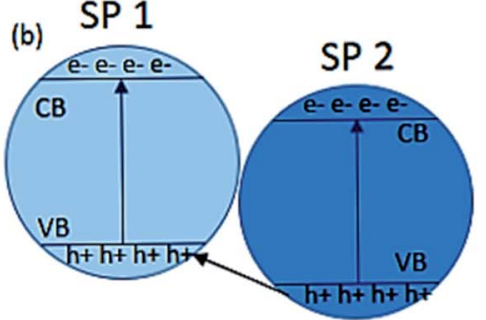

Type 1

(d)

SP 1 Heterojunction

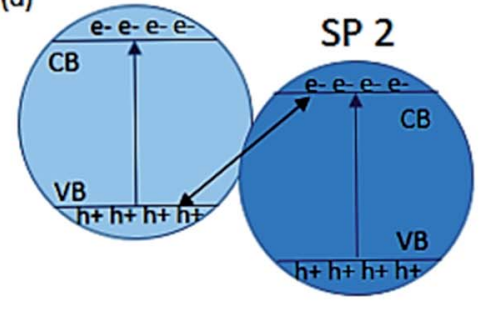

Z- scheme

Type 2

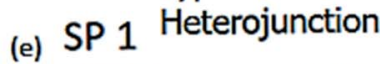

P-n
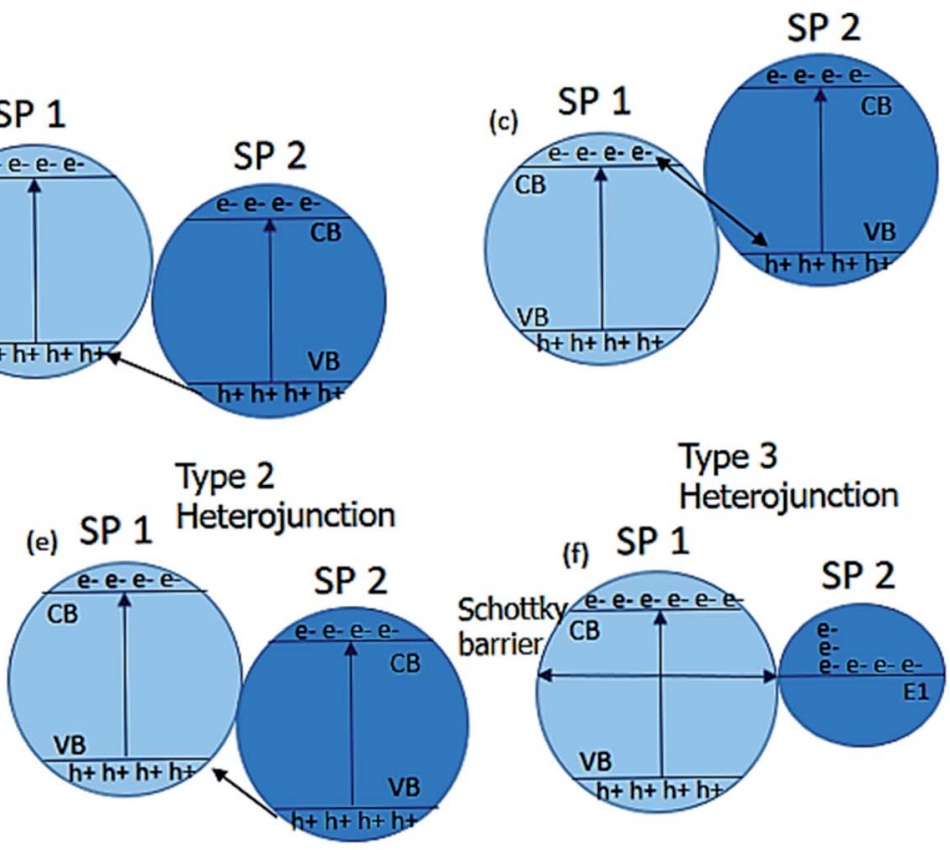

Type 3

Heterojunction

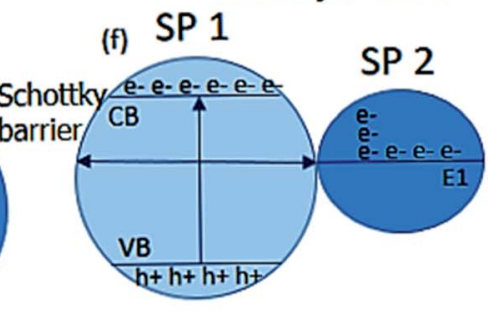

Heterojunction

Schottky Junction

Fig. 6 Charge transfer mechanisms (a-f) in two coupled semiconductors.

a highly negative conduction band and highly positive valence band while the bands of the other photocatalyst semiconductor (SP II) lie within it. The drawback of type I heterojunction is that the charges accumulate on the semiconductor with a lower bandgap which is not favorable. ${ }^{127,130}$

In type II, the conduction and valence band of the one semiconductor SPI lies above the conduction and valence band of the SPII. The charge separation of the photogenerated electron-hole pair is efficient in type II because of the electron's downward movement from the conduction band of SPII and an upward movement of the holes from SPI's valence band. ${ }^{131,132}$

In type III heterojunction, the valence and conduction bands difference is more than type II. The photogenerated electrons of the SPI unite with the photogenerated hole of SPII. The SSPII electron and the SPI hole innate the redox reaction in the semiconductor photocatalyst. ${ }^{\mathbf{1 2 0 , 1 3 0}}$

The understanding of the Z-scheme is necessary to understand the heterojunction. In Z-scheme, two semiconductor photocatalyst materials are linked in a way that they form the letter $\mathrm{Z}$. The electrons from the conduction band of the SPII trans into the valence band of the SPI. SPI acts as a reduction site, and SPII serves as an oxidation site. Due to the redox potential between the two semiconductors, the inbuilt electric field allows efficient charge separation. The direct Z-scheme involves the contact at the interface of two semiconductor materials. In contrast, the indirect Z-scheme involves mediators that allow the charge transfer between the two semiconductor materials. The mediator can be solid or liquid. The iron-based mediators are more commonly used..$^{\mathbf{1 3 3 - 1 3 5}}$
The heterojunction can also be formed by combining the $\mathrm{p}$ and n-type of the semiconductor materials. A free-electron from n-type semi-conductor material migrates toward the p-type semiconductor material upon contact. The migration of free electrons results in the formation of oppositely charged interfaces. This migration also strengthens the inbuilt electric field at the contact of the $\mathrm{p}-\mathrm{n}$ junction. The built-in electric field facilitates the migration of the photogenerated charge carrier after light irradiation, which increases the photocatalytic performance (Fig. 7). ${ }^{136,137}$ Examples of semiconductor-semiconductor photocatalyst are $\mathrm{SnO}_{2}-\mathrm{TiO}_{2}, \mathrm{CdS}-\mathrm{TiO}_{2}, \mathrm{Bi}_{2} \mathrm{O}_{3}-$ $\mathrm{Bi}_{2} \mathrm{WO}_{6}$ and $\mathrm{Bi}_{2} \mathrm{WO}_{6}-\mathrm{TiO}_{2}$, etc. ${ }^{138}$

The increased charge separation of metal-semiconductor photocatalysts arises from the transfer of the electron across the interface of metal-semiconductor. Metal improves photocatalytic performance because it provides active sites and facilitates the separation and transfer of photoinduced charge carriers. When a metal (having a high work function) couples with semiconductor, the electrons flow from the semiconductor to the metal until their Fermi levels get aligned, resulting in upward bending of band edges in semiconductor and accompanied by the band bending, formation of Schottky barrier takes place at the metal-semiconductor interface (Fig. 8). The electron from the conduction band of the semiconductor material migrates to the co-catalyst and causes charge separation, and increases the photocatalytic activity. ${ }^{139-141}$ The prominent examples of metal-semiconductor photocatalysts are $\mathrm{Au} /$ $\mathrm{TiO}_{2}, \mathrm{Au} / \mathrm{ZnO}, \mathrm{Ag} / \mathrm{ZnO}, \mathrm{Ag} / \mathrm{TiO}_{2}$, etc. ${ }^{142}$ 


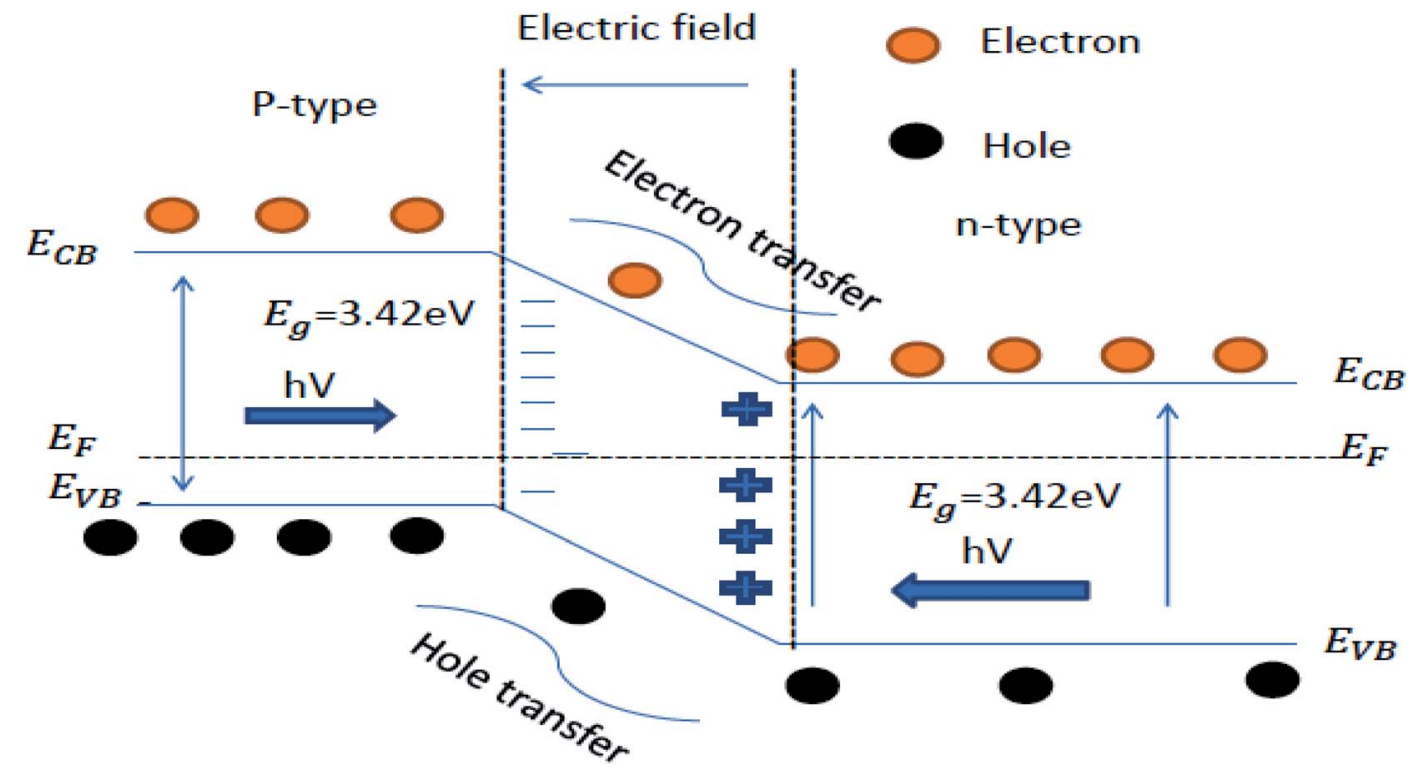

Fig. 7 Schematic energy band structure and electron-hole pair separation in the $p-n$ heterojunction. ${ }^{126}$

Defect engineering. Defect engineering is a suitable and easy way to enhance the photocatalytic efficiency of perovskite materials. Substituting the different materials can introduce defects in the perovskite materials in the perovskite structure. These defects act as a site to trap the charge carriers and thus enhance the separation of charge carriers and increase the photocatalytic efficiency. These defects can be a vacancy of an extra atom that results in the formation of the line or screw dislocation..$^{143-145}$

In perovskite materials, three different alteration sites allow the introduction of the defects or vacancies. The doping at the A and B site cations introduces the dislocation but does not allow structural changes. The structural changes can introduce vacancies at the $\mathrm{A}$ site or $\mathrm{O}$ site. The vacancy at the $\mathrm{B}$ site is challenging to introduce due to the $\mathrm{BO}_{6}$ octahedra. Furthermore, it is thermodynamically unfavorable to introduce the vacancy at the $\mathrm{B}$ site due to the high charge value and the small B site cation size. ${ }^{146,147}$

The vacancies at the A site can be induced by substituting the A-site cation with a cation of the high or low valence. The subsisted single perovskite oxide formula is: $\mathrm{A}_{1-x} \mathrm{~A}_{x} \mathrm{BO}_{3}$ and the oxygen-deficient vacancy can be created by doping the sulphur or nitrites. The second approach is doping at the B site, in which the reduction of the B site produces oxygen vacancy. In recent years, many defect-rich perovskite materials with excellent photocatalytic activity have been reported. Fig. 9 represents different strategies for bandgap tunning of perovskite materials. ${ }^{30,148,149}$

The potential of semiconductor photocatalyst mainly depends on the electron injection capacity of the material, which is controlled by the energies of valence $\left(E_{\mathrm{VB}}\right)$ and conduction bands $\left(E_{\mathrm{CB}}\right)$. Therefore, to investigate the possible applications of semiconductors, it is crucial to have an understanding of the $E_{\mathrm{CB}}$ and $E_{\mathrm{VB}}$ band edges. In a semiconductor, the
Fermi level $\left(E_{\mathrm{F}}\right)$ determines the electrochemical potential of electrons. At thermodynamic equilibrium, $E_{\mathrm{F}}$ tells the occupation of the energy levels, but thermodynamic equilibrium can be perturbed by external bias or irradiation due to injection or photogeneration of holes and electrons. Therefore, the quasiFermi levels define the non-equilibrium densities of electrons in conduction band and holes in valence band. Generally, the quasi-Fermi level for the majority carriers approximates the equilibrium $E_{\mathrm{F}}$ because of the negligible increase of density of majority carriers. However, the quasi-Fermi level can be shifted because of the small minority carriers at equilibrium. ${ }^{150}$

When a semiconductor is in contact with another phase, the ionic interactions at the interface of the two phases cause an electrostatic adjustment in the material. To attain the equilibrium, especially at the semiconductor/electrolyte interface, the electrons flow from the phase of more negative $E_{\mathrm{F}}$ to the other, in which the semiconductor $E_{\mathrm{F}}$ matches the electrolyte $E_{\mathrm{F}}$,redox. This forms a space charge layer (SCL) in the semiconductor phase, which is associated with the upward bending of the band edges in the n-type semiconductor (Fig. 10c) and downward band bending in the p-type semiconductor (Fig. 10d). The SCL contributes to an internal electric field in the semiconductor, where majority carriers are forced away from the interface of semiconductor/electrolyte. Such an SCL accounts for one of the three distinct double layers, in addition to the Helmholtz layer and Gouy-Chapman layer, which are commonly present at the interface of semiconductor/electrolyte. ${ }^{150}$

Recyclability of perovskite photocatalyst. Reusability is crucial for a photocatalyst, reflecting its superiority in the photocatalysis domain. It is worth mentioning that commonly available or used photocatalysts are homogeneous photocatalysts that cannot be recycled in the developed methods. Moreover, their practical applications are limited because of complex synthesis approaches, the high cost of noble metals, conditions of air-free reaction, and modest activity. Therefore, it 
is essential to develop an easily produced heterogeneous photocatalyst that also exhibits the property of easy catalyst separation along with recyclability. The researchers have recently started reporting heterogeneous perovskite photocatalyst in photocatalytic organic synthesis. The perovskites-catalyzed selective oxidation of benzyl alcohols to aldehydes under visible light irradiation has been reported by a group of researchers. Another group reported the photoredox $\mathrm{CsPbBr}_{3}$ catalyzed oxidative coupling of thiols to disulfides and crossdehydrogenative coupling of dialkyl H-phosphonates with tertiary amines to $\alpha$-phosphoryl tertiary amines. Yan and their fellows also reported the $\alpha$-acylmethylation of aldehydes starting from aldehydes and $\alpha$-bromo ketones catalyzed by $\mathrm{CsPbBr}_{3}$ under light. The same group also used $\mathrm{CsPbBr}_{3}$ photocatalyst for the formation of $\mathrm{C}-\mathrm{C}$ bond via $\mathrm{C}-\mathrm{H}$ activation, formation of $\mathrm{C}-\mathrm{N}$, and $\mathrm{C}-\mathrm{O}$ via $\mathrm{N}$-heterocyclization, and arylesterification. A group of researchers prepared a heterogenous perovskite photocatalyst and used it at least five times without noticeable degradation in its activity. ${ }^{151,152}$

\section{Applications of photocatalysis}

There are numerous photocatalysis applications, but during the last couple of decades, a lot of focus has been given to applications having environmental applications such as wastewater treatment, nitrogen fixation, $\mathrm{CO}_{2}$ reduction, air purification, and water splitting. All of these applications except air purification have been discussed in the current article.

\section{Degradation of water pollutants}

Rapid industrial growth, mainly the textile industry, produces increased chemical wastes in the water. Industrial chemical wastes or pollutants are known as dyes. The dyes produced by the textile industry can impede plant growth, impair photosynthesis, and its accumulation in soil disturbs the food chain. The textile dyes in water also cause genetic problems and cancer. The dyes in water aggravate the regulatory functions of the different glands in humans and can also have adverse effects, like infertility and immune suppression in humans. The traditional ways to clean the dyes in water give rise to massive sludge because of adsorbent usage, which can further cause bacterial infections and skin problems. The photocatalytic degradation of the containments in the water is more reliable than the traditional methods. Recycling the adsorbents in conventional methods generally generates secondary pollutants, and recycling adsorbents also requires harsh conditions. ${ }^{153-156}$

The use of the photocatalyst is an eco-friendly way to degrade these water pollutants. The photocatalytic techniques utilize the advanced oxidation process (AOP) for degradation. The interaction of the light with the photocatalyst generates electronhole pair. Generally, oxygen is employed as an electron scavenger to increase the recombination time for enhanced photocatalytic activity. The redox reaction of the photogenerated electron-hole pair gives reactive species such as $\left(\mathrm{OH}^{*}, \mathrm{OH}^{-}\right.$, $\mathrm{H}^{+}$), and these reactive species then attack the organic pollutants and degrade them into low molecular weight products (environmentally friendly products) within no time. ${ }^{\mathbf{1 5 3 , 1 5 7 , 1 5 8}}$

The heterogeneous design and the self-cleaning surface of the catalyst make recyclability much easier. The reactions occur at the catalyst's surface, followed by the desorption of the materials; thus, this method is known as a sustainable solution to address the water contamination crisis. ${ }^{\mathbf{1 5 9 , 1 6 0}}$

The photocatalytic activity can not only be monitored by investigating the absorption spectra of the dye molecule but also involves the investigation of the mineralized products formed due to the cleavage of the chromosphere. The mineralized products can be investigated by measuring the chemical oxygen demand (COD) and total organic carbon (TOC). The photocatalytic reaction for degradation of the containments occurs in an aqueous environment. The irradiation of the light on the aqueous system (consisting of photocatalyst + polluted water) generates photogenerated electron-hole pair in water. The oxygen or different impurities are added as an electron scavenger to increase the recombination time..$^{25,104,161,162}$ The photogenerated electron-hole pair then migrates towards the surface of the photocatalyst and induces the reactive ions (such as $\mathrm{OH}^{*}, \mathrm{O}^{2-*}$, etc.). The redox potential of the created reactive ion species depends upon the bandgap of the photocatalyst. The reactive ion species then degrade the contaminant into the smaller fragments, which are then changed into green compounds. The degradation of the contaminants takes place at the surface of the catalyst. Initially, the dye gets adsorbed at the catalyst surface, and after the degradation product gets desorbed, the new pollutant is adsorbed, and this process continues until no contaminant is left. The overall reaction mechanism is shown in (Fig. 11). ${ }^{30,76,135,163,164}$

Many perovskite materials are used as a photocatalyst, but titanium, bismuth, and ferrite-based single and double perovskite are widely reported due to their excellent photocatalytic properties. ${ }^{165}$ The first reported perovskite material $\mathrm{CaTiO}_{3}$ exhibited photocatalytic activity and degraded pollutants. The wide bandgap of $\mathrm{CaTiO}_{3}(3.0-3.5 \mathrm{eV})$ responds only to the UV light and efficiently degrade the brilliant green (BG), methyl blue (MG), and rhodamine $\mathrm{B}(\mathrm{RHb}){ }^{88,166}$ The synthesis route and the morphology of the $\mathrm{CaTiO}_{3}$ structure change the bandgap and thus affect the photocatalytic performance for pollutant degradation. $\mathrm{CaTiO}_{3}$ nanocuboid showed the excellent photodegradation of the RhB dye upon visible light irradiation. Zirconium ( $\mathrm{Zr}$ ) doping at the Ti site of $\mathrm{CaTiO}_{3}$ generates oxygen vacancies, producing defects and increasing photocatalytic activity by changing the lattice structure. ${ }^{167,168}$ The reported photocatalytic activity of the $\mathrm{Zr}$ doped $\mathrm{CaTiO}_{3}$ is thirteen times greater than the un-doped $\mathrm{CaTiO}_{3}$. Fe-doped $\mathrm{CaTiO}_{3}$ efficiently degraded the methyl blue using the visible light source. ${ }^{166}$ The doping of the $\mathrm{Fe}$ in the $\mathrm{CaTiO}_{3}$ increased the absorption ability of $\mathrm{CaTiO}_{3}$. The photocatalytic activity also depends upon the calcination temperature and the irradiation time of the light. Fe-doped $\mathrm{CaTiO}_{3}$ showed 100\% photodegradation of the methyl blue at optimum condition (temperature, irradiation time, and light source). ${ }^{169} \mathrm{BaTiO}_{3}$, $\mathrm{SrTiO}_{3}$, and other titanium-based perovskite materials have also shown better photodegradation of the pollutants. ${ }^{101,102,170}$ 


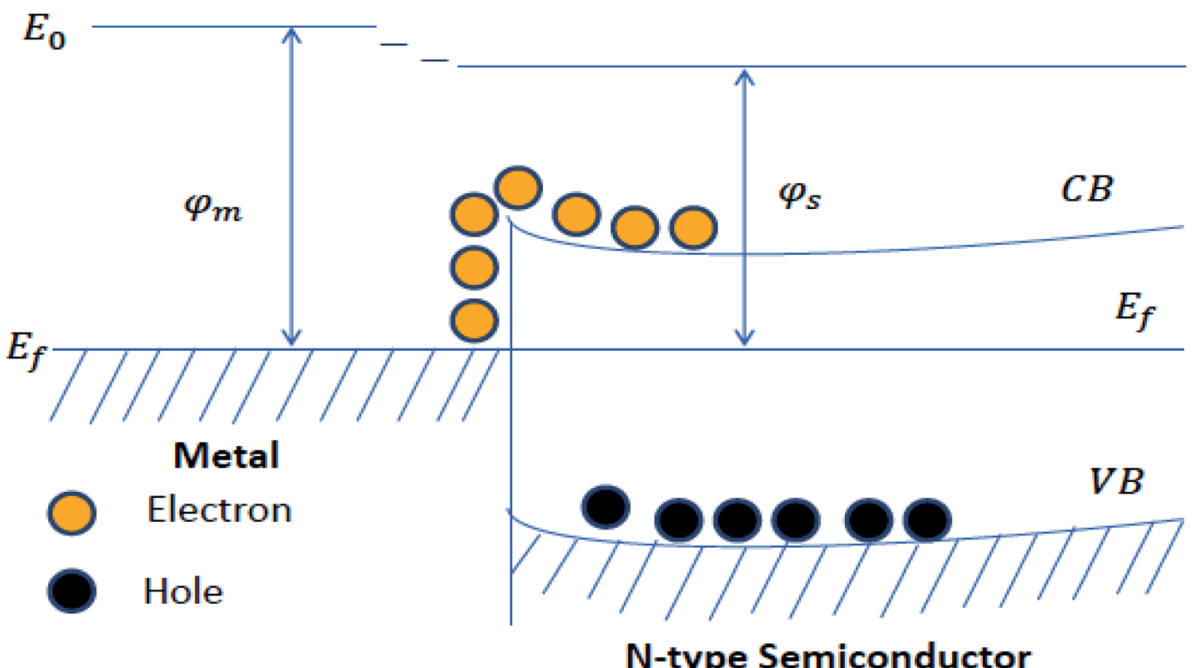

Fig. 8 Schematic of the Schottky barrier. ${ }^{126}$

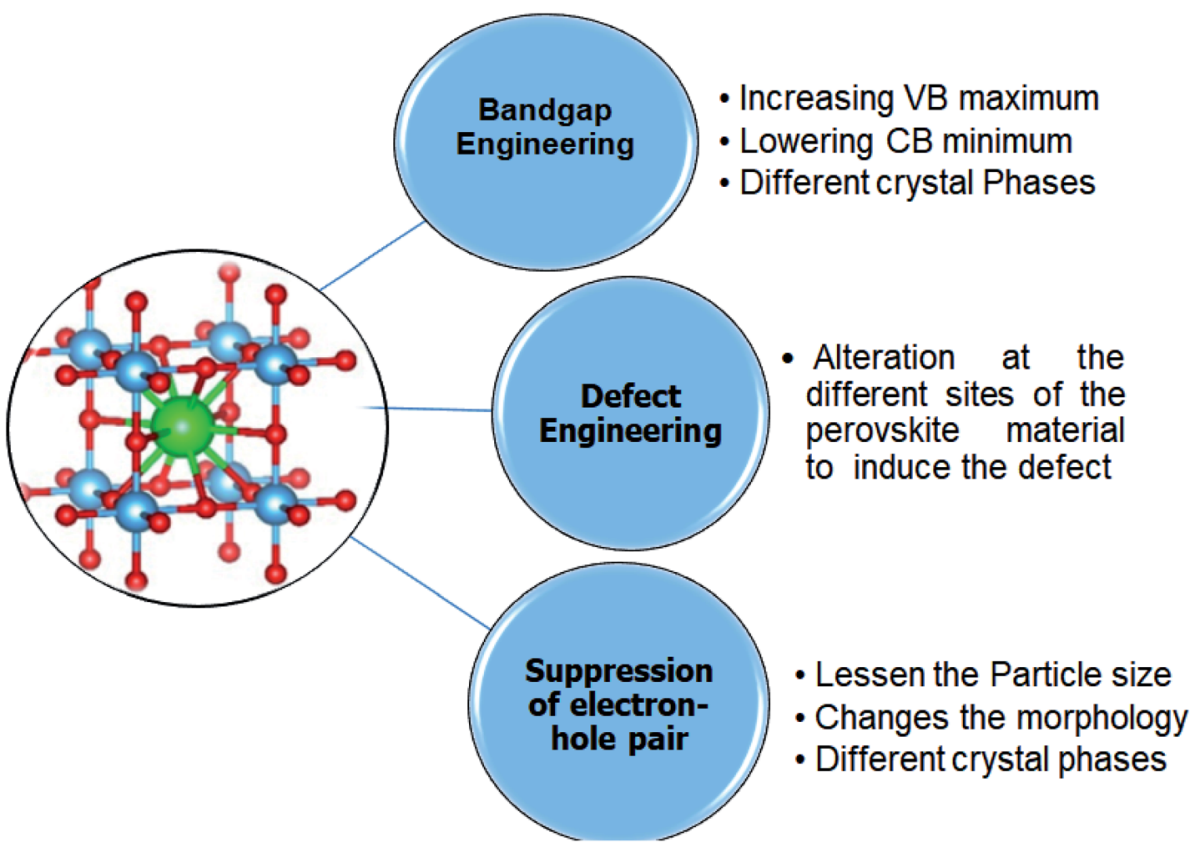

Fig. 9 Strategies for tuning bandgap.

Ferrites-based perovskite $\left(\mathrm{AFeO}_{3}\right.$, where A can be $\mathrm{La}, \mathrm{Bi}, \mathrm{Ca}$, $\mathrm{Sr}, \mathrm{Gd}$, etc.) attracted researchers due to their low cost and small bandgap compared to the titanium-based perovskite. ${ }^{171}$ The widely used ferrite-based perovskite is bismuth ferrite $\left(\mathrm{BiFeO}_{3}\right)$. The small bandgap (2.0-2.77 eV), excellent stability, and strong photoabsorption of $\mathrm{BiFeO}_{3}$ allow the efficient photodegradation of organic dyes from textile and pharmaceutical industries under visible light. ${ }^{172-174}$ The pure $\mathrm{BiFeO}_{3}$ in the sunlight showed $69 \%$ photodegradation of methyl blue. The doping at different sites of $\mathrm{BiFeO}_{3}$ has shown better results. Sc doped $\mathrm{BiFeO}_{3}$ showed $100 \%$ photodegradation of the methyl blue in 3 hours under sunlight. The improved efficiency was attributed to improved ferroelectric properties due to lattice distortion produced by doping. ${ }^{98}$ Mesh of $\mathrm{BiFeO}_{3}$ showed $98 \%$ photodegradation of the methyl blue within 4 hours. The excellent photocatalytic activity of $\mathrm{BiFeO}_{3}$ was due to the high interaction of the dye molecules and photocatalyst. $\mathrm{Bi}_{0.90} \mathrm{La}_{0.10} \mathrm{Fe}_{0.95^{-}}$ $\mathrm{Mn}_{0.05} \mathrm{O}_{3}$ showed $97 \%$ photodegradation of Congo-red within 2 hours under the sunlight. ${ }^{25}$

Tantalite-based perovskite is also reported for the degradation of water pollutants. Due to excellent photochemical stability, sodium tantalite $\left(\mathrm{NaTaO}_{3}\right)$ showed photocatalytic degradation properties. The efficiency of the $\mathrm{NaTaO}_{3}$ based photocatalytic system is quite less due to the wide bandgap of the material. Still, the doping of nonmetals increases its efficiency by creating a local state between the conduction and 

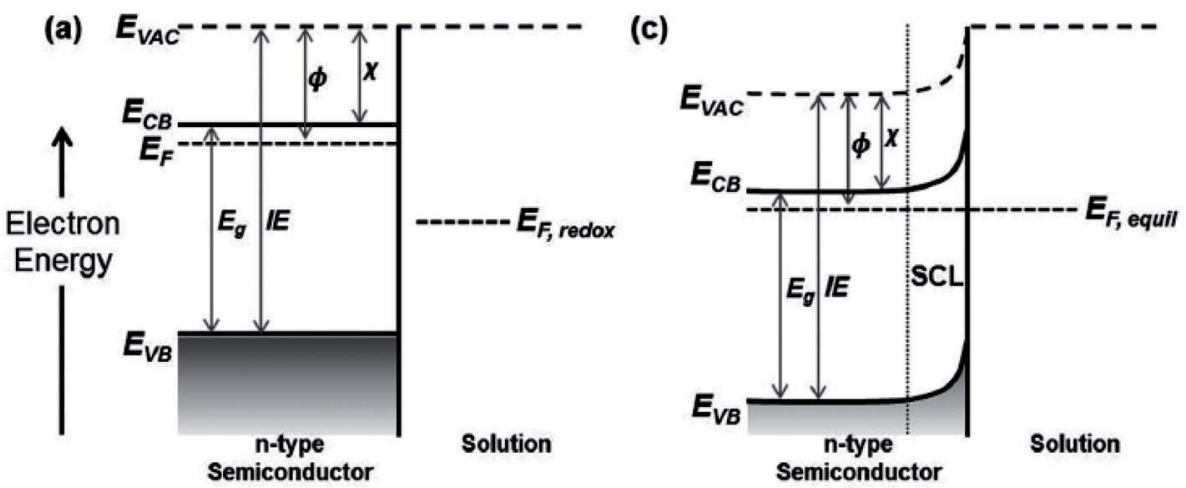

(b)
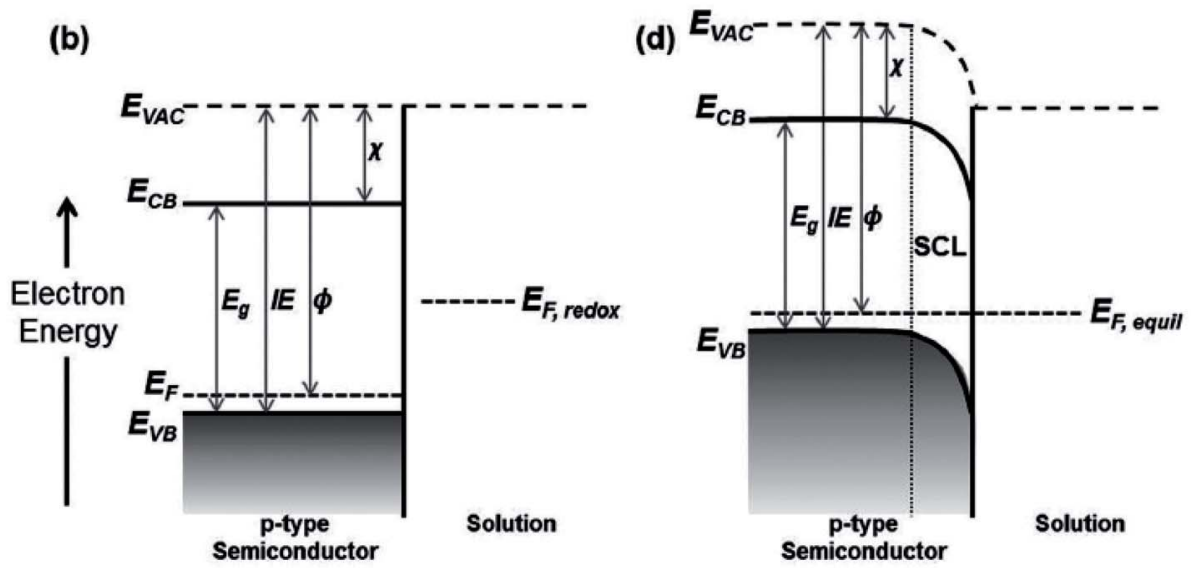

Fig. 10 Energy levels of the semiconductor/electrolyte interface before ( $a$ and b) and after contact (c and d). ${ }^{150}$

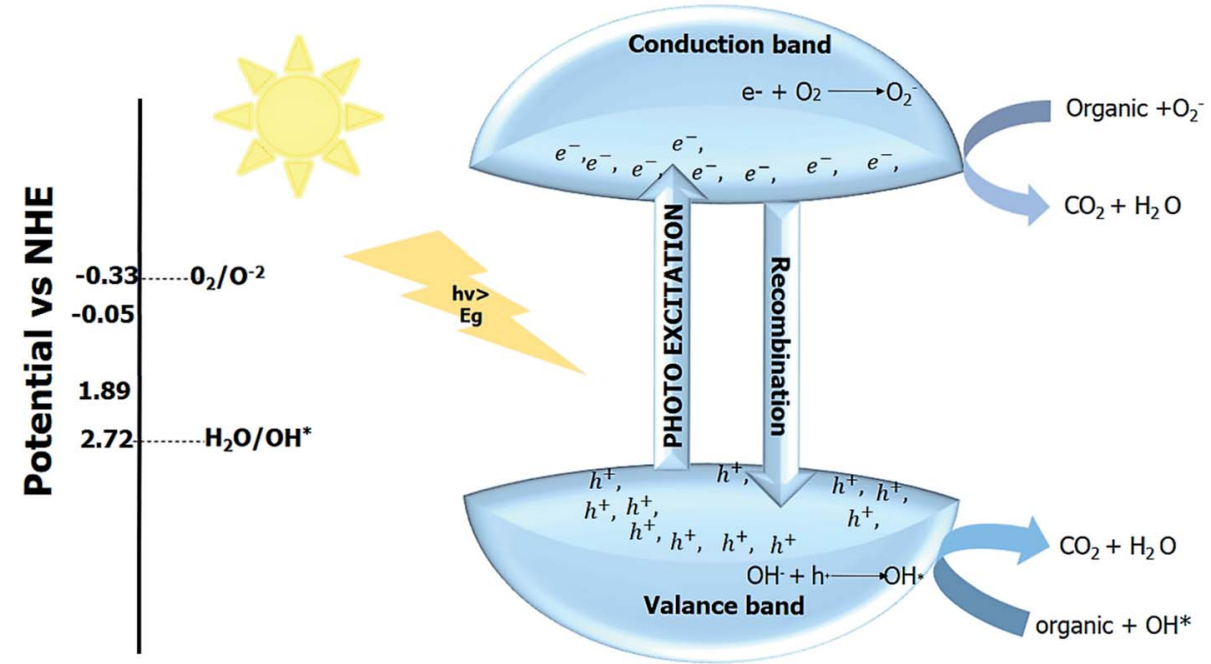

Fig. 11 Photocatalytic pollutant degradation.

valence band. The reported photodegradation of methyl blue is $95.21 \%$ by nitrogen-based $\mathrm{NaTaO}_{3}$ photocatalyst using sunlight as an irradiation source. ${ }^{\mathbf{1 7 5 , 1 7 6}}$ Different perovskite materials used for photocatalytic pollutant degradation are given in Table 2.

Photocatalytic water splitting. Hydrogen is considered a green and clean fuel and one of the best alternatives to fossil and other non-renewable energy resources. The photocatalytic splitting of the water produces $\mathrm{H}_{2}$ and $\mathrm{O}_{2}$ oxygen by the fourelectron process. The overall reaction of water splitting is depicted in eqn (9).

$$
2 \mathrm{H}_{2} \mathrm{O} \rightarrow 2 \mathrm{H}_{2}+\mathrm{O}_{2} \Delta G^{\circ}=+237 \mathrm{~kJ} \mathrm{~mol}^{-1}
$$


Table 2 Reported perovskite materials for photocatalytic pollutant degradation

\begin{tabular}{|c|c|c|c|c|c|}
\hline Material & Morphology & $\begin{array}{l}\text { Bandgap } \\
(\mathrm{eV})\end{array}$ & Pollutants/dyes & Light source & Degradation rate \\
\hline $\mathrm{CaTiO}_{3}$ (ref. 177) & Bare & $\sim 3$ & MO & UV light & $54 \%$ after 60 minutes \\
\hline $\mathrm{CaTiO}_{3}$-graphene ${ }^{178}$ & Composites & $\sim 3$ & MO & UV light & $98 \%$ after 60 minutes \\
\hline $\mathrm{C}$ doped $\mathrm{SrTiO}_{3}$ (ref. 179) & $\begin{array}{l}\text { Cubic particle, nanorod, } \\
\text { nanotube }\end{array}$ & $\begin{array}{l}\text { Less than } \\
3.2\end{array}$ & $\begin{array}{l}\mathrm{MB}, \mathrm{MO}, \mathrm{RhB} \text {, phenol, } \\
\text { and } \mathrm{BPA}\end{array}$ & Visible light & $\begin{array}{l}95 \% \text { of } \mathrm{MB}, \mathrm{MO}, \mathrm{RhB}, \text { and } \\
70 \% \text { of phenol and BPA after } \\
3 \text { hours irradiation }\end{array}$ \\
\hline $\mathrm{S}^{-\mathrm{SrTiO}_{3}}$ (ref. 180) & Powder & $<3.2$ & 2-Propanol & $500 \mathrm{~W}$-Xenon lamp & $\begin{array}{l}\text { After } 60 \text { min of irradiation, } \\
80 \% \text { of propanol is converted } \\
\text { into acetone }\end{array}$ \\
\hline $\mathrm{Cu}$ doped $\mathrm{SrTiO}_{3}$ (ref. 181) & Nanoparticle & 2.96 & Methyl blue & Visible light & $66 \%$ within 120 minutes \\
\hline Fe doped $\mathrm{SrTiO}_{3}$ (ref. 182) & - & 2.6 & Tetracyclin TC & Visible light & $71.6 \%$ in 80 minutes \\
\hline Mn-doped $\mathrm{SrTiO}_{3}$ (ref. 183) & Nanocubes & 2.76 & Tetracyclin TC & Visible light & $66.7 \%$ in 60 minutes \\
\hline $\mathrm{N}$ doped $\mathrm{NaTaO}_{3}$ (ref. 184) & Cubic & 2.48 & $\mathrm{MB}, \mathrm{MO}$ & UV-visible light & $95.1 \%$ in 60 minutes \\
\hline $\mathrm{Ag} / \mathrm{AgGaO}_{2}$ (ref. 185) & Composite & & $\mathrm{MB}$ & Visible light & $95 \%$ in 180 minutes \\
\hline $\mathrm{LaFeO}_{3}$ (ref. 186) & Nanoparticle & 2.36 & MB & Visible light & $100 \%$ after 60 minutes \\
\hline $\begin{array}{l}\mathrm{Z} \text {-scheme } \mathrm{MoS}_{2} / \mathrm{CaTiO}_{3} \text { (ref. } \\
\text { 187) }\end{array}$ & Nanospheres & 3.23 & TC & $\begin{array}{l}\text { Simulated solar } \\
\text { light }\end{array}$ & $70 \%$ in 60 minutes \\
\hline $\begin{array}{l}\text { p-n type }\left(30-60 \% \mathrm{Ag}_{3} \mathrm{PO}_{4}\right) / \\
\mathrm{NaTaO}_{3} \text { (ref. 188) }\end{array}$ & Crystalline & $2.32-3.78$ & $\mathrm{RhB}$ & Visible light & $87 \%$ in 25 minutes \\
\hline $\begin{array}{l}\mathrm{BiOI} / \mathrm{KTaO}_{3} \mathrm{p}-\mathrm{n} \\
\text { heterostructure }^{189}\end{array}$ & Composite & $1.76-2.23$ & RhB and phenol & Visible light & $91 \%$ after three cycles \\
\hline $\mathrm{BiFeO}_{3} / \mathrm{BiVO}_{4}$ (ref. 190) & Nanocomposites & 2.23 & $\mathrm{RhB}$ & Visible light & $69 \%$ within 120 minutes \\
\hline $\mathrm{In}_{2} \mathrm{~S}_{3} / \mathrm{NaTaO}_{3}$ (ref. 191) & Composite & $2.1-4.0$ & $\mathrm{TC}$ & $\begin{array}{l}\text { Stimulated solar } \\
\text { irradiation }\end{array}$ & $\begin{array}{l}53.2 \% \text { for } 20 \mathrm{wt} \% \mathrm{In}_{2} \mathrm{~S}_{3} / \\
\mathrm{NaTaO}_{3} \text { within } 180 \text { minutes }\end{array}$ \\
\hline $\begin{array}{l}(10 \mathrm{wt} \%) \mathrm{LaFeO}_{3} / \mathrm{SnS}_{2} \text { (ref. } \\
192)\end{array}$ & $\begin{array}{l}\text { Composite Z-scheme } \\
\text { heterojunction }\end{array}$ & 2.11 & $\mathrm{TC}$ & Visible light & $28.8 \%$ in 120 minutes \\
\hline$(1.7 \mathrm{wt} \%) \mathrm{Ag}-\mathrm{KNbO}_{3}($ ref. 193) & Nanowires & $2.2-3.35$ & RhB & UV-visible & $\begin{array}{l}95 \% \text { with UV in } 90 \text { minutes } \\
\text { and } 65 \% \text { with VIS in } 120 \\
\text { minutes }\end{array}$ \\
\hline 7\% Ni-doped $\mathrm{BiFeO}_{3}$ (ref. 194) & Nanoparticle & $\sim 2.28$ & MB & Visible light & $92 \%$ within 60 minutes \\
\hline $\mathrm{LaNiO}_{3}$ (ref. 195) & - & 2.26 & MO & Visible light & $74.5 \%$ after 5 hours \\
\hline$(5 \mathrm{wt} \%) \mathrm{NiS} / \mathrm{LaFeO}_{3}$ (ref. 196) & $\begin{array}{l}\text { LFO nanoparticle NiS } \\
\text { nanosheets (heterostructure) }\end{array}$ & $1.2-2.0$ & MO & Simulated sunlight & $90.9 \%$ higher than pure LFO \\
\hline $\mathrm{NaTaO}_{3} / \mathrm{rGO}(1.5 \%)^{197}$ & Composite & 3.87 & MB & 8 W UV lamp & $95 \%$ after 90 minutes \\
\hline N-doped $\mathrm{NaTaO}_{3}$ (ref. 176) & Cubic & $\begin{array}{l}\text { Less than } \\
3.94\end{array}$ & MO & Visible light & $95.21 \%$ after 14 hours \\
\hline $\begin{array}{l}(50 \% \mathrm{wt}) \mathrm{BiFeO}_{3} / \mathrm{V}_{2} \mathrm{O}_{5} \text { (ref. } \\
198)\end{array}$ & Nanoplates & $2.05-2.19$ & MB & Visible light & $96 \%$ after 120 minutes \\
\hline $\begin{array}{l}\mathrm{BiFeO}_{3} / 25 \% \text { wt } \mathrm{ZnFe}_{2} \mathrm{O}_{4} \text { (ref. } \\
\text { 199) }\end{array}$ & Nanocomposites & $2.2-1.96$ & MB & Visible light & $96 \%$ after 30 minutes \\
\hline $\mathrm{Sm}$ and $\mathrm{Mn}$ doped $\mathrm{BiFeO}_{3}$ & Nanoparticles & $1.45-2.08$ & $\mathrm{MB}, \mathrm{MV}$ & Visible light & $65 \%, 64 \%$ after 2 hours \\
\hline Carbon dots $/ \mathrm{BaZrO}_{3}$ (ref. 200) $\mathrm{I}$ & Hybrid nano nanomaterial & 4.8 & $\mathrm{MB}$ & UV light & $90 \%$ after 60 minutes \\
\hline $\begin{array}{l}\text { Z-scheme } \mathrm{LaCoO}_{3} / \mathrm{g}-\mathrm{C}_{3} \mathrm{~N}_{4^{-}} \\
60 \text { wt\% (ref. 135) }\end{array}$ & Composites & 2.46 & Phenol & Visible light & $85 \%$ in 5 hours \\
\hline $\mathrm{CuS} / \mathrm{Bi}_{2} \mathrm{WO}_{6}$ (ref. 201) & Composites & $1.76-2.69$ & $\mathrm{RhB}$ & Visible light & $90.0 \%$ in $50 \mathrm{~min}$ \\
\hline $\mathrm{Bi}_{2} \mathrm{WO}_{6}$ (ref. 202) & - & $2.7-2.85$ & EBT & Visible light & $74 \%$ in $180 \mathrm{~min}$ \\
\hline Sm-doped $\mathrm{Bi}_{2} \mathrm{WO}_{6}$ (ref. 203) & - & $2.4-2.5$ & $\mathrm{RhB}$ & Visible light & $98.4 \%$ in $30 \mathrm{~min}$ \\
\hline$(0.3: 1) \mathrm{Bi}_{2} \mathrm{WO}_{6} / \mathrm{ZnO}^{204}$ & Flower-like composite & $2.6-3.2$ & $\mathrm{MB}, \mathrm{TC}$ & Visible light & $\begin{array}{l}98.4 \% \text { for } \mathrm{MB} \text { in } 120 \mathrm{~min}, \\
90 \% \text { for } \mathrm{TC} \text { in } 120 \mathrm{~min}\end{array}$ \\
\hline $\mathrm{Bi}_{2} \mathrm{MoO}_{6}$ (ref. 205) & Nano sheets & $2.6-2.9$ & MB & Visible light & $90 \%$ of $\mathrm{MB}$ in $120 \mathrm{~min}$ \\
\hline $\mathrm{BiFeO}_{3} / \mathrm{Bi}_{2} \mathrm{Fe}_{4} \mathrm{O}_{9}$ (ref. 206) & Nanofibers & $1.96-2.15$ & $\mathrm{RhB}$ & Visible light & $65 \%$ in $1.5 \mathrm{~h}$ \\
\hline $2 \% \mathrm{Ag} / \mathrm{Bi}_{2} \mathrm{WO}_{6}$ (ref. 207) & $\begin{array}{l}\text { 3D hierarchical hybrid } \\
\text { material }\end{array}$ & - & $\mathrm{RhB}, \mathrm{TC}$ & Visible light & $\begin{array}{l}100 \% \text { in } 50 \mathrm{~min} / 90 \% \text { in } 70 \\
\min \end{array}$ \\
\hline $\mathrm{CQD} / \mathrm{Bi}_{2} \mathrm{WO}_{6}$ (ref. 208) & Composite & 2.6 & $\mathrm{MO}, \mathrm{BPA}$ & Visible/IR light & $\begin{array}{l}(94.1 \% / 18.3 \%) \text { in } 120 / \\
90 \mathrm{~min},(99.5 \% / 25.5 \%) \text { in } 60 / \\
90\end{array}$ \\
\hline $\mathrm{g}-\mathrm{C}_{3} \mathrm{~N}_{4} / \mathrm{Bi}_{2} \mathrm{WO}_{6}$ (ref. 209) & Nanosheets & 2.69 & Ibuprofen & Visible light & $96.1 \%$ in $60 \mathrm{~min}$ \\
\hline $\mathrm{Bi}_{2} \mathrm{WO}_{6} / \mathrm{RGO}^{210}$ & Microsphere & $2.3-2.69$ & $\begin{array}{l}\text { Phenol, MO, RhB, } \\
\text { SMM, SN }\end{array}$ & Sunlight & $\begin{array}{l}65.5 \% \text { in } 480 \mathrm{~min}, 78.5 \% \text { in } \\
480 \mathrm{~min}, 99.5 \% \text { in } 480 \mathrm{~min} \text {, } \\
70.9 \% \text { in } 480 \mathrm{~min}, 57.6 \% \text { in } \\
480 \mathrm{~min}\end{array}$ \\
\hline $\mathrm{La}_{2} \mathrm{NiO}_{4} / \mathrm{ZnO}^{211}$ & Heterosystem & $1.87-3.1$ & MO & Sunlight & $99.9 \%$ in $60 \mathrm{~min}$ \\
\hline $\mathrm{SnSe} / \mathrm{LaNdZr}_{2} \mathrm{O}_{7}$ (ref. 212) & Composites & $1.69-3.34$ & Foron blue & Visible light & $86.3 \%$ in $60 \mathrm{~min}$ \\
\hline $\mathrm{m}-\mathrm{Bi}_{2} \mathrm{O}_{4} / \mathrm{Bi}_{2} \mathrm{O}_{2} \mathrm{CO}_{3}$ (ref. 213) & Composite & $1.53-2.0$ & $\mathrm{RhB}$ & Visible light & $95.3 \%$ in $50 \mathrm{~min}$ \\
\hline
\end{tabular}

$\mathrm{Cu}$ doped $\mathrm{SrTiO}_{3}$ (ref. 181)

Fe doped $\mathrm{SrTiO}_{3}$ (ref. 182)

-doped $\mathrm{SrTiO}_{3}$ (ref. 183)

$\mathrm{Ag} / \mathrm{AgGaO}_{2}$ (ref. 185)

$\mathrm{LaFeO}_{3}$ (ref. 186)

Z-scheme $\mathrm{MoS}_{2} / \mathrm{CaTiO}_{3}$ (ref.$$
\text { p-n type }\left(30-60 \% \mathrm{Ag}_{3} \mathrm{PO}_{4}\right) /
$$$$
\mathrm{NaTaO}_{3} \text { (ref. 188) }
$$$$
\mathrm{BiOI} / \mathrm{KTaO}_{3} \mathrm{p}-\mathrm{n}
$$$$
\mathrm{BiFeO}_{3} / \mathrm{BiVO}_{4} \text { (ref. 190) }
$$

$\mathrm{In}_{2} \mathrm{~S}_{3} / \mathrm{NaTaO}_{3}$ (ref. 191)

\section{$\mathrm{O}_{3} / \mathrm{SnS}_{2}$ (ref.}

$$
192)
$$

Bandgap

3.94

-

$2.2-1.96 \quad \mathrm{MB}$

1.45-2.08 MB, MV

$4.8 \quad \mathrm{MB}$

1.76-2.69 RhB

2.7-2.85 EBT

2.4-2.5 RhB

2.6-2.9 $\mathrm{MB}$

1.96-2.15 RhB

1.53-2.0 RhB Visible light
Visible ligh

Visible light

$54 \%$ after 60 minutes

after 60 minutes

$70 \%$ of phenol and BPA after

of propanol is converted

$66 \%$ within 120 minutes

$71.6 \%$ in 80 minutes

$100 \%$ after 60 minutes

$87 \%$ in 25 minutes

$69 \%$ within 120 minutes

180 minutes

$95 \%$ with UV in 90 minutes $\%$ with VIS in 120

$92 \%$ within 60 minutes

$8 \mathrm{~W}$ UV lamp $\quad 95 \%$ after 90 minutes

$96 \%$ after 120 minutes

$96 \%$ after 30 minutes

$65 \%, 64 \%$ after 2 hours

$90 \%$ after 60 minutes

$90.0 \%$ in $50 \mathrm{~min}$

$74 \%$ in $180 \mathrm{~min}$

8.4\% in $30 \mathrm{~min}$

$90 \%$ for TC in $120 \mathrm{~min}$

$90 \%$ of $\mathrm{MB}$ in $120 \mathrm{~min}$

$65 \%$ in $1.5 \mathrm{~h}$

$\min$

$90 \mathrm{~min},(99.5 \% / 25.5 \%)$ in $60 /$

$65.5 \%$ in $480 \mathrm{~min}, 78.5 \%$ in $480 \mathrm{~min}, 99.5 \%$ in $480 \mathrm{~min}$, in $480 \mathrm{~min}, 57.6 \%$ in $99.9 \%$ in $60 \mathrm{~min}$ $95.3 \%$ in $50 \mathrm{~min}$ 
The positive Gibbs free energy shows that with the help of some external stimuli, the reaction proceeds in the forward direction. The use of some sacrificial layer (or agent) in combination with the photocatalyst material produces hydrogen and oxygen, and the reaction is known as hydrogen or oxygen evolution reaction. The process of producing hydrogen and oxygen from water by using semiconductor photocatalyst material and light as an irradiation source to innate the reaction is known as photocatalytic water splitting. ${ }^{214-216}$ The photocatalytic reaction mainly depends upon the reduction potential required for water splitting. The minimum potential energy needed to convert $\mathrm{H}_{2}$ and $\mathrm{O}_{2}$ from water is $1.23 \mathrm{eV} .^{217}$

One-step photo reaction requires only one semiconductor photocatalyst material, and the overall process is depicted in Fig. 12. The use of two photocatalytic materials to form composite or heterojunction can enhance the performance of the perovskite material. Z-scheme mainly employs two materials in photocatalytic water splitting. Z-scheme is an eight electrons process. The selection of the photocatalyst depends upon the target product. In Z-scheme, the hydrogen-evolving or oxygen-evolving photocatalysts are combined, and both catalysts perform their function separately. The mediators (solid or aqueous) help transfer charge in the Z-scheme. Direct Z-scheme is a process without any mediator. The thermodynamic requirement for the water splitting can be decreased in the Zscheme by allowing only hydrogen and oxygen-evolving semiconductors. Still, the kinetics of the Z-scheme reactions are challenging, and nearly half of the hydrogen and oxygen are produced compared to a one-step reaction. ${ }^{218-221}$

The performance of the photocatalyst can be evaluated by the quantity of $\mathrm{H}_{2}$ evolved and the recyclability of the photocatalyst. The reaction rate is not always proportional to the use of photocatalyst mass; therefore, the preferred way is $\mathrm{H}_{2}$ evolved per unit time $\left(\mu \mathrm{mol} \mathrm{h}{ }^{-1}\right)$ with the mass utilized during reaction rather than writing the amount of $\mathrm{H}_{2}$ produced in a mass normalized from $\left(\mu \mathrm{mol} \mathrm{h} \mathrm{h}^{-1} \mathrm{~g}^{-1}\right) .{ }^{222,223}$ The intensity of the incident light for the photocatalytic performance is the number of photons collected per particle is directly related to the particle size. The reaction rate for the photocatalyst is proportional to the intensity of the incident light. In some cases, the rate of reaction increases with excitation intensity. In contrast, the increase in intensity in some reactions leads to decreased photocatalytic efficiency due to the second-order recombination of the photo-induced charges. ${ }^{224}$ At low intensity, the concentration of the photogenerated charge carrier is insignificant compared to the concentration of intrinsic majority carriers. Thus, it can also be assumed that the concentration of minority charges varies with incident light's intensity, whereas the concentration of majority charges stays nearly constant. ${ }^{225-227}$

The recombination of the photogenerated charges can be determined by the quasi-first-order reaction with respect to the concentration of minority carriers induced by the light source. In simple words, the order of a photocatalytic reaction at a specific intensity gives an idea about the photoexcited charge carrier concentration. For comparison, a standard parameter of the apparent quantum efficiency (AQE) and the solar to hydrogen conversion (STH) are reported for measurements of photocatalytic activity. ${ }^{228-230}$

$$
\begin{aligned}
& \text { Apparent qunatum efficieny (AQE) } \\
& =\frac{\text { number of reacted electron }}{\text { number of incident photon }} \times 100 \% \\
& =\frac{2 \times \text { number of } \mathrm{H}_{2} \text { molecule evolved in } 1 \text { hour }}{\text { number of incident photon in } 1 \text { hour }} \times 100
\end{aligned}
$$

$$
\mathrm{STH}=\frac{\text { enegry of generated } \mathrm{H}_{2}}{\text { solar energy irradiating the reaction cell }} \times 100 \%
$$

Moreover, the stability of photocatalyst for real-world applications is vital as these materials need a life cycle of about ten years with an efficiency of about $5-10 \%$ STH to meet the goal

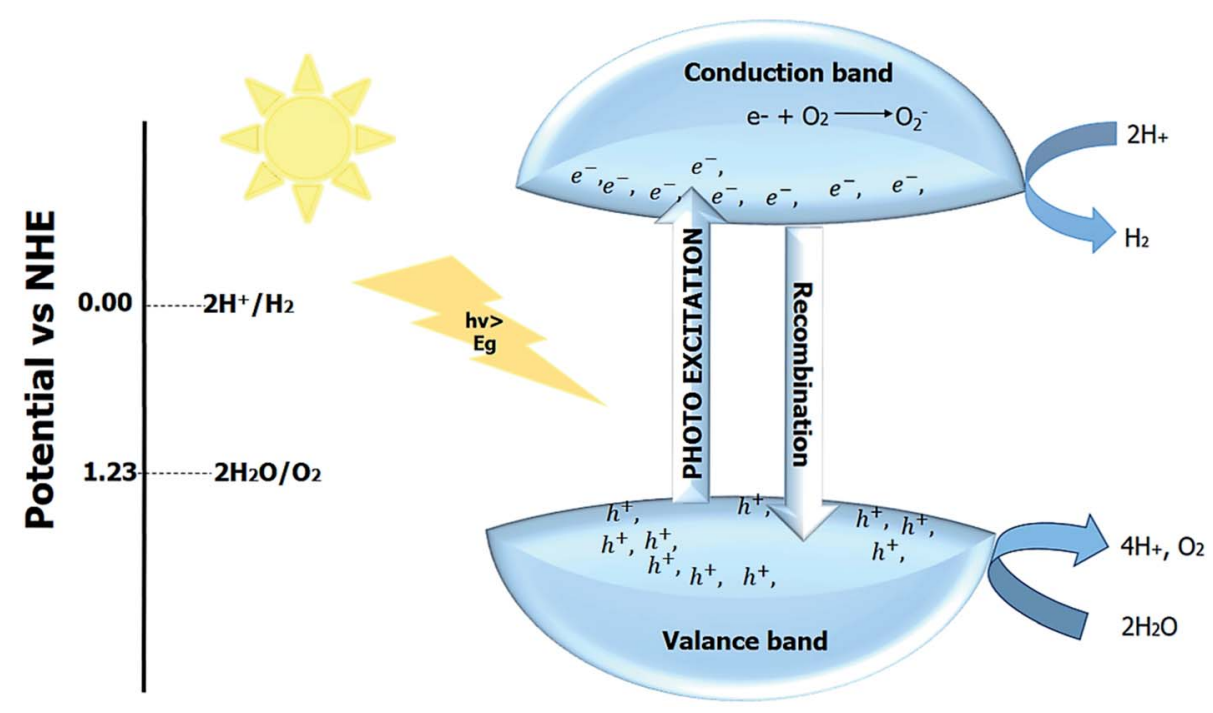

Fig. 12 Photocatalytic water splitting. 
Table 3 Perovskite materials for photocatalytic water splitting

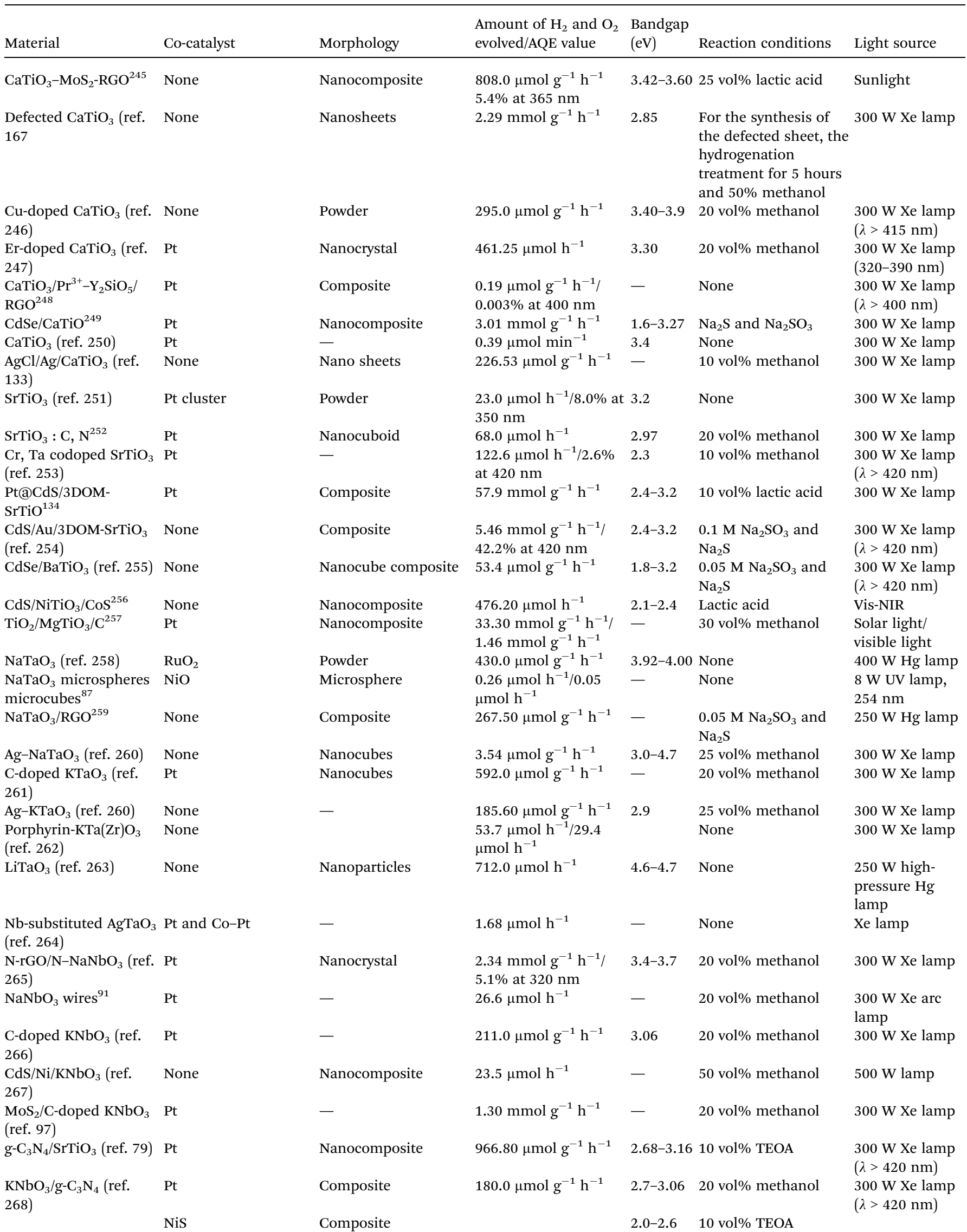




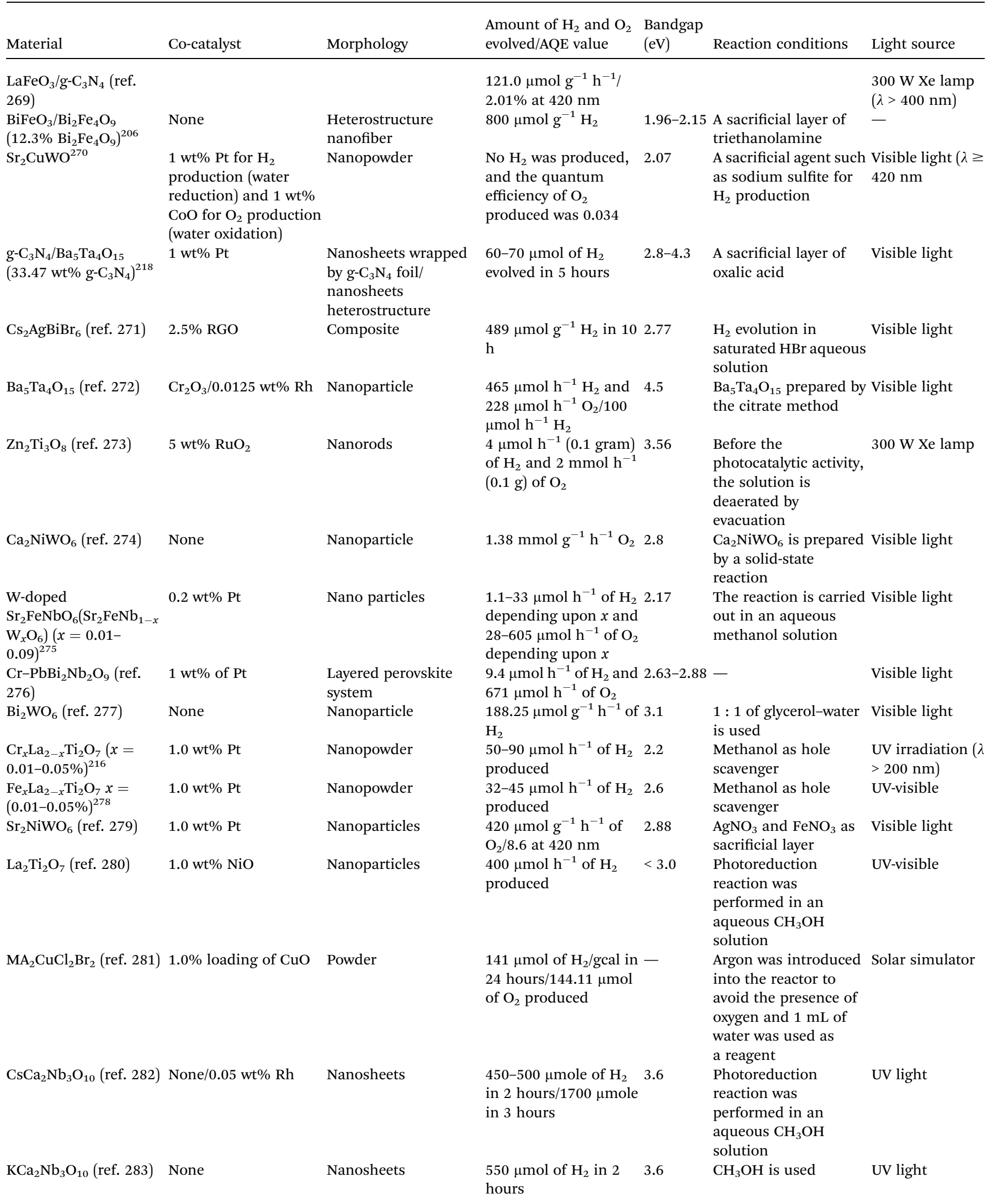


price of \$ 2.00-4.00 per kg. The absorption wavelength for water splitting should be around $526 \mathrm{~nm}(2.36 \mathrm{eV})$ because below this wavelength, the photon's energy is not sufficient to achieve STH efficiency of $5-10 \%$, considering that the reaction takes place for a lower wavelength at the $\mathrm{AQE}=1$. To meet the industrial demand, the practical need for the evolution of $\mathrm{H}_{2}$ under sunlight, the photocatalyst with the bandgap of less than 2.36 must be developed. The perovskites-based photocatalytic materials gained significant attention for the practical application of water splitting under UV light and visible light. ${ }^{\mathbf{2 3 1 - 2 3 4}}$

Titanium-based perovskite materials are widely reported for photocatalytic water splitting. Doping and co-doping change the morphology and bandgap of $\mathrm{SrTiO}_{3}$, thus are making it a suitable visible light photocatalyst for water splitting reaction. The use of the Pt as a co-catalyst induces the Schottky barrier and can make the photocatalyst responsive to visible light. The presence of the $\mathrm{Pt}$ also provides the site for the proton reduction. The quantum yield efficiency by using the visible light as an irradiation source is $0.9 \%$ while using the UV light, the quantum yield efficiency of the system is $1.9 \%$. The use of the other metals as $\mathrm{Au}, \mathrm{Ag}, \mathrm{Fe}, \mathrm{Ce}$, and $\mathrm{Ni}$ are also reported..$^{235-239}$

Alkali tantalates are the best perovskite material reported for photocatalytic water splitting when the parameters like the doping of the metal cations and morphology (nanocubes) of tantalates-based material are optimized well. The reported hydrogen evolution by $\mathrm{KTaO}_{3}$ nanocubes is $375 \mu \mathrm{mol} \mathrm{g} \mathrm{g}^{-1} \mathrm{~h}^{-1}$. The Ag doping at the surface of the $\mathrm{KTaO}_{3}$ increases the hydrogen evolution in UV light. The irradiation of the UV light generates oscillations in the conduction band of absorbed silver and thus allows the easy excitation of the particles to the conduction band of $\mathrm{KTaO}_{3}$. The local electric field of $\mathrm{KTaO}_{3}$ was enhanced with the doping of the silver nanoparticles. The enhanced field promotes the electron-hole pair generation, and therefore, increases the photocatalytic splitting. The reported evolution of the hydrogen in the presence of $\mathrm{Ag}$ as a dopant in $\mathrm{KTaO}_{3}$ is $2072 \mu \mathrm{mol} \mathrm{g}{ }^{-1} \mathrm{~h}^{-1}$. $^{\mathbf{2 4 - 2 4 3}}$ The lanthanum and ferritebased perovskite material are also reported. ${ }^{244}$ Table 3 lists various perovskite materials used for water splitting.

Photocatalytic $\mathrm{CO}_{2}$ reduction. The atmospheric concentration of $\mathrm{CO}_{2}$ is increasing at an alarming rate due to increased human activities, deforestation, burning of fuels, and industrialization. The increased $\mathrm{CO}_{2}$ emission is causing global warming, and for environmental sustainability, it is essential to convert $\mathrm{CO}_{2}$ into valuable products. Mother Nature blessed humans with photosynthesis, in which chlorophyll act as a natural photocatalyst and, in the presence of sunlight, converts $\mathrm{CO}_{2}$ into water, oxygen, and food for plants. The photocatalyst also converts $\mathrm{CO}_{2}$ into valuable products in sunlight. ${ }^{16,277,284,285}$

Photocatalytic $\mathrm{CO}_{2}$ reduction requires more electrons than hydrogen evolution reaction. The end product from depending upon the number of available electrons. One of the limiting factors is the low water solubility of $\mathrm{CO}_{2}$. The complete reduction of the $\mathrm{CO}_{2}$ in water also produces $\mathrm{H}_{2}$. The Z-scheme or heterojunction process for $\mathrm{CO}_{2}$ reduction is reported frequently. ${ }^{30,122}$
The first step in $\mathrm{CO}_{2}$ reduction involves the radical anion formation at $-1.9 \mathrm{eV}$, which is impossible for most perovskite material due to less negative CB potentials of the perovskite material; therefore, high activation energy is required. The surface adsorption of $\mathrm{CO}_{2}$ by catalyst generates the charge $\mathrm{CO}_{2}{ }^{\delta-}$ which facilities the reaction to proceed. Surface engineering can enhance the $\mathrm{CO}_{2}$ adsorption to the photocatalyst's surface and thus, increases the conversion efficiency. The low conversion efficiency of the $\mathrm{CO}_{2}$ is considered a significant concern in dealing with photocatalytic $\mathrm{CO}_{2}$ reduction. ${ }^{286,287}$ The co-catalyst can lower the activation energy resulting in enhanced photocatalytic activity. The reaction mechanism is shown in Fig. 13. In $\mathrm{CO}_{2}$ reduction, the $\mathrm{CO}_{2}$ gets adsorbed on the photocatalyst's surface, and electron-hole pair is produced upon irradiation. The photo-generated charges then move to the surface of the photocatalyst, and $\mathrm{CO}_{2}$ is reduced into the valuable fuel. After the reduction of $\mathrm{CO}_{2}$ by the photogenerated electrons and the formation of $\mathrm{O}_{2}$ by photogenerated holes, the reduced and the oxidized product is formed by the desorbed hole and electron, and the cycle continues. The end product depends upon the total number of electrons used in the procedure. For a better photocatalytic activity, a significant number of electrons should migrate towards the surface of the photocatalyst, and the bottom level of the photocatalyst's conduction band should be more negative than the redox potential of $\mathrm{CO}_{2}$. The water or additional sacrificial reagents must consume the photogenerated holes; otherwise, holes recombine with the oxygen. The photocatalytic $\mathrm{CO}_{2}$ reduction can be enhanced by optimizing $\mathrm{CO}_{2}$ adsorption, charge separation, and desorption of the products. The process of $\mathrm{CO}_{2}$ reduction in the presence of co-catalyst is shown in Fig. 14. ${ }^{288,289}$

The $\mathrm{CO}_{2}$ reduction by photocatalyst takes place in the presence of a water molecule, while the reaction in the gaseous or aqueous phase. The reduction potential of $\mathrm{CO}_{2}$ should be small compared to the reduction potential of conduction band minimum and water to obtain valuable solar fuel. During the oxidation, the oxygen molecule is formed by the reaction of the water with a valence band hole.

Calculation of the AQE is used to access the performance of the perovskite material for photocatalytic $\mathrm{CO}_{2}$ reduction. ${ }^{\mathbf{2 9 0}-\mathbf{2 9 2}}$

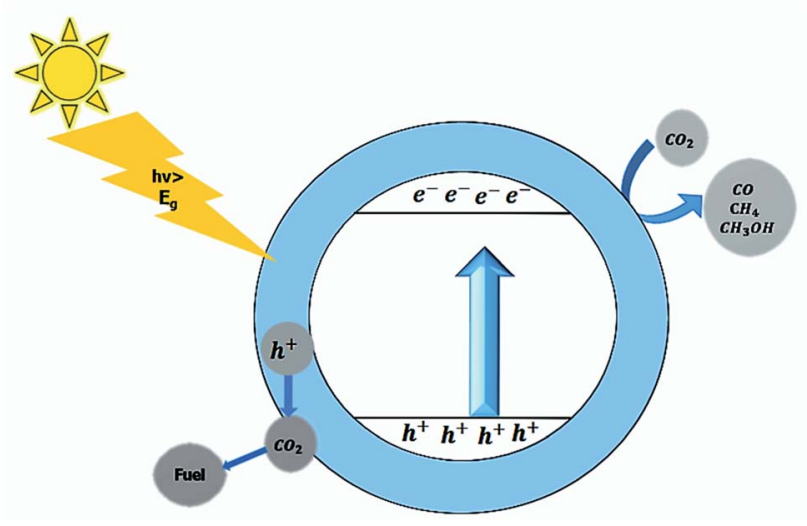

Fig. 13 Photocatalytic $\mathrm{CO}_{2}$ reduction. 


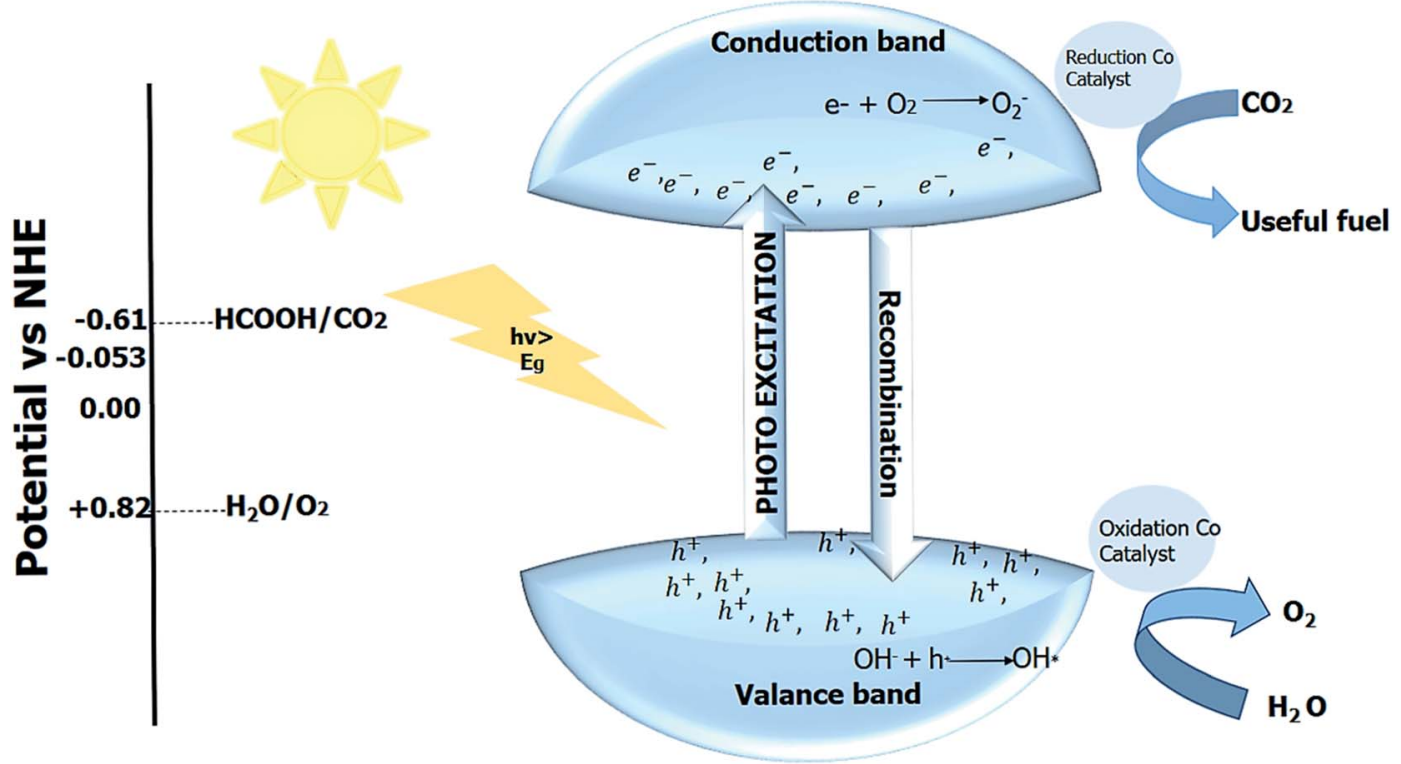

Fig. 14 Photocatalytic reaction in presence of co-catalyst.

The reactions are shown as:

$$
\begin{aligned}
\mathrm{CO}_{2}+2 \mathrm{e}^{-}+2 \mathrm{H}^{+} & \rightarrow \mathrm{HCCOOH} E=-0.61 \mathrm{~V} \\
\mathrm{CO}_{2}+2 \mathrm{e}^{-}+2 \mathrm{H}^{+} & \rightarrow \mathrm{CO}+\mathrm{H}_{2} \mathrm{O} E=-0.53 \mathrm{~V} \\
\mathrm{CO}_{2}+4 \mathrm{e}^{-}+4 \mathrm{H}^{+} & \rightarrow \mathrm{HCHO}+\mathrm{H}_{2} \mathrm{O} E=-0.48 \mathrm{~V} \\
\mathrm{CO}_{2}+6 \mathrm{e}^{-}+6 \mathrm{H}^{+} & \rightarrow \mathrm{CH}_{3} \mathrm{OH}+\mathrm{H}_{2} \mathrm{O} E=-0.38 \mathrm{~V} \\
\mathrm{CO}_{2}+8 \mathrm{e}^{-}+8 \mathrm{H}^{+} & \rightarrow \mathrm{CH}_{4}+2 \mathrm{H}_{2} \mathrm{O} E=-0.24 \mathrm{~V} \\
2 \mathrm{H}^{+}+2 \mathrm{e}^{-} & \rightarrow \mathrm{H}_{2} E=-0.41 \mathrm{~V} \\
2 \mathrm{H}_{2} \mathrm{O}+4 \mathrm{~h}^{+} & \rightarrow \mathrm{O}_{2}+4 \mathrm{H}^{+} E=+0.82 \mathrm{~V}
\end{aligned}
$$

Titanium-based perovskite oxides exhibit excellent photostability for $\mathrm{CO}_{2}$ compared to the tantalates and niobates. $\mathrm{SrTiO}_{3}$ perovskite material is widely reported due to better charge transport properties and bandgap equivalent to $\mathrm{TiO}_{2}(3.2$ $\mathrm{eV}$ ), but the poor $\mathrm{CO}_{2}$ surface adsorption of photocatalyst $\left(\mathrm{SrTiO}_{3}\right)$ creates a problem. This problem can be solved by using the metal as a co-catalyst and introducing the oxygen vacancies to improve the adsorption. In the gas phase reactor using visible light, Fe doped $\mathrm{SrTiO}_{3}$ photocatalyst with $\mathrm{Pd}(0.5 \mathrm{wt} \%)$ as a cocatalyst reduces $\mathrm{CO}_{2}$ to $\mathrm{CH}_{4}$. The yield of the product is 421 , and the CO selectivity is $84 \% .^{{ }^{16,293-295}}$

Tantalum-based perovskites are not widely reported for $\mathrm{CO}_{2}$ reduction because of their wide bandgap. $\mathrm{NaTaO}_{3}$ photocatalyst in combination with $\mathrm{Au}(0.5 \mathrm{wt} \%)$ as a co-catalyst reduces $\mathrm{CO}$ to $\mathrm{CH}_{4}$ fuel in the gas phase reactor and uses UV-vis light as the irradiation source. The selectivity of CO is $96 \%$, but the yield is small. ${ }^{296}$ Table 4 lists perovskite materials used for $\mathrm{CO}_{2}$ reduction.
Nitrogen fixation. Nitrogen plays a vital part in building biomolecules such as amino acids, proteins, and other molecules. Earth's atmosphere has $78 \%$ of the dinitrogen $\left(\mathrm{N}_{2}\right)$. Dinitrogen air converts into ammonia by the process known as nitrogen fixation. Plants and soil then use the ammonia formed by atmospheric nitrogen to build several processes. The mechanism to create ammonia by nitrogen is the Haber cycle. ${ }^{314}$ At standard conditions, the ammonia formation is a thermodynamically spontaneous process $\left(\Delta H=-92.2 \mathrm{~kJ} \mathrm{~mol}^{-1}\right)$. Due to its high ionization energy of $15.58 \mathrm{eV}$ and low electron affinity, the dinitrogen in the air is highly stable; therefore, the atmospheric dinitrogen in the normal conditions cannot be used to prepare the ammonia unless some catalyst or some industrial fixation is used. In industry, by using iron or ruthenium as a base catalyst at high temperatures, the dinitrogen is converted into ammonia by the Haber-Borsch process. But even after the century's advancement, the production of the indusial fixation is still quite low. The $\mathrm{NH}_{3}$ is one of the essential components in manufacturing fertilizers and hydrogen storage. Therefore, it is essential to synthesize an alternative green route to deal with energy crises and global warming. ${ }^{.7,315}$

Recently the photocatalyst material for nitrogen fixation has gained much attention from researchers. The nitrogen fixation by the photocatalyst utilizes only sunlight and water in the presence of the dinitrogen. The six electrons do the complete conversion of $\mathrm{N}_{2}$ into $\mathrm{NH}_{3}$ due to the high activation energy of the process, which makes the process completely impractical. Furthermore, direct electron transfer and proton-coupled electron transfer are not possible for the semiconductor material. Hence, photocatalyst design and surface engineering play an important role in nitrogen fixation. ${ }^{316-318}$ The reaction by using the photocatalyst is designed to reduce the activation energy and weakens the $\mathrm{N} \equiv \mathrm{N}$ bond. Light irradiation generates the electron-hole pair. These photogenerated charge carriers then 
Table 4 Perovskite materials for photocatalytic $\mathrm{CO}_{2}$ reduction

\begin{tabular}{|c|c|c|c|c|c|c|c|}
\hline Perovskite & Co-catalyst & Morphology & $\begin{array}{l}\text { Band } \\
\text { gap } \\
(\mathrm{eV})\end{array}$ & $\begin{array}{l}\text { Synthesis method/ } \\
\text { reaction condition }\end{array}$ & Product & $\begin{array}{l}\text { Product concentration } \\
\text { or conversion } \\
\text { efficiency }\end{array}$ & Light source \\
\hline $\mathrm{NaTaO}_{3}$ (ref. 297) & $2 \mathrm{wt} \% \mathrm{CuO}$ & Nanocubes & 4.1 & $\begin{array}{l}\text { The hydrothermal } \\
\text { method is used for } \\
\text { catalyst synthesis. And } \\
\text { co-catalyst is loaded } \\
\text { via impregnation } \\
\text { method/ }\end{array}$ & $\begin{array}{l}\text { Methanol } \\
\text { and acetone }\end{array}$ & $\begin{array}{l}137.48 \mu \mathrm{mol} \mathrm{g} \text { cat }^{-1} \mathrm{~h}^{-1} \\
335.93 \mu \mathrm{mol} \mathrm{g}_{\text {cat }}{ }^{-1} \mathrm{~h}^{-1}\end{array}$ & UV-visible \\
\hline $\mathrm{KTaO}_{3}$ (ref. 298) & None & Nanoflakes & 3.6 & $\begin{array}{l}\text { Perovskite material is } \\
\text { prepared by solid-state } \\
\text { reaction }\end{array}$ & $\mathrm{CH}_{4}$ & 19.35 $\mathrm{ppm} \mathrm{g}_{\text {cat }}{ }^{-1} \mathrm{~h}^{-1}$ & UV-visible \\
\hline $\mathrm{NaNbO}_{3}$ (ref. 299) & $1.5 \mathrm{wt} \% \mathrm{Pt}$ & $\begin{array}{l}\text { Nanoparticles } \\
\text { (cubic) }\end{array}$ & 3.29 & $\begin{array}{l}\text { Photocatalytic activity } \\
\text { is carried out in a gas- } \\
\text { phase reactor }\end{array}$ & $\mathrm{CH}_{4}$ and $\mathrm{H}_{2}$ & $\begin{array}{l}0.486 \mu \mathrm{mol} \mathrm{g} \text { cat }^{-1} \mathrm{~h}^{-1} \\
127 \mu \mathrm{mol} \mathrm{g}{ }_{\text {cat }}^{-1} \mathrm{~h}^{-1}\end{array}$ & UV-visible \\
\hline $\mathrm{BiFeO}_{3}-\mathrm{ZnO}$ (ref. 300) & None & Composites & $2.1-3.2$ & $\begin{array}{l}\text { Photocatalytic activity } \\
\text { is carried out in a gas- } \\
\text { phase }\end{array}$ & $\mathrm{CH}_{4}$ & $\begin{array}{l}\text { The conversion } \\
\text { efficiency of } \mathrm{CO}_{2} \text { into } \\
\mathrm{CH}_{4} \text { is } 21 \%\end{array}$ & UV-visible \\
\hline $\mathrm{Au}-\mathrm{SrTiO}_{3}$ (ref. 301) & 0.5 wt $\% \mathrm{Rh}$ & Nanoparticles & - & $\begin{array}{l}\mathrm{Ru} \text { is loaded by the } \\
\text { impregnation method, } \\
\text { and at optimized } \\
\text { conditions, } 0.5 \mathrm{wt} \% \text { of } \\
\text { Au is used }\end{array}$ & $\begin{array}{l}\mathrm{CO}, \mathrm{H}_{2} \text {, and } \\
\mathrm{CH}_{4}\end{array}$ & $\begin{array}{l}66.8 \mu \mathrm{mol} \mathrm{g} \mathrm{gat}^{-1} \mathrm{~h}^{-1} \\
50.5 \mu \mathrm{mol} \mathrm{g}{ }_{\text {cat }}^{-1} \mathrm{~h}^{-1} \\
2.8 \mu \mathrm{mol} \mathrm{g} \mathrm{gat}^{-1} \mathrm{~h}^{-1}\end{array}$ & Visible light \\
\hline $\begin{array}{l}\text { Basalt } \\
\text { fiber@perovskite } \\
\mathrm{PbTiO}_{3} \text { (ref. 302) }\end{array}$ & None & $\begin{array}{l}\text { Core-shell } \\
\text { composites }\end{array}$ & 1.92 & $\begin{array}{l}\text { The hydrothermal } \\
\text { method is used for } \\
\text { catalyst synthesis }\end{array}$ & $\mathrm{CH}_{4}$ & $\begin{array}{l}290 \mu \mathrm{mol} \mathrm{g}^{-1} \mathrm{~L}^{-1} \text { in } 6 \\
\text { hours }\end{array}$ & UV light \\
\hline $\mathrm{BiFeO}_{3} / \mathrm{ZnS}$ (ref. 303) & None & Nanocomposites & 2.5 & $\begin{array}{l}\text { The reaction is carried } \\
\text { out in a gas phase } \\
\text { reactor }\end{array}$ & $\mathrm{CO}, \mathrm{CH}_{3} \mathrm{OH}$ & $\begin{array}{l}\text { The conversion } \\
\text { efficiency of } \mathrm{CO}_{2} \text { into } \\
\mathrm{CO} \text { and } \mathrm{CH}_{3} \mathrm{OH} \text { is } 24\end{array}$ & UV-visible \\
\hline g- $\mathrm{C}_{3} \mathrm{~N}_{4} / \mathrm{KNbO}_{3}$ (ref. 79) & None & Composites & $2.7-3.2$ & $\begin{array}{l}\mathrm{KNbO}_{3} \text { is synthesized } \\
\text { by hydrothermal, and } \\
\mathrm{g}-\mathrm{C}_{3} \mathrm{~N}_{4} \text { powder is } \\
\text { deposited by using the } \\
\text { sonication method }\end{array}$ & $\mathrm{CH}_{4}$ & $1.94 \mu \mathrm{mol} \mathrm{g}^{-1} \mathrm{~h}^{-1}$ & Visible light \\
\hline $\begin{array}{l}\text { N-doped } \mathrm{LaFeO}_{3} \text { (ref. } \\
304 \text { ) }\end{array}$ & None & Nanocomposites & 1.82 & - & $\mathrm{CH}_{4}, \mathrm{CO}, \mathrm{O}_{2}$ & $\begin{array}{l}\sim 110 \mu \mathrm{mol} \mathrm{g}^{-1} \mathrm{~h}^{-1} \\
150 \mu \mathrm{mol} \mathrm{g}{ }^{-1} \mathrm{~h}^{-1} \\
230 \mu \mathrm{mol} \mathrm{g}{ }^{-1} \mathrm{~h}^{-1}\end{array}$ & Visible light \\
\hline $\begin{array}{l}\mathrm{RuO}_{2} \text { on } \mathrm{SrTiO}_{3} \text { (ref. } \\
305 \text { ) }\end{array}$ & $\begin{array}{l}\text { Ru } 0.1- \\
0.4 \mathrm{wt} \%\end{array}$ & Nanoparticles & 2.7 & $\begin{array}{l}\text { The reaction is carried } \\
\text { out in a gas phase }\end{array}$ & Ethanol & $80 \mu \mathrm{mol} \mathrm{g}{ }^{-1} \mathrm{~h}^{-1}$ & Simulated sunlight \\
\hline $\mathrm{BaCeO}_{3}$ (ref. 306) & $\begin{array}{l}\text { Ag cocatalyst } \\
(0.3 \mathrm{wt} \%)\end{array}$ & Nanoparticles & 3.2 & $\begin{array}{l}\text { Pechini method is } \\
\text { used to deposit the co- } \\
\text { catalyst }\end{array}$ & $\mathrm{CH}_{4}$ & $0.55 \mu \mathrm{mol} \mathrm{g}{ }^{-1} \mathrm{~h}^{-1}$ & UV light \\
\hline $\mathrm{BaZrO}_{3}$ (ref. 200) & 0.5 wt $\% \mathrm{Cu}$ & Nanoparticles & 3.2 & $\begin{array}{l}\text { The photocatalytic } \\
\text { reaction is carried out } \\
\text { in a cylindrical quartz } \\
\text { cell }\end{array}$ & $\mathrm{CH}_{4}$ & $0.98 \mu \mathrm{mol} \mathrm{g}^{-1} \mathrm{~h}^{-1}$ & UV light \\
\hline $\begin{array}{l}\text { C-doped } \mathrm{LaCoO}_{3} \text { (ref. } \\
307 \text { ) }\end{array}$ & None & - & 2.16 & $\begin{array}{l}\text { Pechini method is } \\
\text { used to deposit the co- } \\
\text { catalyst }\end{array}$ & $\mathrm{HCOOH}$ & $\begin{array}{l}\text { A minimal amount of } \\
\mathrm{HCOH}\end{array}$ & UV-visible \\
\hline $\begin{array}{l}\mathrm{LaNi}_{x} \mathrm{Co}_{1-x} \mathrm{O}(x= \\
0.4)^{308}\end{array}$ & None & Nano particles & 1.42 & $\begin{array}{l}\text { Sol-gel combustion } \\
\text { method is used to } \\
\text { prepare the catalyst }\end{array}$ & $\begin{array}{l}\mathrm{CH}_{4}^{-} \\
\mathrm{CH}_{3} \mathrm{OH}\end{array}$ & $\begin{array}{l}678.57 \mu \mathrm{mol} \mathrm{g}^{-1}, 20.83 \\
\mu \mathrm{mol} \mathrm{g}{ }^{-1} \text { in } 6 \mathrm{~h}\end{array}$ & Visible light \\
\hline $\mathrm{H}_{2} \mathrm{SrTa}_{2} \mathrm{O}_{7}$ (ref. 309) & $0.5 \mathrm{wt} \% \mathrm{Ag}$ & $\begin{array}{l}\text { Layered } \\
\text { perovskite } \\
\text { structure }\end{array}$ & 3.75 & $\begin{array}{l}\mathrm{H}_{2} \mathrm{SrTa}_{2} \mathrm{O}_{7} \\
\text { photocatalyst was } \\
\text { prepared by PC and } \\
\text { ion-exchange } \\
\text { methods, and a photo } \\
\text { deposition method } \\
\text { was used to load Ag co- } \\
\text { catalyst on HST }\end{array}$ & $\mathrm{CO}$ and $\mathrm{H}_{2}$ & $\begin{array}{l}0.39 \mu \mathrm{mol} \mathrm{g}^{-1} \mathrm{~h}^{-1} \text { of } \\
\mathrm{CO} \text { and } 0.25 \text { of } \mathrm{H}_{2} \\
\mu \mathrm{mol} \mathrm{g}^{-1} \mathrm{~h}^{-1}\end{array}$ & UV light $(\lambda>200 \mathrm{~nm})$ \\
\hline $\begin{array}{l}x \mathrm{Bi}_{2} \mathrm{WO}_{6} / \mathrm{BiOI}(x= \\
8 \%)^{123}\end{array}$ & None & $\begin{array}{l}\text { Nano- } \\
\text { composites }\end{array}$ & $2.2-2.9$ & $\begin{array}{l}\mathrm{CO}_{2} \text { is reduced to give } \\
\mathrm{CH}_{4} \text { experiment is } \\
\text { conducted into gas } \\
\text { phase reactor }\end{array}$ & $\mathrm{CH}_{4} / \mathrm{CO}$ & $\begin{array}{l}18.32 \mu \mathrm{mol} \mathrm{g} \mathrm{g}^{-1} \text { of } \mathrm{CH}_{4} \\
\text { and } 320.19 \mu \mathrm{mol} \mathrm{g}^{-1} \\
\text { in } 8 \text { hours }\end{array}$ & Visible light \\
\hline
\end{tabular}




\begin{tabular}{|c|c|c|c|c|c|c|c|}
\hline Perovskite & Co-catalyst & Morphology & $\begin{array}{l}\text { Band } \\
\text { gap } \\
(\mathrm{eV})\end{array}$ & $\begin{array}{l}\text { Synthesis method/ } \\
\text { reaction condition }\end{array}$ & Product & $\begin{array}{l}\text { Product concentration } \\
\text { or conversion } \\
\text { efficiency }\end{array}$ & Light source \\
\hline $\mathrm{Bi}_{2} \mathrm{WO}_{6}$ (ref. 310) & None & Nano sheets & 2.7 & $\begin{array}{l}\mathrm{CO} \text { is reduced to give } \\
\mathrm{CH}_{4} \text { experiment is } \\
\text { conducted into gas } \\
\text { phase reactor }\end{array}$ & $\mathrm{CH}_{4}$ & $19 \mathrm{ppm} \mathrm{g}^{-1} \mathrm{~h}^{-1}$ of $\mathrm{CH}_{4}$ & Visible light \\
\hline $\begin{array}{l}\mathrm{ALa}_{4} \mathrm{Ti}_{4} \mathrm{O}_{15}, \mathrm{~A}=\mathrm{Sr} \\
\mathrm{Ca}^{78}\end{array}$ & $\mathrm{Ag}$ & $\begin{array}{l}\text { Layered } \\
\text { perovskite } \\
\text { structure }\end{array}$ & $\begin{array}{l}3.79- \\
3.85\end{array}$ & $\begin{array}{l}\text { Catalyst is loaded via } \\
\text { liquid-phase } \\
\text { reduction and } \\
\text { impregnation method }\end{array}$ & $\mathrm{CO} / \mathrm{O}_{2} / \mathrm{H}_{2}$ & $\begin{array}{l}10 \mu \mathrm{mol} \mathrm{h}{ }^{-1} \text { of } \mathrm{H}_{2} \text { and } \\
16 \mu \mathrm{mol} \mathrm{h}^{-1} \text { of } \mathrm{O}_{2}, 22 \\
\mu \mathrm{mol} \mathrm{h}^{-1} \text { of } \mathrm{CO}\end{array}$ & $\begin{array}{l}\text { A } 400 \mathrm{~W} \text { high-pressure } \\
\text { mercury lamp, an } \\
\text { inner irradiation } \\
\text { quartz cell }\end{array}$ \\
\hline $\mathrm{BaLa}_{4} \mathrm{Ti}_{4} \mathrm{O}_{15}$ (ref. 78) & $0.5-2 \% \mathrm{Ag}$ & $\begin{array}{l}\text { Layered } \\
\text { perovskite } \\
\text { structure }\end{array}$ & 3.9 & $\begin{array}{l}\text { Catalyst is loaded via } \\
\text { liquid-phase } \\
\text { reduction }\end{array}$ & $\mathrm{H}_{2}, \mathrm{O}_{2}, \mathrm{CO}$ & $\begin{array}{l}20-3.2 \mu \mathrm{mol} \mathrm{h}^{-1} \text { of } \mathrm{H}_{2} \text {, } \\
5.7-16 \mu \mathrm{mol} \mathrm{h}{ }^{-1} \text { of } \mathrm{H}_{2} \\
\text { and } 5.00-22 \mu \mathrm{mol} \mathrm{h}^{-1} \\
\text { CO }\end{array}$ & $\begin{array}{l}\text { A } 400 \mathrm{~W} \text { high-pressure } \\
\text { mercury lamp, an } \\
\text { inner irradiation } \\
\text { quartz cell }\end{array}$ \\
\hline $\mathrm{Bi}_{2} \mathrm{WO}_{6}$ (ref. 311) & $\begin{array}{l}0.5 \% \text { wt } \\
\mathrm{PtO}_{x}\end{array}$ & $\begin{array}{l}\text { Ultra-thin } \\
\text { nanosheets }\end{array}$ & - & $\begin{array}{l}\text { The } \mathrm{PtO}_{x} / \mathrm{Bi}_{2} \mathrm{WO}_{6} \text { was } \\
\text { prepared by } \\
\text { photoreduction } \\
\text { method }\end{array}$ & $\mathrm{CH}_{4}$ & $108.8 \mathrm{ppm} \mathrm{g}^{-1} \mathrm{~h}^{-1}$ & $\begin{array}{l}500 \mathrm{~W} \text { Xe lamp as } \\
\text { a light source }\end{array}$ \\
\hline $\mathrm{Bi}_{4} \mathrm{O}_{5} \mathrm{Br}_{2}$ (ref. 312) & None & $\begin{array}{l}\text { Ultra-thin } \\
\text { nanosheets/bulk }\end{array}$ & $\begin{array}{l}2.64- \\
3.05\end{array}$ & $\begin{array}{l}\text { Ultra-thin sheets are } \\
\text { prepared by precursor } \\
\text { method }\end{array}$ & $\mathrm{CO}$ & $\begin{array}{l}63.13 \mu \mathrm{mol} \mathrm{g}{ }^{-1} \text { of } \mathrm{CO} \\
\text { in } 2 \text { hours } / 27.56 \mu \mathrm{mol} \\
\mathrm{g}^{-1} \text { of } \mathrm{CO} \text { in } 2 \text { hours }\end{array}$ & UV-visible light \\
\hline $\mathrm{A}_{3} \mathrm{Bi}_{2} \mathrm{I}_{9}\left(\mathrm{Cs}_{3} \mathrm{Bi}_{2} \mathrm{I}_{9}\right)^{284}$ & None & Nanocrystals & 2.2 & $\begin{array}{l}\text { Gas-phase reaction the } \\
\text { photoreduction to } \\
\text { carbon take place at } \\
\text { the gas-solid } \\
\text { interface, the reaction } \\
\text { medium was } \mathrm{CO}_{2} \text { and } \\
\mathrm{H}_{2} \mathrm{O} \text { vapors }\end{array}$ & $\mathrm{CH}_{4} / \mathrm{CO}$ & $\begin{array}{l}14.9 \mu \mathrm{mol} \mathrm{g}^{-1} \text { of } \\
\text { methane and } 77.6 \\
\mu \mathrm{mol} \mathrm{g}{ }^{-1} \text { of } \mathrm{CO}\end{array}$ & $\begin{array}{l}32 \mathrm{~W} \text { UV } \operatorname{lamp}(\lambda=305 \\
\mathrm{nm})\end{array}$ \\
\hline $\mathrm{Cs}_{2} \mathrm{AgBiBr}_{6}$ (ref. 313) & None & Nanocrystals & 1.72 & $\begin{array}{l}\text { Medium in which } \\
\text { reaction is carried is } \\
\text { ethyl acetate solvent }\end{array}$ & $\mathrm{CH}_{4} / \mathrm{CO}$ & $\begin{array}{l}14.1 \mu \mathrm{mol} \mathrm{g}^{-1} \text { of } \\
\text { methane and } 9.6 \mu \mathrm{mol} \\
\mathrm{g}^{-1} \text { of } \mathrm{CO}\end{array}$ & 100 W Xe lamp \\
\hline
\end{tabular}

move to the photocatalyst's surface, and at the conduction band, the dinitrogen is reduced to the ammonia by multi-step transfer of the electron and proton available from the water. The hole in the valence band oxidizes the water molecule and gives $\mathrm{O}_{2}$. The chemisorption of the $\mathrm{N}_{2}$ and $\mathrm{H}^{+}$ions occurs on the surface of the conduction band accompanied by the association or dissociation by $\mathrm{H}_{2}$ incorporation of $\mathrm{N}_{2}$ molecules absorption and $\mathrm{NH}_{3}$ formation. Lastly, desorption of $\mathrm{NH}_{3}$ from the photocatalyst's surface after the ammonia formation occurs. ${ }^{85,319-321}$

The nitrogen fixation in the presence of the photocatalyst takes place in two ways, either by the associative way or by the dissociative way. The breakage of the $\mathrm{N} \equiv \mathrm{N}$ bond occurs in the dissociative pathway before adding the hydrogen atom as a reducing agent, which is impossible in an ambient environment. ${ }^{322}$ In an associative pathway, breaking the $\mathrm{N} \equiv \mathrm{N}$ bond is unnecessary, so nitrogen fixation is possible at ambient conditions. The nitrogen is adsorbed at the surface of the photocatalyst and then converted into the $\mathrm{NH}_{3}$, which is then desorbed after the breakage of the $\mathrm{N}-\mathrm{N}$ bond. In the associative pathway, the hydrogenation takes place with the sideway nitrogen, which is not directly attached to the surface of the photocatalyst, which generates the $\mathrm{NH}_{3} \cdot{ }^{323,324}$ The remaining nitrogen attached photocatalyst's surface undergoes hydrogenation and generates $\mathrm{NH}_{3}$. But this route is challenging because the chemisorption of nitrogen molecules on the surface of the catalyst is not easy; therefore, surface engineering is an important parameter to enhance the photocatalyst activity for nitrogen fixation. ${ }^{\mathbf{8} 321,325}$ The yield and the efficiency of the reaction are given by the apparent quantum efficiency (AQE) and can be calculated as; ${ }^{326}$

$$
\mathrm{AQE}=\frac{6 \times \text { number of amonia molecule evolved }}{\text { number of incident photons }} \times 100 \%
$$

Limited numbers of the perovskite materials are reported due to the less AQE and yield. The reported materials are $\mathrm{SrTiO}_{3}, \mathrm{KNbO}_{3}, \mathrm{LaCoO}_{3}$, and layered double perovskite $\mathrm{Bi}_{2} \mathrm{WO}_{6} \cdot{ }^{129,327-329}$ The efficiency of the perovskite material is less due to the selectivity of $\mathrm{N}_{2}$ and adsorption of $\mathrm{N}_{2}$ at the surface of the photocatalyst material; however, more research is needed in the field of photocatalytic nitrogen fixation to compete with the available industrial method of nitrogen fixation (Haber cycle). ${ }^{319,330}$ Some of the reported perovskite photocatalyst materials for nitrogen fixation are listed in Table 5 . 
Table 5 Perovskite materials in photocatalytic nitrogen fixation

\begin{tabular}{|c|c|c|c|c|}
\hline Material & Band gap (eV) & $\begin{array}{l}\mathrm{NH}_{3} \text { concentration/ } \\
\text { generation rate }\end{array}$ & Light source & Reaction conditions \\
\hline $\mathrm{BaTiO}_{3}$ (ref. 331) & 3.2 & $0.09 \mathrm{mg} \mathrm{h}^{-1} \mathrm{~L}^{-1}$ & UV-visible & $\begin{array}{l}\text { Water as the proton source } \\
\text { in the process of } \\
\text { photocatalysis }\end{array}$ \\
\hline Defective $\mathrm{La}_{2} \mathrm{TiO}_{5}(\mathrm{R}-\mathrm{LTO})^{332}$ & 4.07 & $158.13 \mu \mathrm{mol} \mathrm{g}^{-1} \mathrm{~h}^{-1}$ & Simulated sunlight & $\begin{array}{l}\text { Defects at the surface of the } \\
\text { LTO are introduced by } \\
\mathrm{NaBH}_{4} \text { reduction }\end{array}$ \\
\hline $\mathrm{CeO}_{2}-\mathrm{BiFeO}_{3}$ (ref. 320) & - & $117.77 \mu \mathrm{mol} \mathrm{g}^{-1} \mathrm{~h}^{-1}$ & UV-visible & Deionized water + nitrogen \\
\hline $\mathrm{LaCoO}_{3}: \mathrm{Er}^{3+} / \mathrm{ATP}^{328}$ & $2.88-3.45$ & $71.51 \mu \mathrm{mol} \mathrm{g}{ }^{-1} \mathrm{~h}^{-1}$ & Visible & $\begin{array}{l}\text { Water }+ \text { nitrogen and } \\
\text { ethanol as a sacrificial layer }\end{array}$ \\
\hline $\mathrm{Ag} / \mathrm{KNbO}_{3}(0.5 \% \mathrm{Ag})^{333}$ & 3.13 & $385.0 \mu \mathrm{mol} \mathrm{g}{ }^{-1} \mathrm{~h}^{-1} \mathrm{~L}^{-1}$ & Simulated sunlight & Ethanol as a sacrificial layer \\
\hline $\mathrm{NiS} / \mathrm{KNbO}_{3}(5 \% \mathrm{NiS})^{129}$ & 3.11 & $155.6 \mu \mathrm{mol} \mathrm{g}{ }^{-1} \mathrm{~h}^{-1} \mathrm{~L}^{-1}$ & Simulated sunlight & $\begin{array}{l}\text { Ethanol is used as a hole } \\
\text { scavenger }\end{array}$ \\
\hline $\mathrm{TiO}_{2} / \mathrm{SrTiO}_{3} / \mathrm{g}-\mathrm{C}_{3} \mathrm{~N}_{4}$ (ref. 125) & $2.75-3.1$ & $2192 \mu \mathrm{mol} \mathrm{g}{ }^{-1} \mathrm{~h}^{-1} \mathrm{~L}^{-1}$ & Simulated sunlight & $\begin{array}{l}\text { Methanol + nitrogen and } \\
\text { ethanol as a sacrificial layer }\end{array}$ \\
\hline $\mathrm{CaTiO}_{3}$ (ref. 334) & 3.49 & $236.12 \mu \mathrm{mol} \mathrm{g}^{-1} \mathrm{~h}^{-1}$ & Natural sunlight irradiation & $\begin{array}{l}\text { 3D leaf-templated defective } \\
\mathrm{CaTiO}_{3} \text { is prepared by using } \\
\mathrm{NaBH}_{4}+\text { nitrogen } \\
\text { environment }\end{array}$ \\
\hline
\end{tabular}

(A)

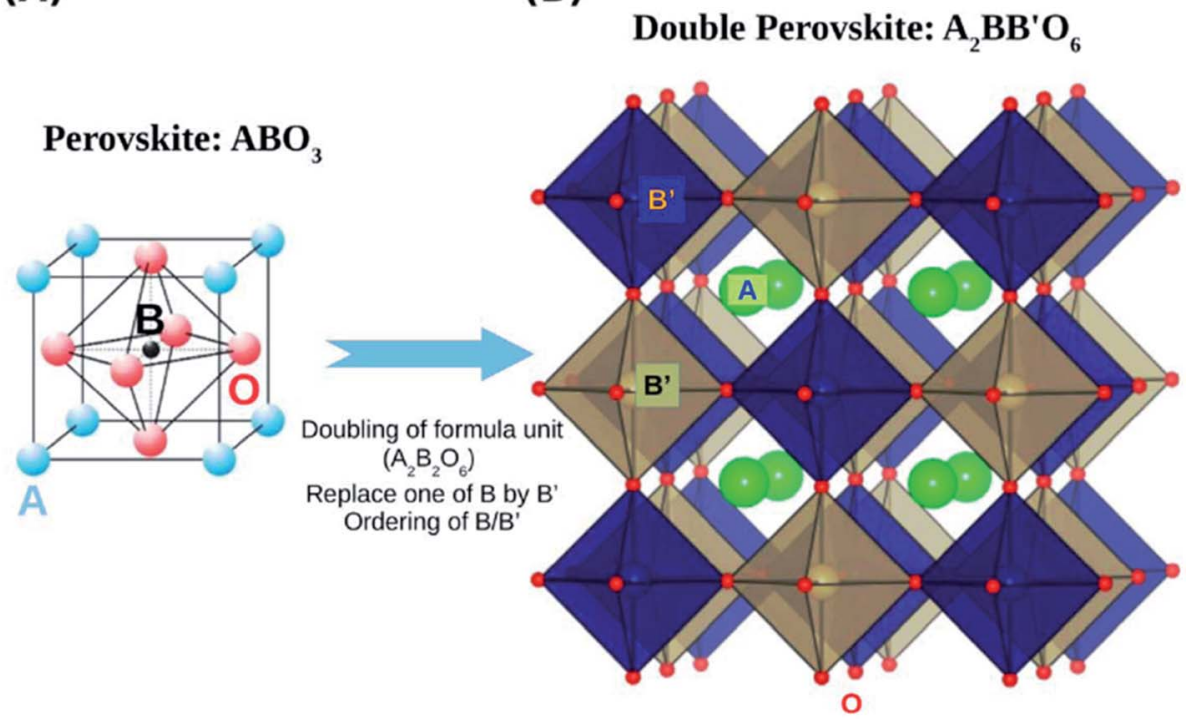

Fig. 15 Schematic representation of a double perovskite structure (B), derived starting from a perovskite structure (A). ${ }^{49}$

\section{Double perovskite and photocatalysis}

Double perovskites can accommodate different cations at the $\mathrm{A}$ and $\mathrm{B}$ sites, forming $\mathrm{AA}^{\prime} \mathrm{BB}^{\prime} \mathrm{O}_{6}$ (Fig. 15). Accommodation of other cations at the $\mathrm{A}$ and $\mathrm{B}$ sites can alter the double perovskite's photophysical properties to a great extent. Among the binary oxides, only a few double perovskites exhibit visible region bandgap because of their small bandgap, such as $\mathrm{Fe}_{2} \mathrm{O}_{3}$, $\mathrm{WO}_{6}, \mathrm{Bi}_{2} \mathrm{O}_{3}$, etc. However, for hydrogen evolution, these materials have deficient conduction band potential. Some materials also have low mobility of the photoexcited carriers and poor stability. Many binary oxides show efficient photocatalytic activity under UV irradiation because of their wide bandgap.
Complex compounds with a combination of 'narrow bandgap' and 'wide bandgap' materials can make use of properties of both types, and therefore, can be exploited as visible light photocatalysts. ${ }^{\mathbf{1 2 4 , 1 2 5}}$

The researchers have investigated photocatalytic activity of rare earth and bismuth-based double perovskites under visible light. Double perovskites $\mathrm{Ba}_{2} \mathrm{XBiO}_{6}(\mathrm{X}=\mathrm{Ce}, \mathrm{La}, \mathrm{Nd}$, Pr, Eu, Sm, Dy, Gd) were synthesized and degraded MB. Researchers reported that rare-earth cation-dependent compounds $\left(\mathrm{Ba}_{2}\right.$ $\mathrm{SmBiO}_{6}, \mathrm{Ba}_{2} \mathrm{EuBiO}_{6}$, and $\left.\mathrm{Ba}_{2} \mathrm{CeBiO}_{6}\right)$ showed significant photocatalytic activity. $\mathrm{CaCu}_{3} \mathrm{Ti}_{4} \mathrm{O}_{12}$ possessed an indirect bandgap of $1.27 \mathrm{eV}$, and $\mathrm{Pt}$ loaded $\mathrm{CaCu}_{3} \mathrm{Ti}_{4} \mathrm{O}_{12}$ showed the degradation of MO under visible irradiation. Double perovskite 
materials such as $\mathrm{Sr}_{2} \mathrm{CoWO}_{6}, \mathrm{Ba}_{2} \mathrm{CoWO}_{6}$, and $\mathrm{Sr}_{2} \mathrm{NiWO}_{6}, \mathrm{Ba}_{2}$ $\mathrm{NiWO}_{6}$, are reported to be stable for $\mathrm{O}_{2}$ evolution with sacrificial agents. ${ }^{\mathbf{1 2 4 , 1 2 5}}$ Although the photophysical properties of certain double perovskites also have been investigated and reported, still a lot of efforts are required before utilizing these materials on an industrial scale.

\section{Summary}

In summary, the abundantly available sun energy can be harvested through photocatalysis to deal with the concerns pertaining to the environment and humankind. This article aimed to discuss the imperative properties of perovskite materials which play vital role in photocatalysis, and will assist in understanding the fundamentals of photocatalytic mechanisms involved in designing highly efficient photocatalysts. The three altercation sites (A, B, and $\mathrm{O}$ sites) of perovskite materials ma them suitable for numerous applications, particularly photocatalysis. These sites help in tailoring chemical, physical, optical, and photocatalytic properties for desired photocatalytic reactions. The structural and compositional suppleness in perovskite photocatalyst strongly affects photo-generated carriers' mobility, separation, and recombination. The current article also describes the defect engineering in perovskite materials for enhanced photocatalytic performance. Recently, defect engineering gained much attention among researchers because it resulted in visible light photocatalytic activity without doping. Furthermore, surface defects provide reactive sites beneficial for a process like nitrogen fixation at ambient conditions. The review also provides an insight into the different applications of photocatalysis, including wastewater treatment, water splitting, $\mathrm{CO}_{2}$ reduction, and nitrogen fixation. The critical perovskite materials for each photocatalytic application are also listed with their properties in this study. Overall, it can be inferred that although perovskite oxide-based materials have exhibited significant photocatalytic performance still, extensive challenges are ahead of their design, fabrication, cost, and efficiency for industrial and large-scale production. The biggest challenge in the industrialization of photocatalyst technology is the development of an ideal photocatalyst, which should possess four features, including high photocatalytic efficiency, a large specific surface area, full utilization of sunlight, and recyclability. Nonetheless, there is no doubt that perovskite-based oxide materials will be investigated more intensively in the coming years due to their exceptional properties and applications for a sustainable future.

\section{Author contributions}

All authors verify their contribution to the current review article as follows: design, study conception, and supervision of the whole article is done by Muneeb Irshad and Quar tul Ain; data collection is done by; Asif Nadeem Tabish, Muhammad Usman, Masood ul Hassan Farooq, Mohammed A. Assiri, Muhammad Imran; analysis and interpretation of results by; Muneeb Irshad, Quar tul Ain, Muhammad Zaman, Muhammad Zeeshan Aslam, Naila Kousar, Muhammad Asim, Muhammad Rafique, and
Khurram Siraj; draft manuscript preparation and proofreading by; Muneeb Irshad, Quar tul Ain, and Muhammad Zaman. Moreover, Mohammed A. Assiri and Muhammad Imran provided the necessary funding to complete the article. All authors reviewed the results and approved the final version of the manuscript.

\section{Conflicts of interest}

There are no conflicts to declare.

\section{Acknowledgements}

The authors, especially M. A. Assiri and M. Imran, express their appreciation to the Deanship of Scientific Research at King Khalid University, Saudia Arabia, through research groups program, under grant number R.G.P. 2/153/42.

\section{References}

1 A. R. Chaurasia, Population effects of the environment, in Population and Sustainable Development in India, Springer Singapore, Singapore, 2020, pp. 243-255.

$2 \mathrm{Y}$. $\mathrm{Li}$, et al., Influence of Industrialization and Environmental Protection on Environmental Pollution: A Case Study of Taihu Lake, China, Int. J. Environ. Res. Public Health, 2018, 15(12), 2628.

3 N. J. Waltham, et al., UN Decade on Ecosystem Restoration 2021-2030-What Chance for Success in Restoring Coastal Ecosystems?, Front. Mar. Sci., 2020, 7(71), 1-5.

4 Y. Cui, B. A. Schubert and A. H. Jahren, A 23 m.y. record of low atmospheric CO2, Geology, 2020, 48(9), 888-892.

5 L. Guppy, et al., Global-Water-Crisis-The-Facts, 2017.

$6 \mathrm{G}$. Nabi, et al., The crisis of water shortage and pollution in Pakistan: risk to public health, biodiversity, and ecosystem, Environ. Sci. Pollut. Res. Int., 2019, 26(11), 10443-10445.

$7 \mathrm{~W}$. Wang, M. O. Tade and Z. Shao, Research progress of perovskite materials in photocatalysis- and photovoltaicsrelated energy conversion and environmental treatment, Chem. Soc. Rev., 2015, 44(15), 5371-5408.

8 A. Kumar, A. Kumar and V. Krishnan, Perovskite Oxide Based Materials for Energy and Environment-Oriented Photocatalysis, ACS Catal., 2020, 10(17), 10253-10315.

9 S. Zhu and D. Wang, Photocatalysis: Basic Principles, Diverse Forms of Implementations and Emerging Scientific Opportunities, Adv. Energy Mater., 2017, 7, 1700841.

$10 \mathrm{P}$. Kanhere and Z. Chen, A review on visible light active perovskite-based photocatalysts, Molecules, 2014, 19(12), 19995-20022.

11 X. Yang and D. Wang, Photocatalysis: From Fundamental Principles to Materials and Applications, ACS Appl. Energy Mater., 2018, 1(12), 6657-6693.

12 A. A. Yaqoob, et al., Role of Nanomaterials in the Treatment of Wastewater: A Review, Water, 2020, 12(2), 495.

13 J. Ran, M. Jaroniec and S. Z. Qiao, Cocatalysts in Semiconductor-based Photocatalytic CO2 Reduction: 
Achievements, Challenges, and Opportunities, Adv. Mater., 2018, 30, 1704649.

14 F. J. Beltran, et al., Ozone and photocatalytic processes to remove the antibiotic sulfamethoxazole from water, Water Res., 2008, 42(14), 3799-3808.

15 M. M. Khan, S. F. Adil and A. Al-Mayouf, Metal oxides as photocatalysts, J. Saudi Chem. Soc., 2015, 19(5), 462-464.

$16 \mathrm{~S}$. Zeng, et al., A review on photocatalytic $\mathrm{CO} 2$ reduction using perovskite oxide nanomaterials, Nanotechnology, 2018, 29(5), 052001.

17 T. Garcia, et al., Vapor-Phase Photocatalytic Overall Water Splitting Using Hybrid Methylammonium Copper and Lead Perovskites, Nanomaterials, 2020, 10(5), 960.

$18 \mathrm{X}$. Xue, et al., Efficient photocatalytic nitrogen fixation under ambient conditions enabled by the heterojunctions of n-type Bi2MoO6 and oxygen-vacancy-rich p-type $\mathrm{BiOBr}$, Nanoscale, 2019, 11(21), 10439-10445.

19 J. M. Coronado, A historical introduction to photocatalysis, in Design of Advanced Photocatalytic Materials for Energy and Environmental Applications, 2013, pp. 1-4.

20 A. Eibner, Action of light on pigments I, Chem.-Ztg., 1911, 35, 753-755.

$21 \mathrm{~K}$. Hashimoto, H. Irie and A. Fujishima, TiO2Photocatalysis: A Historical Overview and Future Prospects, Jpn. J. Appl. Phys., 2005, 44(12), 8269-8285.

22 Chapter 1 history of catalysis, in Studies in Surface Science and Catalysis, ed. J. A. Moulijn, P. W. N. M. van Leeuwen and R. A. van Santen, Elsevier, 1993, pp. 3-21.

23 A. Fujishima and K. Honda, Electrochemical Photolysis of Water at a Semiconductor Electrode, Nature, 1972, 238(5358), 37-38.

24 M. B. Tahir, et al., Nanomaterials for photocatalysis, in Nanotechnology and Photocatalysis for Environmental Applications, 2020, pp. 65-76.

25 S. Fatima, et al., Congo Red Dye Degradation by Graphene Nanoplatelets/Doped Bismuth Ferrite Nanoparticle Hybrid Catalysts under Dark and Light Conditions, Catalysts, 2020, 10(4), 367.

26 D. B. Mitzi, Introduction: Perovskites, Chem. Rev., 2019, 119(5), 3033-3035.

27 J. F. W. Bowles, Oxides, in Encyclopedia of Geology, ed. D. Alderton and S. A. Elias, Academic Press, Oxford, 2nd edn, 2021, pp. 428-441.

28 L. Ortega-San-Martin, Correction to: introduction to perovskites: a historical perspective, in Revolution of Perovskite: Synthesis, Properties and Applications, ed. N. S. Arul and V. D. Nithya, Springer Singapore, Singapore, 2020, p. C1.

29 E. A. Katz, Perovskite: Name Puzzle and German-Russian Odyssey of Discovery, Helv. Chim. Acta, 2020, 103(6), 00061.

30 W.-J. Yin, et al., Oxide perovskites, double perovskites and derivatives for electrocatalysis, photocatalysis, and photovoltaics, Energy Environ. Sci., 2019, 12(2), 442-462.

31 N. F. Atta, A. Galal and E. H. El-Ads, Perovskite nanomaterials - synthesis, characterization, and applications, in Perovskite Materials - Synthesis, Characterisation, Properties, and Applications, 2016.
32 A. S. Bhalla, R. Guo and R. Roy, The perovskite structurea review of its role in ceramic science and technology, Mater. Res. Innovations, 2016, 4(1), 3-26.

33 M. A. Peña and J. L. G. Fierro, Chemical Structures and Performance of Perovskite Oxides, Chem. Rev., 2001, 101(7), 1981-2018.

34 C. N. R. Rao, Perovskites, in Encyclopedia of Physical Science and Technology, ed. R. A. Meyers, Academic Press, New York, 3rd edn, 2003, pp. 707-714.

35 M. T. Sebastian, Chapter six $-\mathrm{ABO}_{3}$ type perovskites, in Dielectric Materials for Wireless Communication, ed. M. T. Sebastian, Elsevier, Amsterdam, 2008, pp. 161-203.

36 R. Mouta, R. X. Silva and C. W. Paschoal, Tolerance factor for pyrochlores and related structures, Acta Crystallogr., Sect. B: Struct. Sci., Cryst. Eng. Mater., 2013, 69(Pt 5), 439445.

37 V. Goldschmidt, Crystal structure and chemical correlation, Ber. Dtsch. Chem. Ges., 1927, 60, 1263-1296.

38 I. M. Reaney and R. Ubic, Dielectric and structural characteristics of perovskites and related materials as a function of tolerance factor, Ferroelectrics, 1999, 228(1), 23-38.

39 R. S. Roth, Classification of Perovskite and Other ABO3Type, J. Res. Natl. Bur. Stand., 1957, 58(2), 75.

$40 \mathrm{~J}$. Attfield, Structure-property relations in doped perovskite oxides, Int. J. Inorg. Mater., 2001, 3(8), 1147-1152.

$41 \mathrm{C}$. Li, K. C. K. Soh and P. Wu, Formability of $\mathrm{ABO} 3$ perovskites, J. Alloys Compd., 2004, 372(1-2), 40-48.

$42 \mathrm{M}$. Johnsson and P. Lemmens, Crystallography and chemistry of perovskites, 2005, arXiv preprint cond-mat/ 0506606.

43 T. K. Todorova, M. V. Ganduglia-Pirovano and J. Sauer, Vanadium Oxides on Aluminum Oxide Supports. 3. Metastable $\kappa-\mathrm{Al} 2 \mathrm{O} 3$ (001) Compared to $\alpha$-Al2O3 (0001), $J$. Phys. Chem. C, 2007, 111(13), 5141-5153.

44 R. J. Tilley, Perovskites: Structure-Property Relationships, John Wiley \& Sons, 2016.

45 E. A. R. Assirey, Perovskite synthesis, properties and their related biochemical and industrial application, Saudi Pharm. J., 2019, 27(6), 817-829.

46 L. Pan and G. Zhu, Perovskite Materials: Synthesis, Characterisation, Properties, and Applications, BoD-Books on Demand, 2016.

47 N. Solanki, P. D. Lodhi and N. Kaurav, Structural and Raman analysis of double perovskite $\mathrm{La}_{2} \mathrm{CoTi}_{0.7} \mathrm{Ni}_{0.3} \mathrm{O}_{6}$, AIP Conf. Proc., 2019, 2100, 020161.

48 M. T. Anderson, et al., B-cation arrangements in double perovskites, Prog. Solid State Chem., 1993, 22(3), 197-233.

49 T. Saha-Dasgupta, Double perovskites with $3 \mathrm{~d}$ and $4 \mathrm{~d} / 5 \mathrm{~d}$ transition metals: compounds with promises, Mater. Res. Express, 2020, 7, 014003.

50 G. King and P. M. Woodward, Cation ordering in perovskites, J. Mater. Chem., 2010, 20(28), 5785-5796.

51 S. Vasala and M. Karppinen, A2B' B "O6 perovskites: a review, Prog. Solid State Chem., 2015, 43(1-2), 1-36. 
52 M. J. Winiarski and P. Dereń, Electronic structure of A2B'B"'O6-type $\left(\mathrm{A}=\mathrm{Ca}, \mathrm{Sr}, \mathrm{Ba} ; \mathrm{B}^{\prime}=\mathrm{Mg}, \mathrm{Zn} ; \mathrm{B}^{\prime \prime}=\mathrm{Mo}, \mathrm{W}\right)$ double perovskite oxides, Opt. Mater., 2019, 90, 95-98.

53 P. Ksoll, et al., B-Site Cation Ordering in Films, Superlattices, and Layer-by-Layer-Grown Double Perovskites, Crystals, 2021, 11(7), 734.

54 J.-W. G. Bos and J. P. Attfield, Structural, Magnetic, and Transport Properties of (La1+xSr1-x)CoRuO6 Double Perovskites, Chem. Mater., 2004, 16(9), 1822-1827.

55 D. Serrate, J. M. D. Teresa and M. R. Ibarra, Double perovskites with ferromagnetism above room temperature, J. Phys.: Condens. Matter, 2007, 19, 023201.

$56 \mathrm{X}$. Xu, Y. Zhong and Z. Shao, Double Perovskites in Catalysis, Electrocatalysis, and Photo(electro)catalysis, Trends Chem., 2019, 1(4), 410-424.

57 M. T. Sebastian, Chapter nine - cation-deficient perovskites, in Dielectric Materials for Wireless Communication, ed. M. T. Sebastian, Elsevier, Amsterdam, 2008, pp. 335-360.

58 W. Xiao, et al., Cubic perovskite polymorph of strontium metasilicate at high pressures, Am. Mineral., 2013, 98(1112), 2096-2104.

59 G. Burns and A. M. Glazer, Chapter 7 - space group applications, in Space Groups for Solid State Scientists, ed. G. Burns and A. M. Glazer, Academic Press, Oxford,3rd edn, 2013, pp. 187-274.

60 Chapter $10 \mathrm{ABX} 3$, perovskite-ilmenite structure, in Developments in Geochemistry, ed. S. Mitra, Elsevier, 2004, pp. 711-792.

61 B. Kurniawan, et al., Effect of Temperature and Duration of Sintering on Perovskite Material (La1-xAgx)0.8Ca0.2MnO3, IOP Conf. Ser.: Mater. Sci. Eng., 2018, 367, 012055.

62 P. Woodward, Octahedral Tilting in Perovskites. II. Structure Stabilizing Forces, Acta Crystallogr., Sect. B: Struct. Sci., 1997, 53(1), 44-66.

$63 \mathrm{~J}$. S. Bechtel and A. Van der Ven, Octahedral tilting instabilities in inorganic halide perovskites, Phys. Rev. Mater., 2018, 2(2), 025401.

64 S. Mukherjee, et al., Structure and Electronic Effects from $\mathrm{Mn}$ and $\mathrm{Nb}$ Co-doping for Low Band Gap BaTiO3 Ferroelectrics, J. Phys. Chem. C, 2021, 125(27), 14910-14923.

65 L. Fu, et al., Magnetic, electronic, and optical properties of perovskite materials, in Revolution of Perovskite: Synthesis, Properties and Applications, ed. N. S. Arul and V. D. Nithya, Springer Singapore, Singapore, 2020, pp. 43-59.

$66 \mathrm{Y}$. Du, et al., Strain accommodation by facile $\mathrm{WO}(6)$ octahedral distortion and tilting during $\mathrm{WO}(3)$ heteroepitaxy on SrTiO(3)(001), ACS Appl. Mater. Interfaces, 2014, 6(16), 14253-14258.

67 M. Madi, M. Tahir and S. Tasleem, Advances in Structural Modification of Perovskite Semiconductors for Visible Light Assisted Photocatalytic CO2 Reduction to Renewable Solar Fuels: A Review, J. Environ. Chem. Eng., 2021, 9(11), 106264.

68 S. Khalfin and Y. Bekenstein, Advances in lead-free double perovskite nanocrystals, engineering band-gaps and enhancing stability through composition tunability, Nanoscale, 2019, 11(18), 8665-8679.

69 R. Alagheband, et al., Synthesis and Evaluation of $\mathrm{ABO} 3$ Perovskites $(\mathrm{A}=\mathrm{La}$ and $\mathrm{B}=\mathrm{Mn}, \mathrm{Co})$ with Stoichiometric and Over-stoichiometric Ratios of B/A for Catalytic Oxidation of Trichloroethylene, Bull. Chem. React. Eng. Catal., 2018, 13(1), 47-56.

70 S. Krishnamurthy, et al., Organic-inorganic hybrid and inorganic halide perovskites: structural and chemical engineering, interfaces and optoelectronic properties, $J$. Phys. D: Appl. Phys., 2021, 54(13), 133002.

71 Y. Zhou, et al., Metal-Doped Lead Halide Perovskites: Synthesis, Properties, and Optoelectronic Applications, Chem. Mater., 2018, 30(19), 6589-6613.

72 K. S. Schanze, et al., Progress in Perovskite Photocatalysis, ACS Energy Lett., 2020, 5(8), 2602-2604.

73 S. Mazumdar, Y. Zhao and X. Zhang, Stability of Perovskite Solar Cells: Degradation Mechanisms and Remedies, Frontiers in Electronics, 2021, 2, 712785.

74 N. Labhasetwar, et al., Perovskite-type catalytic materials for environmental applications, Sci. Technol. Adv. Mater., 2015, 16(3), 036002.

75 B.-M. Bresolin, Y. Park and D. W. Bahnemann, Recent Progresses on Metal Halide Perovskite-Based Material as Potential Photocatalyst, Catalysts, 2020, 10(6), 709.

$76 \mathrm{H}$. Anwer, et al., Photocatalysts for degradation of dyes in industrial effluents: Opportunities and challenges, Nano Res., 2019, 12(5), 955-972.

77 R. Li, Photocatalytic nitrogen fixation: An attractive approach for artificial photocatalysis, Chin. J. Catal., 2018, 39(7), 1180-1188.

$78 \mathrm{~K}$. Iizuka, et al., Photocatalytic reduction of carbon dioxide over Ag cocatalyst-loaded ALa4Ti4O15 (A = Ca, Sr, and Ba) using water as a reducing reagent, J. Am. Chem. Soc., 2011, 133(51), 20863-20868.

$79 \mathrm{D}$. $\mathrm{Xu}$, et al., Heterojunction composites of g-C3N4/KNbO3 enhanced photocatalytic properties for water splitting, Int. J. Hydrogen Energy, 2018, 43(34), 16566-16572.

80 R. Molinari, C. Lavorato and P. Argurio, Visible-Light Photocatalysts and Their Perspectives for Building Photocatalytic Membrane Reactors for Various Liquid Phase Chemical Conversions, Catalysts, 2020, 10(11), 1334.

81 M. Mishra and D.-M. Chun, $\alpha$-Fe 2 O 3 as a photocatalytic material: A review, Appl. Catal., A, 2015, 498, 126-141.

82 O. V. Nkwachukwu and O. A. Arotiba, Perovskite OxideBased Materials for Photocatalytic and Photoelectrocatalytic Treatment of Water, Front. Chem., 2021, 9, 634630.

83 C.-H. Lu, et al., Doping and ion substitution in colloidal metal halide perovskite nanocrystals, Chem. Soc. Rev., 2020, 49(14), 4953-5007.

$84 \mathrm{Z}$. Guo, et al., Band gap engineering in huge-gap semiconductor SrZrO3 for visible-light photocatalysis, Int. J. Hydrogen Energy, 2014, 39(5), 2042-2048.

85 R. Shi, et al., Defect engineering in photocatalytic nitrogen fixation, ACS Catal., 2019, 9(11), 9739-9750. 
86 S. Suzuki, A. Iwase and A. Kudo, Long wavelength visible light-responsive $\mathrm{SrTiO} 3$ photocatalysts doped with valence-controlled $\mathrm{Ru}$ for sacrificial $\mathrm{H} 2$ and $\mathrm{O} 2$ evolution, Catal. Sci. Technol., 2020, 10(15), 4912-4916.

87 Y. Li, et al., A two-step synthesis of NaTaO3 microspheres for photocatalytic water splitting, Int. J. Hydrogen Energy, 2014, 39(25), 13481-13485.

88 L. Ernawati, et al., Experimental data of CaTiO3 photocatalyst for degradation of organic pollutants (Brilliant green dye) - Green synthesis, characterization and kinetic study, Data Brief, 2020, 32, 106099.

89 S. Sharma and M. Kumar, Band gap tuning and optical properties of BiFeO3 nanoparticles, Mater. Today: Proc., 2020, 28, 168-171.

90 M. Ismael and M. Wark, Perovskite-type LaFeO3: Photoelectrochemical Properties and Photocatalytic Degradation of Organic Pollutants Under Visible Light Irradiation, Catalysts, 2019, 9(4), 342.

91 Q. Liu, et al., Highly efficient $\mathrm{Pt} / \mathrm{NaNbO} 3$ nanowire photocatalyst: Its morphology effect and application in water purification and $\mathrm{H} 2$ production, Appl. Catal., B, 2017, 205, 505-513.

92 T. Jia, et al., First-principles study on the electronic, optical and thermodynamic properties of $\mathrm{ABO} 3(\mathrm{~A}=\mathrm{La}, \mathrm{Sr}, \mathrm{B}=$ Fe,Co) perovskites, RSC Adv., 2017, 7(62), 38798-38804.

93 C. Huang, et al., Synthesis and application of Bi2WO6 for the photocatalytic degradation of two typical fluoroquinolones under visible light irradiation, RSC Adv., 2019, 9(48), 27768-27779.

94 D. Arney, et al., New molten-salt synthesis and photocatalytic properties of La2Ti2O7 particles, $J$. Photochem. Photobiol., A, 2008, 199(2-3), 230-235.

$95 \mathrm{P}$. Li, H. Abe and J. Ye, Band-Gap Engineering of NaNbO3for Photocatalytic H2Evolution with Visible Light, Int. J. Photoenergy, 2014, 2014, 1-6.

96 A. Suzuki and T. Oku, Effects of transition metals incorporated into perovskite crystals on the electronic structures and magnetic properties by first-principles calculation, Heliyon, 2018, 4(8), e00755.

$97 \mathrm{~J} . \mathrm{Yu}$, et al., Giant enhancement of photocatalytic $\mathrm{H} 2$ production over KNbO3 photocatalyst obtained via carbon doping and MoS2 decoration, Int. J. Hydrogen Energy, 2018, 43(9), 4347-4354.

98 A. Haruna, I. Abdulkadir and S. O. Idris, Photocatalytic activity and doping effects of $\mathrm{BiFeO} 3$ nanoparticles in model organic dyes, Heliyon, 2020, 6(1), e03237.

99 N. D. Phu, et al., Photocatalytic activity enhancement of Bi2WO6 nanoparticles by $\mathrm{Ag}$ doping and $\mathrm{Ag}$ nanoparticles modification, J. Alloys Compd., 2020, 824, 153914.

100 A. Kumar, et al., Three-Dimensional Carbonaceous Aerogels Embedded with Rh-SrTiO3 for Enhanced Hydrogen Evolution Triggered by Efficient Charge Transfer and Light Absorption, ACS Appl. Energy Mater., 2020, 3(12), 12134-12147.

101 T. S. Jamil, et al., The synthesis of nano-sized undoped, Bi doped and $\mathrm{Bi}, \mathrm{Cu}$ co-doped SrTiO3 using two sol-gel methods to enhance the photocatalytic performance for the degradation of dibutyl phthalate under visible light, C. R. Chim., 2017, 20(2), 97-106.

102 B. G. Anitha and L. G. Devi, Study of reaction dynamics of photocatalytic degradation of 4-chlorophenol using SrTiO3, sulfur doped SrTiO3, silver metallized SrTiO3 and silver metallized sulfur doped $\mathrm{SrTiO} 3$ catalysts: Detailed analysis of kinetic results, J. Photochem. Photobiol., A, 2019, 16, 50-58.

103 H. Bentour, M. Boujnah, M. Houmad and M. Yadari, DFT Study of Se and Te Doped SrTiO 3 for Enhanced VisibleLight Driven Phtocatalytic Hydrogen Production, Opt. Quantum Electron., 2021, 53, 589.

104 S. Shajahan, et al., Optimization and detailed stability study on $\mathrm{Pb}$ doped ceria nanocubes for enhanced photodegradation of several anionic and cationic organic pollutants, Arabian J. Chem., 2020, 13(1), 1309-1322.

$105 \mathrm{H}$. Wang, et al., Synthesis and application of perovskitebased photocatalysts in environmental remediation: A review, J. Mol. Liq., 2021, 334, 116029.

106 L. Zhang, et al., Kinetics and mechanisms of charge transfer processes in photocatalytic systems: A review, $J$. Photochem. Photobiol., C, 2012, 13(4), 263-276.

107 R. Qian, et al., Charge carrier trapping, recombination and transfer during TiO2 photocatalysis: An overview, Catal. Today, 2019, 335, 78-90.

108 A. Bumajdad and M. Madkour, Understanding the superior photocatalytic activity of noble metals modified titania under UV and visible light irradiation, Phys. Chem. Chem. Phys., 2014, 16(16), 7146-7158.

109 S. Natarajan, H. C. Bajaj and R. J. Tayade, Recent advances based on the synergetic effect of adsorption for removal of dyes from waste water using photocatalytic process, $J$. Environ. Sci., 2018, 65, 201-222.

$110 \mathrm{~J}$. Liang, et al., Recent progress and development in inorganic halide perovskite quantum dots for photoelectrochemical applications, Small, 2020, 16(15), 1903398.

111 M. Adly, S. M. El-Dafrawy and S. El-Hakam, Application of nanostructured graphene oxide/titanium dioxide composites for photocatalytic degradation of rhodamine B and acid green 25 dyes, J. Mater. Res. Technol., 2019, 8(6), 5610-5622.

112 K. Takanabe, Photocatalytic Water Splitting: Quantitative Approaches toward Photocatalyst by Design, ACS Catal., 2017, 7(11), 8006-8022.

113 L. M. Peter, Chapter 1 photoelectrochemistry: from basic principles to photocatalysis, in Photocatalysis: Fundamentals and Perspectives, The Royal Society of Chemistry, 2016, pp. 1-28.

114 W. Leng, et al., Electron Diffusion Length in Mesoporous Nanocrystalline TiO2 Photoelectrodes during Water Oxidation, J. Phys. Chem. Lett., 2010, 1(6), 967-972.

$115 \mathrm{~J}$. Li and N. Wu, Semiconductor-based photocatalysts and photoelectrochemical cells for solar fuel generation: a review, Catal. Sci. Technol., 2015, 5(3), 1360-1384.

116 F. M. Pesci, et al., Efficient Suppression of Electron-Hole Recombination in Oxygen-Deficient Hydrogen-Treated 
TiO2 Nanowires for Photoelectrochemical Water Splitting, J. Phys. Chem. C, 2013, 117(48), 25837-25844.

117 W. Wang, M. O. Tadé and Z. Shao, Research progress of perovskite materials in photocatalysis- and photovoltaicsrelated energy conversion and environmental treatment, Chem. Soc. Rev., 2015, 44(15), 5371-5408.

118 A. Gnanaprakasam, V. M. Sivakumar and M. Thirumarimurugan, Influencing Parameters in the Photocatalytic Degradation of Organic Effluent via Nanometal Oxide Catalyst: A Review, Indian Journal of Materials Science, 2015, 2015, 1-16.

119 M. Antonopoulou, et al., An overview of homogeneous and heterogeneous photocatalysis applications for the removal of pharmaceutical compounds from real or synthetic hospital wastewaters under lab or pilot scale, Sci. Total Environ., 2021, 765, 144163.

120 V. Kitsiou, et al., Heterogeneous and homogeneous photocatalytic degradation of the insecticide imidacloprid in aqueous solutions, Appl. Catal., B, 2009, 86(1-2), 27-35.

121 E. Pelizzetti and N. Serpone, Homogeneous and Heterogeneous Photocatalysis, Springer Science \& Business Media, 2012, vol. 174.

122 K. Li, B. Peng and T. Peng, Recent Advances in Heterogeneous Photocatalytic $\mathrm{CO} 2$ Conversion to Solar Fuels, ACS Catal., 2016, 6(11), 7485-7527.

$123 \mathrm{X}$. Y. Kong, et al., Effective steering of charge flow through synergistic inducing oxygen vacancy defects and $\mathrm{p}-\mathrm{n}$ heterojunctions in 2D/2D surface-engineered Bi2WO6/ BiOI cascade: Towards superior photocatalytic CO2 reduction activity, Chem. Eng. J., 2019, 372, 1183-1193.

124 A. Kumar, et al., Perovskite-structured CaTiO3 coupled with g-C3N4 as a heterojunction photocatalyst for organic pollutant degradation, Beilstein J. Nanotechnol., 2018, 9, 671-685.

125 R. Tao, et al., TiO2/SrTiO3/g-C3N4 ternary heterojunction nanofibers: gradient energy band, cascade charge transfer, enhanced photocatalytic hydrogen evolution, and nitrogen fixation, Nanoscale, 2020, 12(15), 8320-8329.

$126 \mathrm{H}$. Wang, et al., Semiconductor heterojunction photocatalysts: design, construction, and photocatalytic performances, Chem. Soc. Rev., 2014, 43(15), 5234-5244.

127 S. N. Ahmed and W. Haider, Heterogeneous photocatalysis and its potential applications in water and wastewater treatment: a review, Nanotechnology, 2018, 29(34), 342001.

128 Z. Zhang, et al., Review on constructed strategies of heterojunctional nanocomposites as efficient visible-light catalysts by modulating excited electrons with appropriate thermodynamic energy, J. Mater. Chem. A, 2019, 7, 1087910897.

129 W. Zhang, et al., Facile preparation of novel nickel sulfide modified $\mathrm{KNbO} 3$ heterojunction composite and its enhanced performance in photocatalytic nitrogen fixation, J. Colloid Interface Sci., 2021, 590, 548-560.

130 J. Low, et al., Heterojunction Photocatalysts, Adv. Mater., 2017, 29, 01694.
$131 \mathrm{H}$. Cai, et al., Orienting the charge transfer path of type-II heterojunction for photocatalytic hydrogen evolution, Appl. Catal., B, 2019, 256, 117853.

$132 \mathrm{X}$. Zhang, et al., NiSe2/Cd0. 5Zn0. 5S as a type-II heterojunction photocatalyst for enhanced photocatalytic hydrogen evolution, Int. J. Hydrogen Energy, 2021, 46(29), 15389-15397.

133 Z. Jiang, et al., Two dimensional Z-scheme AgCl/Ag/CaTiO3 nano-heterojunctions for photocatalytic hydrogen production enhancement, Appl. Surf. Sci., 2018, 436, 519526.

134 Y. Chang, et al., Z-Scheme Pt@CdS/3DOM-SrTiO3 composite with enhanced photocatalytic hydrogen evolution from water splitting, Catal. Today, 2019, 327, 315-322.

135 Z. Jin, et al., One-step impregnation method to prepare direct Z-scheme LaCoO3/g-C3N4 heterojunction photocatalysts for phenol degradation under visible light, Appl. Surf. Sci., 2019, 491, 432-442.

136 X. Wang, et al., Synthesis of p-n heterojunction Ag3PO4/ NaTaO3 composite photocatalyst for enhanced visiblelight-driven photocatalytic performance, Mater. Lett., 2019, 251, 192-195.

137 J. Ge, et al., Advanced Design and Synthesis of Composite Photocatalysts for the Remediation of Wastewater: A Review, Catalysts, 2019, 9(2), 122.

138 L. Zhang and M. Jaroniec, Toward designing semiconductor-semiconductor heterojunctions for photocatalytic applications, Appl. Surf. Sci., 2018, 430, 2-17.

$139 \mathrm{H}$. Chen, et al., Structuring a TiO2-based photonic crystal photocatalyst with Schottky junction for efficient photocatalysis, Environ. Sci. Technol., 2010, 44(1), 451-455.

140 J. S. Jang, H. G. Kim and J. S. Lee, Heterojunction semiconductors: A strategy to develop efficient photocatalytic materials for visible light water splitting, Catal. Today, 2012, 185(1), 270-277.

141 A. Murali, et al., Synergetic effect of surface plasmon resonance and schottky junction in Ag-AgX-ZnO-rGO (X= $\mathrm{Cl} \& \mathrm{Br}$ ) nanocomposite for enhanced visible-light driven photocatalysis, Colloids Surf., A, 2020, 595, 124684.

142 Y. S. Fu, J. Li and J. Li, Metal/Semiconductor Nanocomposites for Photocatalysis: Fundamentals, Structures, Applications and Properties, Nanomaterials, 2019, 9(3), 359.

143 S. Bai, et al., Defect engineering in photocatalytic materials, Nano Energy, 2018, 53, 296-336.

$144 \mathrm{~W}$. Zhou and $\mathrm{H}$. Fu, Defect-mediated electron-hole separation in semiconductor photocatalysis, Inorg. Chem. Front., 2018, 5(6), 1240-1254.

145 A. Kumar and V. Krishnan, Vacancy Engineering in Semiconductor Photocatalysts: Implications in Hydrogen Evolution and Nitrogen Fixation Applications, Adv. Funct. Mater., 2021, 31(28), 2009807.

$146 \mathrm{H}$. Arandiyan, et al., Defect engineering of oxide perovskites for catalysis and energy storage: synthesis of chemistry and materials science, Chem. Soc. Rev., 2021, 50, 10116-10211. 
147 Y. Sun, et al., Defect engineering in perovskite oxide thin films, Chem. Commun., 2021, 57(68), 8402-8420.

148 Q. Ji, et al., The role of oxygen vacancies of $\mathrm{ABO} 3$ perovskite oxides in the oxygen reduction reaction, Energy Environ. Sci., 2020, 13(5), 1408-1428.

149 Q. Shen, et al., A Review on the Catalytic Decomposition of NO by Perovskite-Type Oxides, Catalysts, 2021, 11(5), 622.

150 H. L. Tan, F. F. Abdi and Y. H. Ng, Heterogeneous photocatalysts: an overview of classic and modern approaches for optical, electronic, and charge dynamics evaluation, Chem. Soc. Rev., 2019, 48(5), 1255-1271.

151 T. Shi, et al., Recyclable Perovskite as Heterogeneous Photocatalyst for Aminomethylation of Imidazo-Fused Heterocycles, Adv. Synth. Catal., 2020, 362(11), 2143-2149.

152 A. Kumar, et al., Recyclable, bifunctional composites of perovskite type $\mathrm{N}-\mathrm{CaTiO} 3$ and reduced graphene oxide as an efficient adsorptive photocatalyst for environmental remediation, Mater. Chem. Front., 2017, 1(11), 2391-2404.

153 J. J. Rueda-Marquez, et al., A critical review on application of photocatalysis for toxicity reduction of real wastewaters, J. Cleaner Prod., 2020, 258(4), 120694.

154 M. F. Hossain, Water, in Sustainable Design and Build, 2019, pp. 301-418.

155 M. L. Sikosana, et al., Municipal wastewater treatment technologies: A review, Procedia Manuf., 2019, 35, 10181024.

$156 \mathrm{H}$. Xiao, et al., Industrial disposal processes for treatment of polychlorinated dibenzo-p-dioxins and dibenzofurans in municipal solid waste incineration fly ash, Chemosphere, 2020, 243, 125351.

157 N. N. Yunus, et al., Effect of Catalyst Loading on Photocatalytic Degradation of Phenol by Using N, S Codoped TiO2, IOP Conf. Ser.: Mater. Sci. Eng., 2017, 206, 012092.

158 S. Singh, et al., Ti doped BaMnO3 perovskite structure as photocatalytic agent for the degradation of noxious air and water pollutants, SN Appl. Sci., 2020, (2), 310.

159 K. Khan, et al., Recent Progress, Challenges, and Prospects in Two-Dimensional Photo-Catalyst Materials and Environmental Remediation, Nano-Micro Lett., 2020, 12(1), 167.

160 A. Kumar, A Review on the Factors Affecting the Photocatalytic Degradation of Hazardous Materials, Material Science \& Engineering International Journal, 2017, 1(3), 106-114.

161 S. Em, et al., Sn-Doped Hematite Nanoparticles for Potential Photocatalytic Dye Degradation, IOP Conf. Ser.: Mater. Sci. Eng., 2020, 739(1), 012042.

162 M. Tsvetkov, J. Zaharieva and M. Milanova, Ferrites, modified with silver nanoparticles, for photocatalytic degradation of malachite green in aqueous solutions, Catal. Today, 2020, 357, 453-459.

163 W. Zhang, et al., Photocatalytic Performance of SiO2/CNOs/ TiO2 to Accelerate the Degradation of Rhodamine B under Visible Light, Nanomaterials, 2019, 9(12), 1671.
164 K. A. Huynh, et al., Halide perovskite photocatalysis: progress and perspectives, J. Chem. Technol. Biotechnol., 2020, 6342 .

$165 \mathrm{~J}$. Kong, et al., Perovskite-based photocatalysts for organic contaminants removal: Current status and future perspectives, Catal. Today, 2019, 327, 47-63.

166 A. M. Ferrari, et al., CaTiO3 Perovskite in the Photocatalysis of Textile Wastewater, Rev. Ambient. Água, 2019, 14(3), 2336.

$167 \mathrm{~J}$. Cai, et al., Understanding oxygen vacancies in disorderengineered surface and subsurface of CaTiO3 nanosheets on photocatalytic hydrogen evolution, Appl. Catal., B, 2020, 267, 118378.

168 Y. Yan, et al., A Hydrothermal Route to the Synthesis of CaTiO3 Nanocuboids Using P25 as the Titanium Source, J. Electron. Mater., 2018, 47(5), 3045-3050.

169 H. Yang, C. Han and X. Xue, Photocatalytic activity of Fedoped CaTiO(3) under UV-visible light, J. Environ. Sci., 2014, 26(7), 1489-1495.

170 S. Kappadan, et al., Tetragonal BaTiO3 nanoparticles: An efficient photocatalyst for the degradation of organic pollutants, Mater. Sci. Semicond. Process., 2016, 51, 42-47.

$171 \mathrm{P}$. Mehdizadeh, et al., Effective removal of organic pollution by using sonochemical prepared LaFeO3 perovskite under visible light, Ultrason. Sonochem., 2020, 61, 104848.

$172 \mathrm{~S}$. Irfan, et al., Critical review: Bismuth ferrite as an emerging visible light active nanostructured photocatalyst, J. Mater. Res. Technol., 2019, 8(6), 6375-6389.

173 T. Gao, et al., Synthesis of BiFeo 3 nanoparticles for the visible-light induced photocatalytic property, Mater. Res. Bull., 2014, 59, 6-12.

174 S. R. Khan, et al., A Versatile Material: Perovskite Bismuth Ferrite Microparticles as a Potential Catalyst for Enhancing Fuel Efficiency and Degradation of Various Organic Dyes, J. Inorg. Organomet. Polym. Mater., 2020, 30(9), 3761-3770.

175 S. Chang, Y. Sang and H. Liu, Efficient Photocatalytic Degradation of RhB by Constructing Sn3O4 Nanoflakes on Sulfur-Doped NaTaO3 Nanocubes, Crystals, 2021, 11(1), 59.

176 D.-R. Liu, Y.-S. Jiang and G.-M. Gao, Photocatalytic degradation of an azo dye using N-doped NaTaO3 synthesized by one-step hydrothermal process, Chemosphere, 2011, 83(11), 1546-1552.

177 L. Ernawati, et al., Experimental data of CaTiO3 photocatalyst for degradation of organic pollutants (Brilliant green dye) - Green synthesis, characterization and kinetic study, Data Brief, 2020, 32, 106099.

178 Y. Yan, et al., Enhanced photocatalytic activity of surface disorder-engineered CaTiO 3, Mater. Res. Bull., 2018, 105, 286-290.

179 C.-W. Chang and C. Hu, Graphene oxide-derived carbondoped SrTiO3 for highly efficient photocatalytic degradation of organic pollutants under visible light irradiation, Chem. Eng. J., 2020, 383, 123116.

180 T. Ohno, et al., Preparation of S, C cation-codoped SrTiO3 and its photocatalytic activity under visible light, Appl. Catal., A, 2005, 288(1-2), 74-79. 
181 Q. I. Rahman, et al., Efficient degradation of Methylene Blue dye over highly reactive $\mathrm{Cu}$ doped strontium titanate (SrTiO3) nanoparticles photocatalyst under visible light, $J$. Nanosci. Nanotechnol., 2012, 12(9), 7181-7186.

182 M. Abdi, V. Mahdikhah and S. Sheibani, Visible light photocatalytic performance of La-Fe co-doped SrTiO3 perovskite powder, Opt. Mater., 2020, 102, 109803.

$183 \mathrm{G}$. Wu, et al., Hydrothermal synthesis and visible-lightdriven photocatalytic degradation for tetracycline of $\mathrm{Mn}$ doped SrTiO3 nanocubes, Appl. Surf. Sci., 2015, 333, 39-47.

184 D. R. Liu, Y. S. Jiang and G. M. Gao, Photocatalytic degradation of an azo dye using N-doped NaTaO3 synthesized by one-step hydrothermal process, Chemosphere, 2011, 83(11), 1546-1552.

$185 \mathrm{X}$. Zhang, et al., Enhanced visible-light-driven photocatalytic performance of $\mathrm{Ag} / \mathrm{AgGaO} 2$ metal semiconductor heterostructures, J. Alloys Compd., 2017, 701, 16-22.

186 P. Tang, et al., Microwave-assisted synthesis of nanoparticulate perovskite $\mathrm{LaFeO} 3$ as a high active visible-light photocatalyst, Curr. Appl. Phys., 2013, 13(2), 340-343.

187 E. Jiang, et al., Construction of a Z-scheme MoS2/CaTiO3 heterostructure by the morphology-controlled strategy towards enhancing photocatalytic activity, Chem. Eng. J., 2020, 399, 125721.

188 X. Wang, et al., Synthesis of p-n heterojunction Ag3PO4/ NaTaO3 composite photocatalyst for enhanced visiblelight-driven photocatalytic performance, Mater. Lett., 2019, 251(15), 192-195.

$189 \mathrm{X} . \mathrm{Lu}$, et al., Fabrication of a novel BiOI/KTaO3 p-n heterostructure with enhanced photocatalytic performance under visible-light irradiation, RSC Adv., 2020, 10(18), 10921-10931.

190 T. Soltani, A. Tayyebi and B.-K. Lee, BiFeO3/BiVO4 p-n heterojunction for efficient and stable photocatalytic and photoelectrochemical water splitting under visible-light irradiation, Catal. Today, 2020, 340, 188-196.

$191 \mathrm{~J} . \mathrm{Xu}$, et al., Fabrication of In2S3/NaTaO3 composites for enhancing the photocatalytic activity toward the degradation of tetracycline, New J. Chem., 2018, 42(7), 5052-5058.

192 J. Luo, et al., Rational design of Z-scheme LaFeO3/SnS2 hybrid with boosted visible light photocatalytic activity towards tetracycline degradation, Sep. Purif. Technol., 2019, 210, 417-430.

193 T. Zhang, et al., Organic Pollutant Photodecomposition by $\mathrm{Ag} / \mathrm{KNbO} 3$ Nanocomposites: A Combined Experimental and Theoretical Study, J. Phys. Chem. C, 2016, 120(5), 2777-2786.

194 L. G. Betancourt-Cantera, et al., Structural transitions and multiferroic properties of high Ni-doped BiFeO3, J. Magn. Magn. Mater., 2018, 456, 381-389.

195 Y. Li, et al., Sol-gel combustion synthesis and visible-lightdriven photocatalytic property of perovskite LaNiO3, J. Alloys Compd., 2010, 491(1), 560-564.
196 X.-T. Wang, et al., Design and fabrication of NiS/LaFeO3 heterostructures for high efficient photodegradation of organic dyes, Appl. Surf. Sci., 2020, 504, 144363.

197 Z. Fu, S. Zhang and Z. Fu, Hydrothermal preparation of NaTaO3/rGO composite photocatalyst to enhance UV photocatalytic activity, Results Phys., 2019, 15, 102669.

198 V. Jayaraman, et al., Synergistic effect of band edge potentials on BiFeO3/V2O5 composite: Enhanced photo catalytic activity, J. Environ. Manage., 2019, 247, 104-114.

199 B. Safizade, et al., Photocatalytic activity of BiFeO 3/ZnFe 2 O 4 nanocomposites under visible light irradiation, $R S C$ Adv., 2018, 8, 6988-6995.

200 Y. Yuan, et al., Synthesis and photocatalytic characterization of a new photocatalyst BaZrO3, Int. J. Hydrogen Energy, 2008, 33(21), 5941-5946.

201 S. Yuan, et al., Investigation of photocatalytic performance of CuS/Bi2WO6 and degradation pathway of RhB in water, Journal of Water Supply: Research and Technology-Aqua, 2020, 69(2), 145-159.

202 M. Shang, et al., Bi2WO6 Nanocrystals with High Photocatalytic Activities under Visible Light, J. Phys. Chem. C, 2008, 112(28), 10407-10411.

203 X. Zhang, M. Zhang and K. Cao, Hydrothermal synthesis of Sm-doped Bi2WO6 flower-like microspheres for photocatalytic degradation of rhodamine $\mathrm{B}$, CrystEngComm, 2019, 21(41), 6208-6218.

204 J. Cheng, et al., Flower-like Bi2WO6/ZnO composite with excellent photocatalytic capability under visible light irradiation, Chin. J. Catal., 2018, 39(4), 810-820.

205 L. Zhang, et al., Controllable synthesis of Bi2MoO6 and effect of morphology and variation in local structure on photocatalytic activities, Appl. Catal., B, 2010, 98(3), 138146.

206 T. Zhang, et al., Facial Synthesis and Photoreaction Mechanism of $\mathrm{BiFeO} 3 / \mathrm{Bi} 2 \mathrm{Fe} 4 \mathrm{O} 9$ Heterojunction Nanofibers, ACS Sustainable Chem. Eng., 2017, 5(6), 46304636.

207 L. Zhang, et al., AgBr-Ag-Bi2WO6 nanojunction system: A novel and efficient photocatalyst with double visible-light active components, Appl. Catal., A, 2009, 363(1), 221-229.

208 Y. Liu, et al., In situ assembly of CQDs/Bi2WO6 for highly efficient photocatalytic degradation of VOCs under visible light, New J. Chem., 2020, 44(8), 3455-3462.

209 L. Ge, C. Han and J. Liu, Novel visible light-induced g-C3N4/ Bi2WO6 composite photocatalysts for efficient degradation of methyl orange, Appl. Catal., B, 2011, 108-109, 100-107.

210 S. Dong, et al., Self-assembled hollow sphere shaped Bi2WO6/RGO composites for efficient sunlight-driven photocatalytic degradation of organic pollutants, Chem. Eng. J., 2017, 316, 778-789.

211 S. Boumaza, et al., Photoelectrochemical study of La2NiO4 synthesized using citrate sol gel method-application for hydrogen photo-production, J. Solid State Electrochem., 2020, 24(2), 329-337.

212 N. Karamat, et al., Synthesis, characterization and photocatalytic activity of LaNdZr2O7 supported SnSe 
nanocomposites for the degradation of Foron blue dye, Appl. Surf. Sci., 2019, 463, 1019-1027.

213 Y. Zhang, et al., Hydrothermal synthesis of Bi2O4/NaBiO3 heterostructures with enhanced visible light photocatalytic properties, J. Phys. Chem. Solids, 2021, 149, 109766.

214 S. Tasleem and M. Tahir, Recent progress in structural development and band engineering of perovskites materials for photocatalytic solar hydrogen production: A review, Int. J. Hydrogen Energy, 2020, 45(38), 19078-19111.

215 Y. Qu, et al., Facile Synthesis of Porous Zn2Ti3O8Nanorods for Photocatalytic Overall Water Splitting, ChemCatChem, 2014, 6(8), 2258-2262.

216 J. S. Lee, Photocatalytic Water Splitting Under Visible Light with Particulate Semiconductor Catalysts, Catal. Surv. Asia, 2006, 9(4), 217-227.

217 J. Kang, et al., Design of Three-Dimensional Hollow-Sphere Architecture of Ti3C2Tx MXene with Graphitic Carbon Nitride Nanoshells for Efficient Photocatalytic Hydrogen Evolution, ACS Appl. Energy Mater., 2020, 3(9), 9226-9233.

218 E. Hua, et al., In situ fabrication of two-dimensional gC3N4/Ba5Ta4O15 nanosheet heterostructures with efficient charge separations and photocatalytic hydrogen evolution under visible light illumination, Dalton Trans., 2018, 47(12), 4360-4367.

219 E. Hua, et al., Double perovskite compounds A2CuWO6 (A $=\mathrm{Sr}$ and $\mathrm{Ba})$ with p-type semiconductivity for photocatalytic water oxidation under visible light illumination, Inorg. Chem. Front., 2019, 6(8), 2096-2103.

220 A. M. Idris, et al., A Novel Double Perovskite Oxide Semiconductor Sr2CoWO6as Bifunctional Photocatalyst for Photocatalytic Oxygen and Hydrogen Evolution Reactions from Water under Visible Light Irradiation, Sol. $R R L, 2019,4(3), 00456$.

221 A. Kudo and Y. Miseki, Heterogeneous photocatalyst materials for water splitting, Chem. Soc. Rev., 2009, 38(1), 253-278.

222 A. Kudo, H. Kato and S. Nakagawa, Water splitting into H2 and $\mathrm{O} 2$ on new $\mathrm{Sr} 2 \mathrm{M} 2 \mathrm{O} 7(\mathrm{M}=\mathrm{Nb}$ and $\mathrm{Ta})$ photocatalysts with layered perovskite structures: factors affecting the photocatalytic activity, J. Phys. Chem. B, 2000, 104(3), 571575.

223 N. Fajrina and M. Tahir, A critical review in strategies to improve photocatalytic water splitting towards hydrogen production, Int. J. Hydrogen Energy, 2019, 44(2), 540-577.

224 M. B. Tahir, et al., Role of nanotechnology in photocatalysis, in Encyclopedia of Smart Materials, ed. A.G. Olabi, Elsevier, Oxford, 2022, pp. 578-589.

225 N. M. Gupta, Factors affecting the efficiency of a water splitting photocatalyst: a perspective, Renewable Sustainable Energy Rev., 2017, 71, 585-601.

$226 \mathrm{H}$. Kato and A. Kudo, Photocatalytic water splitting into H2 and $\mathrm{O} 2$ over various tantalate photocatalysts, Catal. Today, 2003, 78(1-4), 561-569.

227 S. Chandrasekaran, et al., Advanced nano-structured materials for photocatalytic water splitting, J. Electrochem. Sci. Technol., 2016, 7(1), 1-12.
228 T. Takata, et al., Photocatalytic water splitting with a quantum efficiency of almost unity, Nature, 2020, 581(7809), 411-414.

229 C.-F. Fu, et al., Intrinsic electric fields in two-dimensional materials boost the solar-to-hydrogen efficiency for photocatalytic water splitting, Nano Lett., 2018, 18(10), 6312-6317.

230 Q. Wang, et al., Scalable water splitting on particulate photocatalyst sheets with a solar-to-hydrogen energy conversion efficiency exceeding 1\%, Nat. Mater., 2016, 15(6), 611-615.

231 T. Hisatomi and K. Domen, Reaction systems for solar hydrogen production via water splitting with particulate semiconductor photocatalysts, Nat. Catal., 2019, 2(5), 387-399.

232 S. Cao, L. Piao and X. Chen, Emerging Photocatalysts for Hydrogen Evolution, Trends Chem., 2019, 2(1), 57-70.

233 X. Sun, et al., Activating layered perovskite compound $\mathrm{Sr} 2 \mathrm{TiO} 4 \mathrm{via} \mathrm{La} / \mathrm{N}$ codoping for visible light photocatalytic water splitting, ACS Catal., 2018, 8(4), 3209-3221.

234 H. Xiao, et al., Ruddlesden-Popper Perovskite Oxides for Photocatalysis-Based Water Splitting and Wastewater Treatment, Energy Fuels, 2020, 34(8), 9208-9221.

235 C. Wang, et al., Band gap engineering of SrTiO3 for water splitting under visible light irradiation, Int. J. Hydrogen Energy, 2014, 39(24), 12507-12514.

236 Y. Liu, et al., Synthesis and high photocatalytic hydrogen production of SrTiO3 nanoparticles from water splitting under UV irradiation, J. Power Sources, 2008, 183(2), 701707.

237 Y. Fan, et al., Photocatalytic Overall Water Splitting by SrTiO3 with Surface Oxygen Vacancies, Nanomaterials, 2020, 10(12), 2572.

238 K. Ikeue, Y. Yamamoto and M. Suzuki, Photocatalytic Activity for Hydrogen Evolution of Heteroatom-Doped SrTiO3 Prepared Using a Graphitic-Carbon Nitride Nanosheet, Ceramics, 2020, 3(1), 22-30.

239 A. K. Wahab, et al., Comparing Pt/SrTiO3 to Rh/SrTiO3 for hydrogen photocatalytic production from ethanol, Appl. Petrochem. Res., 2013, 3(3), 83-89.

240 C. R. Kalaiselvi, et al., Synthesis of $\mathrm{Ag}$ and $\mathrm{N}$ doped potassium tantalate perovskite nanocubes for enhanced photocatalytic hydrogen evolution, Mater. Lett., 2020, 275, 128166.

241 T. Ahmad, U. Farooq and R. Phul, Fabrication and photocatalytic applications of perovskite materials with special emphasis on alkali-metal-based niobates and tantalates, Ind. Eng. Chem. Res., 2018, 57(1), 18-41.

242 Y. W. Teh, et al., An insight into perovskite-based photocatalysts for artificial photosynthesis, Sustainable Energy Fuels, 2020, 4(3), 973-984.

243 T. Fujiwara, et al., Single-Crystal Model of Highly Efficient Water-Splitting Photocatalysts: A KTaO3 Wafer Doped with Calcium Cations, Chem. Mater., 2020, 32(4), 14391447.

244 L. I. Ibarra-Rodriguez, et al., Photocatalytic evolution of H2 over visible-light active LaMO3 (M: Co, Mn, Fe) perovskite 
materials: Roles of oxygenated species in catalytic performance, J. Phys. Chem. Solids, 2020, 136, 109189.

245 A. Kumar, et al., Interplay between Mesocrystals of CaTiO3 and Edge Sulfur Atom Enriched MoS2 on Reduced Graphene Oxide Nanosheets: Enhanced Photocatalytic Performance under Sunlight Irradiation, ChemPhotoChem, 2020, 4(6), 427-444.

246 L. Meng, et al., Controlled synthesis of CaTiO3:Ln3+ nanocrystals for luminescence and photocatalytic hydrogen production, RSC Adv., 2016, 6(7), 5761-5766.

247 S. N. Lim, et al., H2 Production Under Visible Light Irradiation from Aqueous Methanol Solution on CaTiO3:Cu Prepared by Spray Pyrolysis, J. Electron. Mater., 2017, 46(10), 6096-6103.

$248 \mathrm{~W}$. Gao, et al., Visible light driven water splitting over CaTiO3/Pr3+-Y2SiO5/RGO catalyst in reactor equipped artificial gill, Appl. Catal., B, 2018, 224, 553-562.

249 J. Han, et al., Fabrication of CdSe/CaTiO3 nanocomposties in aqueous solution for improved photocatalytic hydrogen production, Appl. Surf. Sci., 2018, 459, 520-526.

$250 \mathrm{H}$. Yoshida, R. Yamada and T. Yoshida, Platinum Cocatalyst Loaded on Calcium Titanate Photocatalyst for Water Splitting in a Flow of Water Vapor, ChemSusChem, 2019, 12(9), 1958-1965.

251 M. Qureshi, et al., Catalytic consequences of ultrafine Pt clusters supported on SrTiO3 for photocatalytic overall water splitting, J. Catal., 2019, 376, 180-190.

252 I. Tamiolakis, et al., Mesoporous implantable Pt/ SrTiO3:C,N nanocuboids delivering enhanced photocatalytic H2-production activity via plasmoninduced interfacial electron transfer, Appl. Catal., B, 2018, 236, 338-347.

$253 \mathrm{~W}$. Chen, et al., Polymerizable complex synthesis of SrTiO3:(Cr/Ta) photocatalysts to improve photocatalytic water splitting activity under visible light, Appl. Catal., B, 2016, 192, 145-151.

254 Y. Chang, et al., Ternary CdS/Au/3DOM-SrTiO3 composites with synergistic enhancement for hydrogen production from visible-light photocatalytic water splitting, Appl. Catal., B, 2017, 215, 74-84.

255 D. Zhong, et al., Insights into the synergy effect of anisotropic $\{001\}$ and $\{230\}$ facets of BaTiO3 nanocubes sensitized with CdSe quantum dots for photocatalytic water reduction, Appl. Catal., B, 2018, 227, 1-12.

256 Z. Wang, et al., Wide spectrum responsive CdS/NiTiO3/CoS with superior photocatalytic performance for hydrogen evolution, Catal. Sci. Technol., 2017, 7(12), 2524-2530.

257 Z. Yang, et al., Solid-State, Low-Cost, and Green Synthesis and Robust Photochemical Hydrogen Evolution Performance of Ternary $\mathrm{TiO} 2 / \mathrm{MgTiO} 3 / \mathrm{C}$ Photocatalysts, iScience, 2019, 14, 15-26.

258 C. Gómez-Solís, et al., Facile solvo-combustion synthesis of crystalline $\mathrm{NaTaO} 3$ and its photocatalytic performance for hydrogen production, Fuel, 2014, 130, 221-227.

259 L. Huang, et al., Improved Photocatalytic Hydrogen Production Performance Over NaTaO3/Reduced Graphene
Oxide Composite Photocatalyst, J. Nanosci. Nanotechnol., 2018, 18(7), 4982-4986.

260 D. Xu, et al., Ag-Decorated ATaO3 (A = K, Na) Nanocube Plasmonic Photocatalysts with Enhanced Photocatalytic Water-Splitting Properties, Langmuir, 2015, 31(35), 96949699.

261 Z. Chen, et al., Synthesis of carbon doped KTaO3 and its enhanced performance in photocatalytic $\mathrm{H} 2$ generation, Catal. Commun., 2018, 109, 6-9.

262 H. Hagiwara, et al., Effect of Porphyrin Molecular Structure on Water Splitting Activity of a KTaO3 Photocatalyst, Catalysts, 2016, 6(3), 42.

263 S. Takasugi, et al., The hydrothermal and solvothermal synthesis of LiTaO3 photocatalyst: Suppressing the deterioration of the water splitting activity without using a cocatalyst, Int. J. Hydrogen Energy, 2015, 40(16), 56385643.

264 T. Takashima, T. Sano and H. Irie, Cocatalyst modification of niobium-substituted silver tantalate photocatalyst for enhanced solar water-splitting activity, Int. J. Hydrogen Energy, 2019, 44(42), 23600-23609.

265 F. Yang, et al., Facile synthesis of highly efficient Pt/N-rGO/ $\mathrm{N}-\mathrm{NaNbO} 3$ nanorods toward photocatalytic hydrogen production, Appl. Catal., B, 2019, 257, 117901.

$266 \mathrm{~J}$. Yu, et al., Synthesis of carbon-doped KNbO3 photocatalyst with excellent performance for photocatalytic hydrogen production, Sol. Energy Mater. Sol. Cells, 2018, 179, 45-56.

267 W. C. Balcerski, S. Y. Ryu and M. R. Hoffmann, Photocatalytic hydrogen production with visible light using nanocomposites of CdS and Ni on niobium oxide, Sep. Purif. Technol., 2015, 156, 915-921.

$268 \mathrm{~J}$. Yu, et al., Synthesis of KNbO3/g-C3N4 composite and its new application in photocatalytic $\mathrm{H} 2$ generation under visible light irradiation, J. Mater. Sci., 2018, 53(10), 74537465.

$269 \mathrm{~K}$. Xu, et al., Photocatalytic hydrogen evolution performance of NiS cocatalyst modified LaFeO3/g-C3N4 heterojunctions, New J. Chem., 2017, 41(23), 14602-14609.

270 S. Vasala, et al., Magnetic structure of Sr 2 CuWO 6, J. Phys.: Condens. Matter, 2014, 26, 496001.

271 E. Greul, et al., Highly stable, phase pure Cs2AgBiBr6 double perovskite thin films for optoelectronic applications, J. Mater. Chem. A, 2017, 5(37), 19972-19981.

272 K. Wang, et al., Ba5Ta4O15 Nanosheet/AgVO3 Nanoribbon Heterojunctions with Enhanced Photocatalytic Oxidation Performance: Hole Dominated Charge Transfer Path and Plasmonic Effect Insight, ACS Sustainable Chem. Eng., 2018, 6(5), 6682-6692.

273 J. Yang and J. H. Swisher, The phase stability of Zn2Ti3O8, Mater. Charact., 1996, 37(2), 153-159.

274 C. López, et al., Magnetic behavior of Ca2NiWO6 double perovskite, Phys. B, 2007, 398, 256-258.

275 P. Borse, et al., Improved Photolysis of Water from $\mathrm{Ti}$ Incorporated Double Perovskite Sr2FeNbO6 Lattice, Bull. Korean Chem. Soc., 2012, 33, 3407-3412. 
276 S. Hong, et al., Structure of $\mathrm{PbBi} 2 \mathrm{Nb} 2 \mathrm{O} 9$ and Its Cr-Doped Layered Perovskite System and Their Photocatalytic Activities, J. Korean Phys. Soc., 2007, 51, S27-S31.

277 C. Peng, et al., Perspective: Photocatalytic reduction of CO2 to solar fuels over semiconductors, J. Chem. Phys., 2017, $147(3), 030901$.

278 D. W. Hwang, et al., Photocatalytic Hydrogen Production from Water over M-Doped La2Ti2O7 ( $\mathrm{M}=\mathrm{Cr}$, Fe) under Visible Light Irradiation $(\lambda>420 \mathrm{~nm}), J$. Phys. Chem. B, 2005, 109(6), 2093-2102.

279 A. M. Idris, et al., Sr2NiWO6 Double Perovskite Oxide as a Novel Visible-Light-Responsive Water Oxidation Photocatalyst, ACS Appl. Mater. Interfaces, 2020, 12(23), 25938-25948.

280 S. Nanamatsu, et al., A new ferroelectric: La2Ti2o7, Ferroelectrics, 1974, 8(1), 511-513.

281 D. Cortecchia, et al., Lead-Free MA2CuClxBr4-x Hybrid Perovskites, Inorg. Chem., 2016, 55.

282 N. Kulischow, C. Ladasiu and R. Marschall, Layered DionJacobson type niobium oxides for photocatalytic hydrogen production prepared via molten salt synthesis, Catal. Today, 2017, 287, 65-69.

283 H. Fukuoka, T. Isami and S. Yamanaka, Crystal Structure of a Layered Perovskite Niobate KCa2Nb3O10, J. Solid State Chem., 2000, 151(1), 40-45.

284 S. S. Bhosale, et al., Mechanism of Photocatalytic CO2 Reduction by Bismuth-Based Perovskite Nanocrystals at the Gas-Solid Interface, J. Am. Chem. Soc., 2019, 141(51), 20434-20442.

285 R. Shi, G. I. N. Waterhouse and T. Zhang, Recent Progress in Photocatalytic CO2Reduction Over Perovskite Oxides, Sol. RRL, 2017, 1(11), 00126.

286 C. Lu, et al., Synthesis of lead-free Cs3Sb2Br9 perovskite alternative nanocrystals with enhanced photocatalytic CO2 reduction activity, Nanoscale, 2020, 12(5), 2987-2991.

287 A. Razzaq, et al., Layered Double Hydroxide (LDH) Based Photocatalysts: An Outstanding Strategy for Efficient Photocatalytic CO2 Conversion, Catalysts, 2020, 10(10).

288 J. Ran, M. Jaroniec and S. Z. Qiao, Cocatalysts in semiconductor-based photocatalytic $\mathrm{CO} 2$ reduction: achievements, challenges, and opportunities, Adv. Mater., 2018, 30(7), 1704649.

289 J. Albero, Y. Peng and H. García, Photocatalytic CO2 reduction to $\mathrm{C} 2+$ products, ACS Catal., 2020, 10(10), 57345749.

290 Y.-F. Xu, et al., A CsPbBr3 perovskite quantum dot/ graphene oxide composite for photocatalytic $\mathrm{CO} 2$ reduction, J. Am. Chem. Soc., 2017, 139(16), 5660-5663.

291 R. Shi, G. I. Waterhouse and T. Zhang, Recent progress in photocatalytic $\mathrm{CO} 2$ reduction over perovskite oxides, Sol. $R R L, 2017,1(11), 1700126$.

292 B. N. Nunes, et al., Recent Advances in Niobium-Based Materials for Photocatalytic Solar Fuel Production, Catalysts, 2020, 10(1), 126.

293 K. Kočí, L. Obalová and Z. Lacný, Photocatalytic reduction of $\mathrm{CO} 2$ over TiO2 based catalysts, Chem. Pap., 2008, 62(1), 1-9.
294 L. F. Da Silva, et al., An improved method for preparation of SrTiO3 nanoparticles, Mater. Chem. Phys., 2011, 125(1-2), 168-173.

295 S. Kahng, H. Yoo and J. H. Kim, Recent advances in earthabundant photocatalyst materials for solar $\mathrm{H} 2$ production, Adv. Powder Technol., 2020, 31(1), 11-28.

296 F. Fresno, et al., CO2 reduction over NaNbO3 and $\mathrm{NaTaO} 3$ perovskite photocatalysts, Photochem. Photobiol. Sci., 2017, 16(1), 17-23.

297 C.-C. Hu and H. Teng, Influence of structural features on the photocatalytic activity of $\mathrm{NaTaO} 3$ powders from different synthesis methods, Appl. Catal., A, 2007, 331, 44-50.

$298 \mathrm{~K}$. Li, et al., Photocatalytic reduction of $\mathrm{CO} 2$ and protons using water as an electron donor over potassium tantalate nanoflakes, Nanoscale, 2014, 6(16), 9767-9773.

299 H. Shi, et al., Polymeric g-C3N4 Coupled with NaNbO3 Nanowires toward Enhanced Photocatalytic Reduction of CO2 into Renewable Fuel, ACS Catal., 2014, 4(10), 36373643.

300 E. Karamian and S. Sharifnia, Enhanced visible light photocatalytic activity of $\mathrm{BiFeO}-\mathrm{ZnO} \mathrm{p}-\mathrm{n}$ heterojunction for CO2 reduction, Mater. Sci. Eng., B, 2018, 238-239, 142-148.

301 D. Li, et al., Synergistic effect of Au and Rh on SrTiO3 in significantly promoting visible-light-driven syngas production from $\mathrm{CO} 2$ and $\mathrm{H} 2 \mathrm{O}$, Chem. Commun., 2016, 52(35), 5989-5992.

302 J. Y. Do, et al., Preparation of basalt fiber@perovskite PbTiO3 core-shell composites and their effects on $\mathrm{CH} 4$ production from CO2 photoreduction, Ceram. Int., 2016, 42(5), 5942-5951.

303 Z. Qu, et al., Preparation of a coated Z-scheme and H-type SrTiO3/(BiFeO3@ZnS) composite photocatalyst and application in degradation of 2,4-dichlorophenol with simultaneous conversion of $\mathrm{Cr}(\mathrm{VI})$, Sep. Purif. Technol., 2020, 240, 116653.

304 M. Humayun, et al., Exceptional Visible-Light Activities of TiO2-Coupled N-Doped Porous Perovskite LaFeO3 for 2,4Dichlorophenol Decomposition and CO2 Conversion, Environ. Sci. Technol., 2016, 50(24), 13600-13610.

305 L. O. Paulista, et al., Turning Carbon Dioxide and Ethane into Ethanol by Solar-Driven Heterogeneous Photocatalysis over RuO2- and NiO-co-Doped SrTiO3, Catalysts, 2021, 11(4), 461.

306 Y. Yuan, et al., BaCeO3 as a novel photocatalyst with $4 \mathrm{f}$ electronic configuration for water splitting, Solid State Ionics, 2008, 178(33), 1711-1713.

307 L. Jia, et al., Visible-light-induced photocatalyst based on Cdoped LaCoO3 synthesized by novel microorganism chelate method, Catal. Commun., 2009, 10(8), 1230-1234.

308 A. A. Shah, S. Ahmad and A. Azam, Investigation of structural, optical, dielectric and magnetic properties of LaNiO3 and LaNi1-xMxO3 ( $\mathrm{M}=\mathrm{Fe}, \mathrm{Cr} \& \mathrm{Co} ; \mathrm{x}=5 \%)$ nanoparticles, J. Magn. Magn. Mater., 2020, 494, 165812. 
309 Y. Wang, et al., Ag loaded on layered perovskite H2SrTa2O7 to enhance the selectivity of photocatalytic $\mathrm{CO} 2$ reduction with H2O, J. Alloys Compd., 2019, 786, 149-154.

310 S. Murcia-Lopez, et al., Photocatalytic reduction of $\mathrm{CO} 2$ over platinised Bi2WO6-based materials, Photochem. Photobiol. Sci., 2015, 14(4), 678-685.

311 Q. Wang, et al., Photocatalytic reduction of CO2 to methane over PtOx-loaded ultrathin Bi2WO6 nanosheets, Appl. Surf. Sci., 2019, 470, 832-839.

312 Y. Bai, et al., Ultrathin Bi4O5Br2 nanosheets for selective photocatalytic $\mathrm{CO} 2$ conversion into $\mathrm{CO}$, Chem. Eng. J., 2019, 360, 473-482.

313 P. Chen, et al., Improving the Catalytic CO2 Reduction on Cs2AgBiBr6 by Halide Defect Engineering: A DFT Study, Materials, 2021, 14(10), 2469.

314 J. M. Modak, Haber process for ammonia synthesis, Resonance, 2002, 7(9), 69-77.

315 J. Humphreys, R. Lan and S. Tao, Development and Recent Progress on Ammonia Synthesis Catalysts for Haber-Bosch Process, Advanced Energy and Sustainability Research, 2020, 2(1), 00043.

316 Y. Shiraishi, et al., Nitrogen fixation with water on carbonnitride-based metal-free photocatalysts with $0.1 \%$ solar-toammonia Energy Conversion Efficiency, ACS Appl. Energy Mater., 2018, 1(8), 4169-4177.

317 H. Huang, et al., Toward visible-light-assisted photocatalytic nitrogen fixation: A titanium metal organic framework with functionalized ligands, Appl. Catal., B, 2020, 267, 118686.

318 K. Vikrant, et al., Photocatalytic platforms for removal of ammonia from gaseous and aqueous matrixes: status and challenges, ACS Catal., 2020, 10(15), 8683-8716.

319 S. Mansingh, et al., Recent advances in wireless photofixation of dinitrogen to ammonia under the ambient condition: A review, J. Photochem. Photobiol., C, 2021, 47, 100402.

320 S. Mansingh, et al., Efficient Photon Conversion via Double Charge Dynamics $\mathrm{CeO} 2-\mathrm{BiFeO} 3 \mathrm{p}-\mathrm{n}$ Heterojunction Photocatalyst Promising toward N2 Fixation and PhenolCr(VI) Detoxification, Inorg. Chem., 2020, 59(6), 3856-3873.

321 S. Zhang, et al., Photocatalytic ammonia synthesis: Recent progress and future, EnergyChem, 2019, 1(2), 100013.

322 K. Ithisuphalap, et al., Photocatalysis and Photoelectrocatalysis Methods of Nitrogen Reduction for Sustainable Ammonia Synthesis, Small Methods, 2018, 3(6), 00352.
323 Y. Bo, et al., Altering Hydrogenation Pathways in Photocatalytic Nitrogen Fixation by Tuning Local Electronic Structure of Oxygen Vacancy with Dopant, Angew. Chem., Int. Ed., 2021, 60(29), 04001.

$324 \mathrm{R}$. Shi, et al., The journey toward low temperature, low pressure catalytic nitrogen fixation, Adv. Energy Mater., 2020, 10(19), 2000659.

325 G. Zhang, et al., Nanostructured photocatalysts for nitrogen fixation, Nano Energy, 2020, 71, 104645.

326 S. Chen, D. Liu and T. Peng, Fundamentals and Recent Progress of Photocatalytic Nitrogen-Fixation Reaction over Semiconductors, Sol. RRL, 2021, 5(2), 2000487.

327 B. Huang, et al., Boosting the photocatalytic activity of mesoporous SrTiO3for nitrogen fixation through multiple defects and strain engineering, J. Mater. Chem. A, 2020, 8(42), 22251-22256.

$328 \mathrm{H}$. Zhang, et al., Sol-gel synthesis of upconversion perovskite/attapulgite heterostructures for photocatalytic fixation of nitrogen, J. Sol-Gel Sci. Technol., 2019, 92(1), 154-162.

329 S. Zhou, et al., Formation of an oriented Bi2WO6 photocatalyst induced by in situ $\mathrm{Bi}$ reduction and its use for efficient nitrogen fixation, Catal. Sci. Technol., 2019, $\mathbf{9}(20), 5562-5566$.

330 R. Huang, et al., Recent advances in photocatalytic nitrogen fixation: from active sites to ammonia quantification methods, RSC Adv., 2021, 11(24), 14844-14861.

331 Z. Zhao, et al., Magnetic-Field-Stimulated Efficient Photocatalytic N2 Fixation over Defective BaTiO3 Perovskites, Angew. Chem., Int. Ed. Engl., 2021, 60(21), 11910-11918.

332 M. Song, et al., Defect density modulation of La2TiO5: An effective method to suppress electron-hole recombination and improve photocatalytic nitrogen fixation, $J$. Colloid Interface Sci., 2021, 602, 748-755.

333 P. Xing, et al., New Application and Excellent Performance of $\mathrm{Ag} / \mathrm{KNbO} 3$ Nanocomposite in Photocatalytic NH3 Synthesis, ACS Sustainable Chem. Eng., 2019, 7(14), 1240812418.

334 A. Kumar, et al., Unraveling the structural and morphological stability of oxygen vacancy engineered leaftemplated $\mathrm{CaTiO} 3$ towards photocatalytic $\mathrm{H} 2$ evolution and N2 fixation reactions, J. Mater. Chem. A, 2021, 9(31), 17006-17018. 